\title{
WestVirginiaUniversity
}

THE RESEARCH REPOSITORY @ WVU

Graduate Theses, Dissertations, and Problem Reports

2002

\section{Antitumor activity of antimalarials in human breast cancer cells}

Qun Zhou

West Virginia University

Follow this and additional works at: https://researchrepository.wvu.edu/etd

\section{Recommended Citation}

Zhou, Qun, "Antitumor activity of antimalarials in human breast cancer cells" (2002). Graduate Theses, Dissertations, and Problem Reports. 1612.

https://researchrepository.wvu.edu/etd/1612

This Dissertation is protected by copyright and/or related rights. It has been brought to you by the The Research Repository @ WVU with permission from the rights-holder(s). You are free to use this Dissertation in any way that is permitted by the copyright and related rights legislation that applies to your use. For other uses you must obtain permission from the rights-holder(s) directly, unless additional rights are indicated by a Creative Commons license in the record and/ or on the work itself. This Dissertation has been accepted for inclusion in WVU Graduate Theses, Dissertations, and Problem Reports collection by an authorized administrator of The Research Repository @ WVU.

For more information, please contact researchrepository@mail.wvu.edu. 


\title{
Antitumor Activity of Antimalarials in Human Breast Cancer Cells
}

\author{
Qun Zhou
}

\begin{abstract}
Dissertation submitted to the School of Medicine
of West Virginia University

in partial fulfillment of the requirements

for the degree of Doctor of Philosophy in

Pharmacology and Toxicology
\end{abstract}

Jeannine S. Strobl, Ph.D, Chair

Stephen Graber, Ph.D

William Wonderlin, Ph.D

Marilyn I. Evans, Ph.D

Knox Van Dyke, Ph.D

Department of Pharmacology and Toxicology

Morgantown, West Virginia

2002

Key Words: Antimalarials, Differentiation, Apoptosis, Histone H4, Breast Cancer 


\section{ABSTRACT \\ Antitumor Activity of Antimalarials in Human Breast Cancer Cells}

Qun Zhou

Previously we showed that quinidine arrested MCF-7 cells in G1 phase of the cell cycle and led to a G1 to G0 transition followed by apoptotic cell death (Wang et al., 1998). The present experiments demonstrate that MCF-7, MCF-7ras, T47D, MDA-MB-231, and MDA-MB-435 cells transiently differentiate before undergoing apoptosis in response to quinidine. The cells accumulated lipid droplets and the cytokeratin 18 cytoskeleton was reorganized. Hyperacetylated histone $\mathrm{H} 4$ appeared within $2 \mathrm{~h}$ of the addition of quinidine to the medium, and levels were maximal by $24 \mathrm{~h}$. Quinidine treated MCF7 cells showed elevated p21/WAF1, hypophosphorylation and suppression of retinoblastoma protein, and down-regulation of cyclin D1. Quinidine did not show evidence for direct inhibition of histone deacetylase enzymatic activity in vitro. HDAC-1 was undetectable in MCF-7 cells 30 min after addition of quinidine to the growth medium. The proteasome inhibitors, MG-132 and lactacystin completely protected HDAC- 1 from the action of quinidine. These data demonstrate that quinidine is a breast tumor cell differentiating agent that causes the loss of HDAC-1 via a proteasomal sensitive mechanism. Moreover, to determine whether effects of quinidine on cell differentiation and apoptosis is generalizable to quinoline antimalarials, we tested typical quinoline antimalarial drugs for their ability to regulate MCF-7 cell differentiation, hyperacetylation histone H4 and apoptosis. MTS IC50 of amodiaquin, chloroquine, halofantrine, primaquine, quinidine as well as quinine induced hyperacetylation of histone $\mathrm{H} 4$ without inhibiting HDAC activity. These results indicate that an alkylamino-substituted antimalarial ring might be important for acetylation of histone H4. Accumulation of lipid droplets was observed in cells treated with chloroquine, primaquine, quinidine and quinine. Only MTS IC50 of chloroquine and quinidine increased p21(WAF1) protein levels and apoptosis. The data imply that p21(WAF1) might play a determining role in apoptosis in MCF-7 cells treated with antimalarials. Chloroquine was most active in stimulating MCF-7 apoptosis, and quinine was most active in promoting MCF-7 cell differentiation. We conclude that distinct mechanisms are responsible for breast tumor cell differentiation and activation of apoptosis by quinoline antimalarials. Alkylamino-substituted antimalarial ring compounds represented by quinidine, quinine and chloroquine will be useful model compounds in the search for more active breast tumor differentiating agents. 


\section{ACKNOWLEDGMENTS}

I would first like to express my sincerest gratitude to my advisor, Dr. Jeannine S. Strobl, for her advice, guidance and support during my graduate study. Her insight and ideas have nourished and inspired me greatly and have added enormously to my understanding of cancer cell biology. I am grateful as well for her sense of humor and insight into the creative process. Big thanks to Drs. Stephen Graber, William Wonderlin, Marilyn I. Evans and Knox Van Dyke for their encouragement, kindness, help and service on my graduate committee.

I gratefully acknowledge the support of Dr. Robert E. Stitzel. A special thank-you goes out to Dr. Takamitsu Kawai, for his help on the computer language and data analysis. Appreciation is extended to Chris Van Dyke for computer image technical support. I am grateful to my colleagues, Meredith McCracken, Zara K. Melkoumian, Anna Martirosyan, and Rayhana Bata for their help and friendship.

Finally, I wish to acknowledge my taproots: my mother and father, my brother and sister and their families, as well as my wife. All of you have enriched my life beyond my wildest dreams. I continue to find this process close to miraculous. 


\section{TABLE OF CONTENTS}

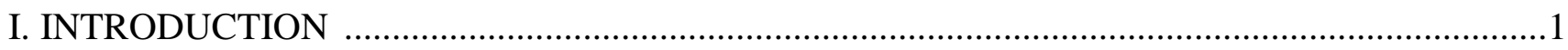

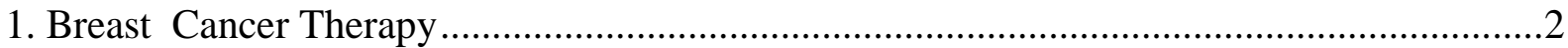

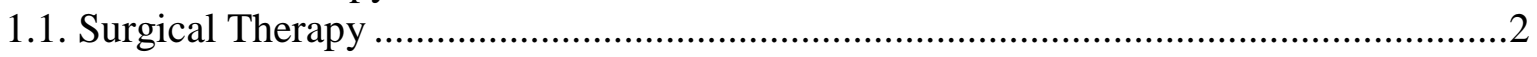

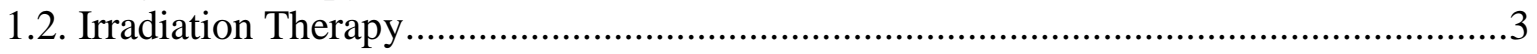

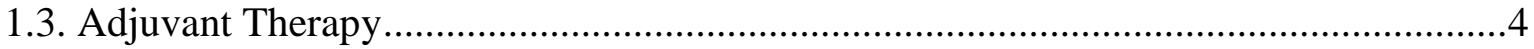

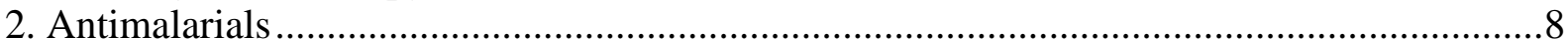

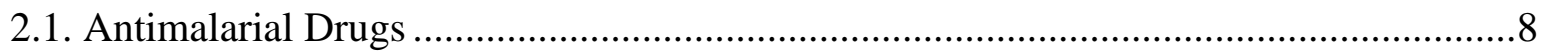

2.2. Cancer Treatment by Antimalarials.............................................................................10

3. Mechanism for Regulating Tumor Cell Growth ...............................................................13

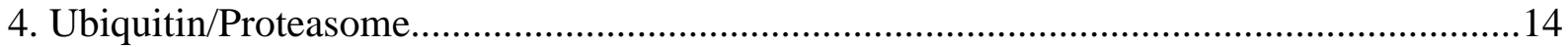

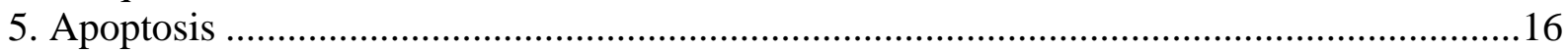

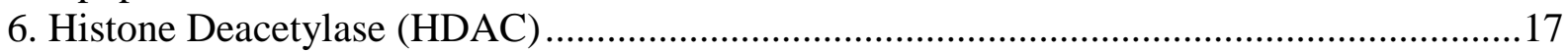

6.1. Disruption of HAT and /or HDAC Activity and Development of Cancer....................19

6.2. Pharmacological HDAC Inhibitors ...........................................................................19

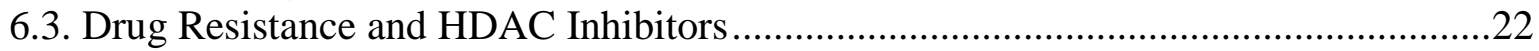

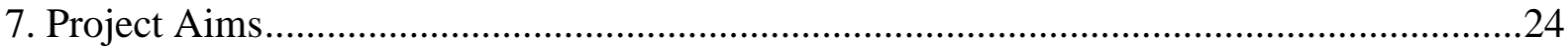

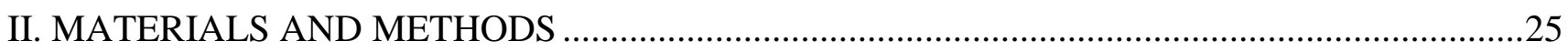

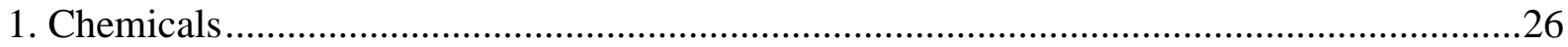

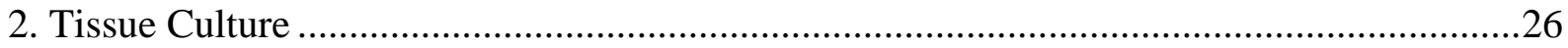

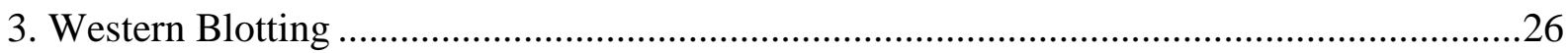

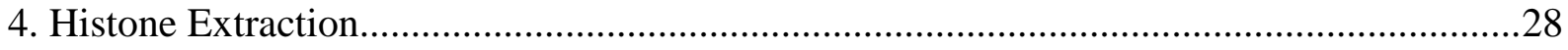

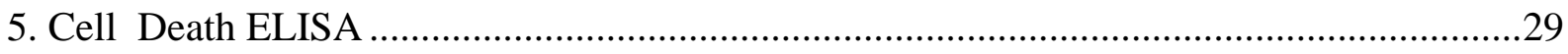

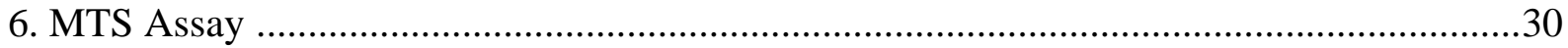

7. Ki67 Immunohistochemical Assay ............................................................................

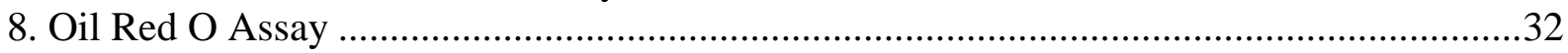

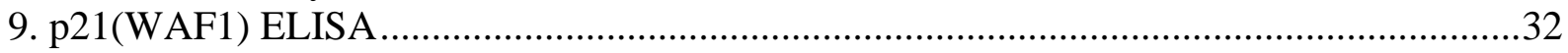

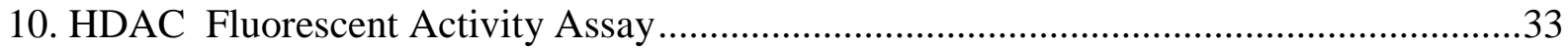

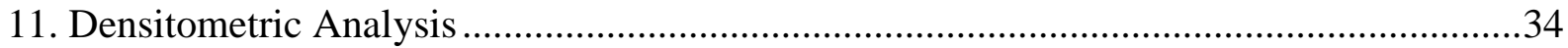

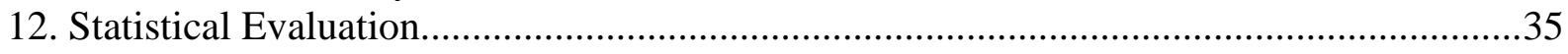

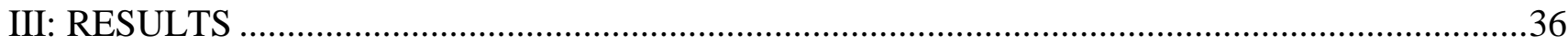

1. Rapid Induction of Histone Hyperacetylation and Cellular Differentiation in Human Breast Tumor Cell lines Following Degradation of Histone Deacetylase-1 .......................................37

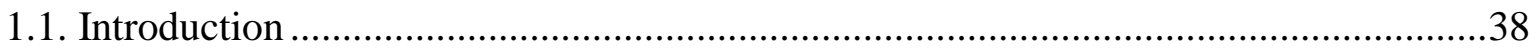

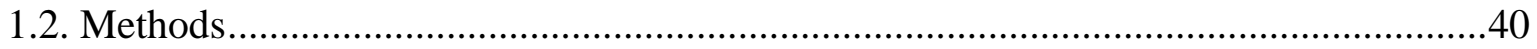

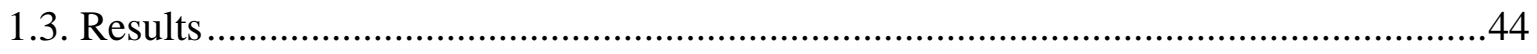

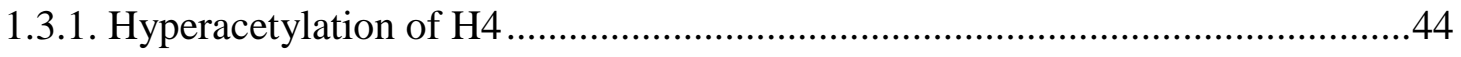


1.3.2. G1 phase Cell Cycle Regulatory Profile in MCF-7 cells ......................................50

1.3.3. Growth Arrest Cellular Differentiation in Human Breast Tumor Cell Lines .....58

1.3.4. Hyperacetylation of Histone H4 in Mammary Tumor Cell Lines by Quinidine66

1.4. Discussion

2. Effects of Antimalarials on Cell Growth, Differentiation and Apoptotic Response in Human Breast Cancer Cells

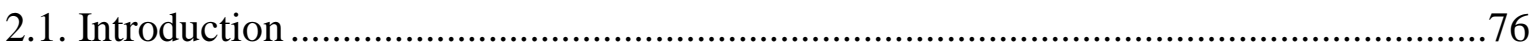

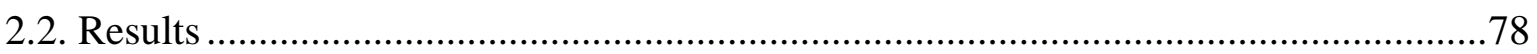

2.2.1. Effects of TSA on Cell Growth and HDAC Activity .......................................78

2.2.2. Effects of TSA on Ki67 Antigen and p21(WAF1) Protein in MCF-7 Cells.......78

2.2.3. Induction of Differentiation by TSA in MCF-7 Cells ........................................... 81

2.2.4. Effect of TSA on Apoptosis in MCF-7 Cells....................................................... 81

2.2.5. Antimalarials Inhibit MCF-7 Cell Growth.........................................................86

2.2.6. Hyperacetylation of Histone $\mathrm{H} 4$ by Antimalarials in MCF-7 Cells.....................86

2.2.7. Effects of Quinoline Antimalarials on HDAC Activity in vitro ..........................94

2.2.8. Effects of Antimalarials on Ki67 Antigen in MCF-7 Cells .................................94

2.2.9. Effects of Antimalarials on p21(WAF1) Protein in MCF-7 Cells ......................98

2.2.10. Effects of Antimalarials on Lipid Droplet Accumulation in MCF-7 Cells.......98

2.2.11. Effect of Antimalarials on Apoptosis in MCF-7 Cells ....................................103

2.2.12. Role of Caspase-3 in Quinidine-Induced Apoptosis .......................................111

2.2.13. Role of $\mathrm{pRb}$ on Quinidine-Induced Apoptosis...........................................112

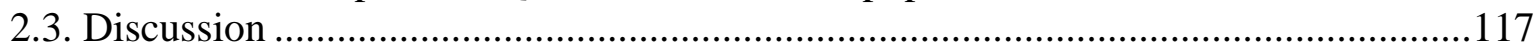

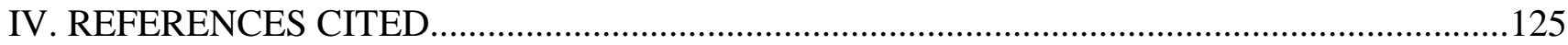

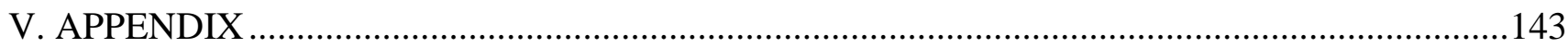




\section{LIST OF FIGURES}

Figure 1. Chemical Structures of Antimalarials......................................................................12

Figure 2. Cell Cycle Regulatory Proteins for G1 to S Phase Transition..........................................15

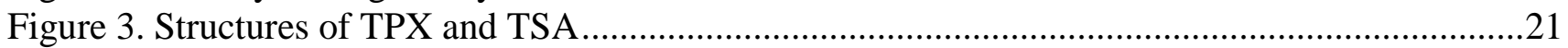

Figure 4. Histone Hyperacetylation in MCF-7 Cells .................................................................45

Figure 5. Protection of HDAC1 Protein by Proteasome Inhibitors ...............................................48

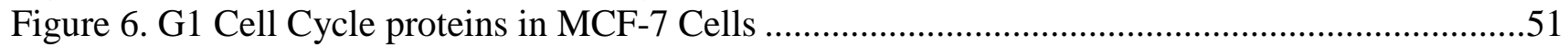

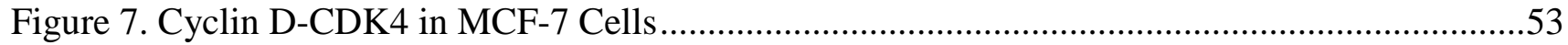

Figure 8. Proteasome Inhibitor Modulates Retinoblastoma Protein Levels .....................................56

Figure 9. Growth of Human Breast Cell Lines in Quinidine ....................................................59

Figure 10. Cytokeratin 18 in MCF-7 Cells ............................................................................62

Figure 11. Lipid Accumulation as an Index of Cellular Differentiation in Human Breast Tumor Cell

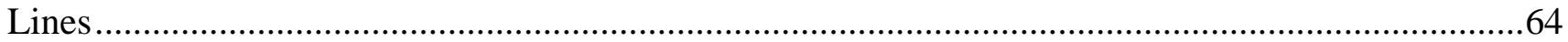

Figure 12. Histone H4 Hyperacetylation in Human Breast Tumor Cell Lines ..................................67

Figure 13. Effects of TSA on Cell Growth and HDAC Activity in Human Carcinoma Cells .............79

Figure 14. Effects of TSA on Ki67 Negative Cell Population and p21(WAF1) in MCF-7 Cells ........80

Figure 15. Induction of Differentiation by TSA Treatment in MCF-7 Cells for $48 \mathrm{~h}$.......................82

Figure 16. Induction of Differentiation by TSA in MCF-7 Cells ....................................................84

Figure 17. Nucleosome Release in the Cytoplasm of MCF-7 Cells Treated with TSA .....................85

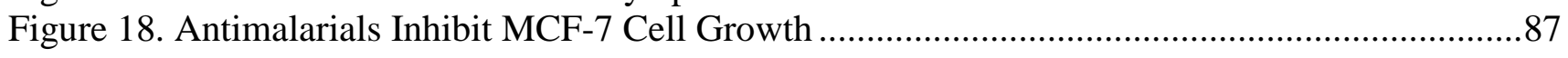

Figure 19. Effects of Antimalarials and TSA on MTS Metabolism in MCF-7 Cells ........................89

Figure 20. Effects of Antimalarials and TSA on Cell Viability ..................................................91

Figure 21. Hyperacetylation of Histone H4 by Antimalarials in MCF-7 Cells .................................92

Figure 22. Effect of Antimalarials on HDAC Activity in HeLa Cell Nuclear Extracts ......................96

Figure 23. Ki67 Expression in MCF-7 Cells after Treatment with Antimalarials..............................97

Figure 24. Effect of Antimalarials and TSA on Expression of p21(WAF1) Protein in MCF-7 cells...99

Figure 25. Effect of Antimalarials on p21(WAF1) Protein Expression in MCF-7 Cells ..................100

Figure 26. Effect of Antimalarials on Lipid Droplet Accumulation in MCF-7 Cells ......................102

Figure 27. The Apoptotic Response to Antimalarials in MCF-7 Cells...........................................104

Figure 28. Quinidine Induces Apoptosis Response in Caspase-3(-/-) MCF-7 and YAMA(MCF-7,

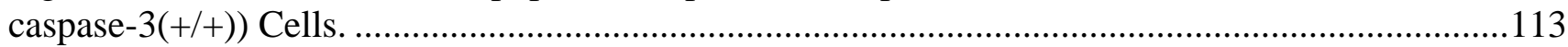

Figure 29. Effects of Quinidine on Cell Proliferation and Apoptosis in MCF-7 and MDA-MB-468

Human Breast Cancer Cells ................................................................................................ 115 


\section{LIST OF TABLES}

Table 1. Summary of Effects of Quinidine on Cell Cycle Proteins in MCF-7Cells .........................69

Table 2. Enrichment of Nucleosome Release in the Cytoplasm of MCF-7 Cells Treated with MTS

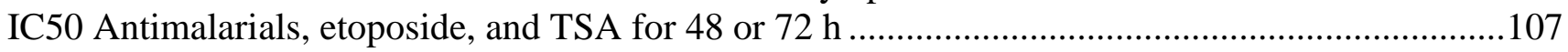

Table 3. A Comparison of Ki67, ORO, p21(WAF1) Protein, Acetylated H4 and Apoptosis in MCF-7

Human Breast Cancer Cells treated with MTS IC50 Antimalarials ...............................................109 


\section{LIST OF ABBREVIATIONS}

AQ Amodiaquin

BSA Bovine Serum Albumin

CDK Cyclin Dependent Kinase

CL Chloroquine

DTT Dithiothreitol

DMEM Dulbecco's Modified Eagle's Medium

EDTA Ethelenediamine Tetraacetic Acid

ETOH Ethanol

FBS Fetal Bovine Serum

HAT Histone Acetyltransferases

$\mathrm{HCl}$ Hydrochloric Acid

HDAC Histone Deacetylase

HF Halofantrine

HBSS Hank's Balanced Salt Solution

MG-132 Carbobenzoxy-L-leucyl-L-leucyl-L-leucinal

MQ Mefloquine

MTP Microtiter Plate

MTS 3-(4,5-dimethylthiazol-2-yl)-5-(3-carboxmethoxypheyl)-2-(4-sulfophenyl)-2H-tetrazolium

$\mathrm{NaB}$ Sodium Butyrate

PBS Phosphate Buffered Saline

PMSF Phenymethylsulfonyl Fluoride

PQ Primaquine

PVDF Polyvinylidene Difluoride

QA Quinolinic Acid

QL Quinoline

QD Quinidine

QN Quinine

$\mathrm{Rb} \quad$ Retinoblastoma protein

SAHA Superoylanilide Hydroxamic Acid

TBS Tris Buffered Saline

TPXT Trapoxin

TSA Trichostatin A 


\section{INTRODUCTION}




\section{Breast Cancer Therapy}

Breast cancer is the most commonly diagnosed invasive malignancy and a leading cause (after lung cancer) of cancer deaths in American women (Greenlee et al., 2000). Most women succumb to breast cancer when their cancers metastasize; long-term survival depends on if the cancer remains localized. The approach to control this malignancy has made significant strides during the last decades of the $20^{\text {th }}$ century. Surgical removal of the primary tumor in patients can reduce breast cancer mortality (Early Breast cancer Trialists' Collaborative Group, 1995); radiation therapy techniques and adjuvant systemic therapy can delay or prevent recurrence and thereby improve survival rates (Hortobagyi, et al., 2000).

\subsection{Surgical Therapy}

The primary goal of cancer surgery is the complete eradication of local and regional tumor. Traditionally, axillary lymph node dissection (ALND) has been considered as a standard part of the surgical management of patients with breast cancer, which provides accurate prognosis information, maintains local control of disease in the axilla and provides a rational basis for decision about adjuvant therapy (Sakorafas, 2000). Recently, there has been increased interest in extending the local treatment of breast cancer to "incision-less surgery". The idea is to destroy all the tissue in a radius around the tumor while leaving the remaining breast unaltered using different energy sources such as laser for interstitial hyperthermia (Feyerabend, et al., 1996 ). This approach has been used in number of patients who are diagnosed with as a small, local and single focus of infiltrating ductal breast carcinoma (Feyerabend, et al., 1996). 


\subsection{Irradiation Therapy}

The objective of radiation treatment of the patient with breast cancer is eradication of the tumor with preservation of the structure and function of normal tissues. For radiation therapy, as for surgery, this means local-regional control of tumor cells, implying also a careful pretreatment evaluation and long-term post-treatment observation.

One radiation treatment is external beam radiotherapy, which is very effective when treating localized disease by reducing the tumor bulk, so reducing the amount of dying tissue and the possibility for infection and odor (Regnard, et al., 1998). The challenge for radiotherapy is for more radiosensitivity that is a measure of the susceptibility to cellular injury by ionizing radiation. Mammalian cells vary in their radiosensitivity as they progress through the mitotic division cycle (Sullivan, et al.,1980). In general, G0 and late S-phase cells are most resistant, and late G2 and mitotic (M) cells are the most sensitive (Sullivan, et al.,1980). Following irradiation with 4-8 Gy (gray), MCF7 human breast cancer cells exhibit transient delay in progression from G1 into S phase (Nagasawa et al., 1998). The use of combination radiation therapy and chemotherapy have increased strikingly over the past few years. Radiation therapy is directed at the primary tumor masses and regional nodes, whereas chemotherapeutic agents may modify the response of tumor and normal tissues to irradiation. It has been reported that cytotoxic drugs that are S-phase-specific could synergize with radiation therapy to overcome radioresistance in the S phase (Sondel et al., 1986). 


\subsection{Adjuvant Therapy}

There are two major types of systemic therapy: cancer chemotherapy and biological therapy (immunotherapy). There is considerable overlap between these two types of therapy, and they are increasingly employed together in various combinations (Trail et al., 1993).

Chemotherapy involves the use of cytotoxic drugs and hormones to induce tumor cell death. The typical chemotherapeutical agents include cyclophosphamide, doxorubicin, methotrexate and tamoxifen

Cyclophosphamide is used to treat a wide range of human malignancies. Bioactivation of cyclophosphamide yields 4-hydroxycyclophosphamide, which then interconverts with its tautomer aldophosphamide. Through an elimination mechanism, aldophosphamide fragments to acrolein and phosphoramide mustard (PM) (Anderson et al., 1995). It has been reported that PM and acrolein are reactive species toward DNA. The covalent DNA adducts formed by PM are intra/interstand cross-link DNA adducts and mono adducts at the N7 position of guanine (Anderson et al., 1995). The DNA adducts from PM and acrolein have been found in rodents after administration of cyclophosphamide (Hemminki 1985). The alkylating agent cyclophosphamide is a potent immunosuppressive drug that has been synthesized. The proliferating lymphoid cells are primarily targeted by this agent. It is a known carcinogen and is associated with induction of therapy-related leukemia and bladder cancer (Ortiz et al., 1992). In vivo genotoxic activity including chromosome aberrations, sister chromatid exchange, and gene mutation has been reported in both animals and humans after administration of cyclophosphamide (Anderson et al., 1995).

Doxorubicin is considered one of the most active drugs in breast cancer, with response rates of $40 \%$ when given as a first-line single agent (Houstone et al., 1993). This drug is capable of binding to DNA, usually by interposition between base pairs with subsequent uncoiling of the DNA helix. 
Intercalation impairs DNA synthesis and RNA synthesis which inhibit tumor cell proliferation (Houstone et al., 1993).

Methotrexate (MTX) is one of the most commonly used agents in the treatment of solid malignancies as well as leukemias and lymphomas. However, the toxicities of MTX to bone marrow and gastrointestinal tract accompany this therapy (Moscow 1998). This drug is a member of the antifolate class of compounds that exerts its cytotoxicity by blocking DNA/RNA synthesis pathways, MTX binds to the active catalytic site of dihydrofolate reductase (DHFR), and blocks the synthesis of the reduced form of folate that acts as a one-carbon unit donor in biochemical syntheses. Lack of this cofactor interrupts the biosynthesis of thymidylate and purine nucleotides, thereby interfering with the formation of DNA and RNA (Moscow 1998).

Endocrine Therapy is an effective treatment for breast cancer patients. Normally, estrogens function by binding to estrogen receptor. Subsequent to ligand (estrogen)-ER binding, ligand-ER complexes undergo conformation change, dissociate from the chaperone heat shock protein Hsp90 and become active complexes (Hurd and Moudgil 1998). In the nucleus, ER-ligand complexes bind to a transcriptional complex and an estrogen response element on DNA (Beato et al., 1996). Recent evidence suggests that the activated ligand-ER complexes participate a switching between binding of a multisubunit co-repressor complex containing factors (not completely identified yet) with histone deacetylase activity (HDAC) and binding of a co-activator complex containing factors, SRC (steroid receptor co-activators)/NcoA (nuclear receptor co-activators), with histone acetylase activity (HAT) such as p300/CBP(CREB (cyclic AMP-responsive element binding)-binding protein) and PCAF (p300/CBP- associated factor)(Grunstein 1997). Ligand-ER binding results in the replacement of the repressor complex, by a co-activator SRC-1/NcoA-1 complex with multiple HAT proteins which catalyze histone acetylation (Torchia et al, 1998). The net effect is that estrogen activates gene expression and increases cell proliferation (Katzenellenbogen, 1997). 
In about one-third of advanced breast cancers, estrogens stimulate tumor growth, whereas estrogen deprivation causes tumor regression. Inhibition of estrogenic stimulation is the main target in endocrine treatment of breast cancer. This is achieved by either blocking the estrogen receptor or the inhibition of estrogen production.

Tamoxifen (TAM) is a typical agent for hormone therapy, which binds to estrogen receptors, competes with endogenous estrogens, and occludes the coactivator association between the activation function domain 2 (AF2) and the receptor ligand-binding domain (LBD), leading to inhibition of tumor cell growth (Shiau et al., 1998). Inhibition of ER by TAM blocks the secretion of polypeptide growth factors such as epidermal growth factor and transforming growth factor $\alpha$, leading to growth arrest of ER-positive cells (Taylor et al., 1984). In addition to its cytostatic effects mediated through the ER in ER-positive MCF-7 cells, TAM delays G1 cell cycle transit leading to an accumulation of non-dividing cells in G0/G1 phase (Sutherland, et al., 1983). The cell cycle delay is ER-independent, since TAM also inhibits the growth of the ER-negative cell line BT20 by accumulation of cells in the G0/G1 phase (Osborne et al., 1989). TAM cytotoxicity is proposed to be mediated by the induction of apoptosis (Perry et al., 1995).

A doxorubicin based chemotherapy combined with tamoxifen proved superior to tamoxifen alone (Fisher et al., 1990). This finding was supported by in vitro studies. Clinical studies suggest an additive or even synergistic effect of doxorubicin and tamoxifen, especially in postmenopausal women, where addition of tamoxifen to chemotherapy increases the recurrence-free survivability in breast cancer patient. This benefit is more pronounced for ER positive patients than for ER negative ones (Osborne et al., 1989).

Femara (letrozole). Aromatase is an enzyme that catalyzes the conversion of the androgens androstenedione and testosterone to estrone and estradiol. The cytochrome P-450 enzyme complex aromatase is the main target for inhibition of estrogen biosynthesis. In recent years, several new 
aromatase inhibitors including Femara have been developed. Femara is the selective aromatase inhibitor and recently licensed by the FDA for advanced breast cancer treatment in postmenopausal women where tamoxifen therapy has failed (Harvey 1998). It is a potent inhibitor of cell proliferation and more effective than tamoxifen in MCF-7 cells (Brodie et al., 1998).

Immunotherapy involves the use of biological molecules known as biological modifiers. The HER2 receptor is the protein product of protooncogene $H E R 2$ (also known as neu and as $c$-erbB-2), and is a member of EGFR (epidermal growth factor receptor) family of transmembrane tyrosine kinases. Upon binding of ligand to the EGFR, HER2 is recruited as the preferred partner of these ligand-bound receptors into an active, phosphorylated heterodimeric complex that activates several signaling pathways involved in the proliferation and survival of breast cancer cells (Riese et al., 1998). Overexpression of HER2 in breast cancer patients is associated with poor prognosis (Riese et al., 1998).

HER2 has been proposed to contribute to antiestrogen-resistance because tumors expressing high levels of HER2 exhibit lower clinical response rates after antiestrogen therapy (Houston 1999). HER2-overexpressing estrogen receptor positive breast cancer cells failed to respond to tamoxifen (Elledge et al., 1998). HER2 overexpression activates the MAPK (mitogen-activated protein kinase) signaling pathway, which causes phosphorylation of ER, and ligand-independent ER activation with loss of the inhibitory effect of tamoxifen (Bunone et al., 1996). Immunotherapy using a monoclonal antibody against HER2, has proved to be clinically efficacious in breast cancer patients (Baselga et al., 1996). Herceptin, an antibody against HER2, increased the inhibitory effect of tamoxifen against HER2 overexpressed BT-474 human breast cancer cells in culture (Witters et al., 1997). Herceptin targets the HER2 ectodomain and blocks HER2 cleavage preventing the production of an active truncated HER2 fragment (Molina et al., 2001). Treatment with herceptin and doxorubicin showed 
greater inhibition of cell proliferation than that observed with any agent alone in BT-474 cells (Baselga et al., 1998).

Summary. Adjuvant therapy has led to a reduction in the risk of relapse of only $20-40 \%$, depending on the chemotherapeutic agents used (Hortobagyi et al., 2000). Frequent toxic effects, including nausea, vomiting and alopecia, are usually connected with adjuvant therapies. In addition, the emergence of multidrug resistance poses a considerable obstacle to success of breast cancer chemotherapy. Therefore, the development of new target-selective 'smart' drugs that are less toxic and circumvent drug resistance, is an important goal.

\section{Antimalarials}

Malaria is the common devastating human infection in the developing countries. There are nearly 2.5 million deaths each year (Phillips 2001). The human malaria parasites have P.falciparum, P.vivax, P.ovale and P.malariae species (Galinski et al., 1996). Much of human mortality is caused by infection with P. falciparum (Phillips 2001). Although this mosquito-born infection has been eradicated from the USA, immigration from and travel to endemic regions still cause health problems.

The asexual erythrocytic cycle produces more merozites that are released with the destruction of the red blood cell after 48 or $72 \mathrm{~h}$; for the human malaria parasites, depending on the species, merozites then immediately invade additional erythrocytes (Hawking et al., 1968). For the past 50 years, quinoline-containing drugs have been the main class of antimalarial agents in use. In most cases, these agents are targeted at the asexual erythrocytic stage of the parasite. The quinoline-containing drugs include the cinchona alkaloids which are quinine and quinidine, the aminoalcohol quinine analogue mefloquine, halofantrine, primaquine, chloroquine and its relative amodiaquin (White 1994). 


\subsection{Antimalarial drugs}

The structures of quinoline antimalarials are shown in Figure1. Most of the aminoquinoline compounds behave like quinine in many respects, but each drug has individual properties.

Quinidine has a quinoline group through a secondary alcohol linkage to a quinuclidine ring. A vinyl side chain is attached to the quinuclidine ring while a methoxy side chain is linked to the quinoline ring. Quinine has the same structure as quinidine except for the steric configuration of the secondary alcohol group. Quinidine is more potent as an antimalarial and more toxic than quinine. It has been reported that quinine inhibits incorporation of adenosine into parasitic DNA, whereas the mechanism by which quinidine acts as an antimalarial is not known (Whinstanley et al., 1993).

Mefloquine is a 4-quinolinemethanol derivative that has four optional isomers with about the same antimalarial potency. Melfloquine is selective against mature trophozoite and schizont forms of malarial parasites. The exact mechanism of action of mefloquine is unknown. It does not intercalate with DNA (Davidson et al., 1997).

Chloroquine is a 4-alkylamino substituted quinoline that also possesses a chlorine substitution at the 7-position of the ring. Chloroquine is a more potent antimalarial than either quinidine or quinine, but despite chloroquine's structural similarities with quinine and quinidine, chloroquine has a different mechanism of antimalarial activity, and chloroquine-resistant malaria responds to quinine treatment (White, et al., 1994). Chloroquine's antimalarial action is mediated through binding to a $\mathrm{Hb}$ (hemoglobin) degradation product which becomes toxic to the parasite. It selectively inhibits haem polymerization which is an essential defense mechanism to detoxify haem (Wellems, et al., 1992).

Amodiaquin is a analog of chloroquine, which is no longer used as an antimalarial because its use increases hepatic toxicity and agranulocytosis (White et al., 1994). 
Primaquine is a quinoline derivative that is synthesized with methoxy and substituted 8-amino groups. The great clinical value of primaquine is active against the primary exoerythrocytic forms of P. falciparum. The 8-aminoquinolines exert the most potent antimalarial effect (Tarlov et al., 1962).

Halofantrine The (+) and (-) enantiomers of halofantrine are equally active against malaria (Carrol et al., 1978). Halofantrine acts against the asexual erythrocytic stage of Plasmodium; it is primarily used as an alternative to quinidine and mefloquine to treat acute malarial attacks caused by chloroquine-resistant and multidrug-resistant strains of P.falciparum (Basco et al., 1992). Halofantrine also acts on parasite mitochondria to form toxic complexes, which destroy biomembranes (Warhurst et al., 1987).

\subsection{Cancer Treatment by Antimalarials}

In the past twenty years, the potential of antimalarial drug such as chloroquine to improve cancer therapy has been investigated. Chloroquine treatment $(20 \mathrm{mg} / \mathrm{ml})$ in cultured mouse myeloid leukemia M1 cells for 4 days induced differentiation, inhibited DNA and RNA polymerases, and interfered with lysosomal function (Takenaga, et al. 1980; Morrow, et al., 1989). Chloroquine inhibited cell proliferation in a dose and time-dependent manner in malignant B cells obtained from a patient with Bcell chronic lymphocytic leukaemia, and induced apoptosis as demonstrated by a decrease in the amount of bcl-2 protein, increased caspase-3 activation and DNA fragmentation (Lagneaux et al., 2001).

Chloroquine also acts as an effective potentiator of hyperthermia, which is an adjunctive treatment modality in neural crest tumors such as melanoma and murine neuroblastoma (Morrow, et al., 1989; Thomas 1990). In C3H/He mice bearing transplantable mammary adenocarcinomas (C3HBA), 5fluorouracil (5-FU) and chloroquine phosphate increased complete remissions compared with 5-FU treatment alone (Shoemaker, et al., 1978; Shoemaker, et al., 1979). Chloroquine therapy also enhanced radiosensitization in patients with chest wall necrosis; the acute radiation reaction was also 
greater in chloroquine treated animals (Utley, et al., 1997). Moreover, chloroquine was used to reduce the toxicity of the anti-brain tumor drug TFCRM107 by selectively suppressing toxicity to the vasculature without altering the antitumor efficacy (Hagihara et al., 2000).

Chloroquine increased the effect of Aluminium Chloride Phthalocyanine (ALCIPc), a second generation sensitizer for the photodynamic therapy of EMT-6 mouse mammary tumor cells. In the photodynamic cancer therapy model, ALCIPc was incorporated together and formed the polymeric micelles by dialysis. Chloroquine, a weak base, raised the internal $\mathrm{pH}$ of acidic organelles such as the lysosome. Endosomal lysosomal acidity is important for the $\mathrm{pH}$-sensitive polymeric micelles to be fully effective (cytotoxicity) (Taillefer, et al., 2001). Chloroquine and its analogues have the potential for enhancing the efficient gene transfer into various gynecological tumors by their endosomal buffering capacity, therefore these compounds are also used in gene therapy applications (Keil, et al., 2001). Interestingly, chloroquine and its derivative hydroxychloroquine have been reported to possess anti-HIV-1 activity in lymphocytic and monocytic cells. The anti-HIV effect by chloroquine has been confirmed in vivo in two clinical trials (Boelaert et al., 2001). Combination therapy with the antimalarial agent chloroquine may be an interesting option for treatment for cancer and HIV infected individuals in the developing countries. 
Quinoline (QL)
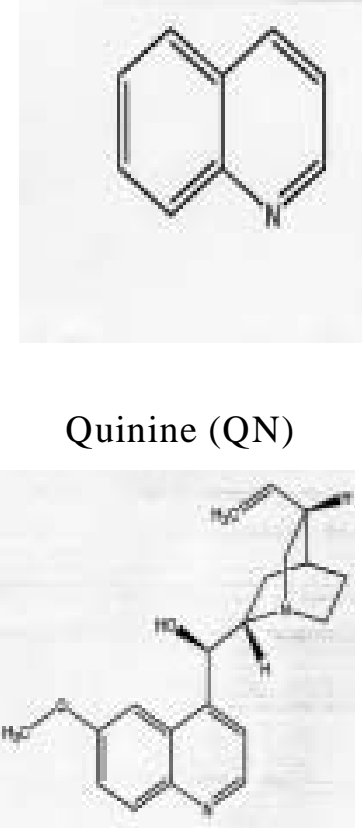

Chloroquine (CL)<smiles>CCN(CC)CCC(O)Nc1ccnc2cc(Cl)ccc12</smiles>

Quinolinic Acid (QA)

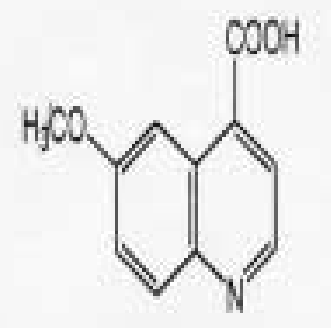

Quinidine (QD)

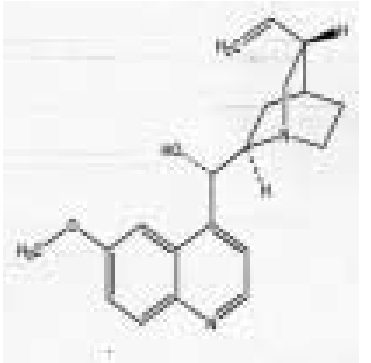

Mefloquine (MQ)

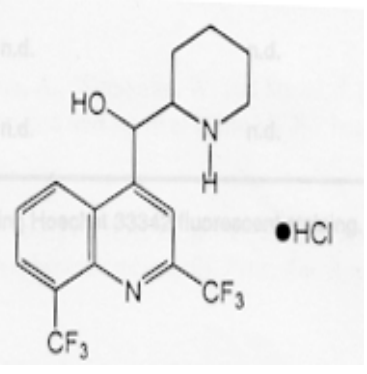

Primaquine (PQ)

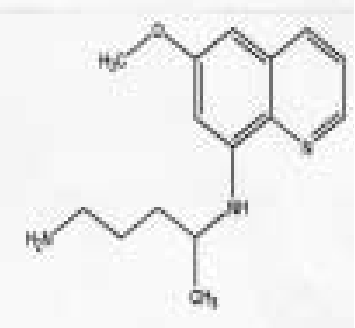

Amodiaquin (AQ)

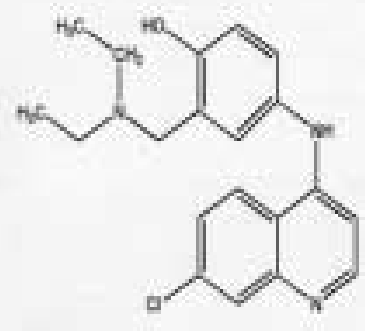

Halofantrine (HF)

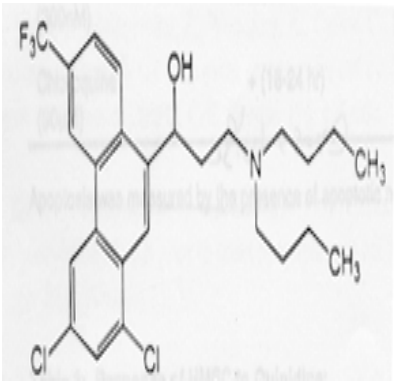

Figure. 1. Chemical Structures of Antimalarials 


\section{Mechanism for Regulating Tumor Cell Growth}

The cell cycle is regulated by the sequential activation of cyclin-dependent kinases (CDKs). The activation of CDKs and subsequent phosphorylation of specific substrates govern progress through the cell cycle on multiple levels (Figure 2). CDKs are inactive in the absence of cyclin binding; therefore, cyclin abundance is a major determinant of cyclin-CDK activity (Sherr 1996). Each cyclin is typically present for only a restricted portion of the cell cycle, and changes in cyclin abundance are sufficient to alter the rate of cell cycle progression (Hunter et al., 1994). Specific CDK-inhibitory (CKI) proteins including p15, p16, p21(WAF1/cip1) and p27 target CDK4 that associates with the D-type cyclins in G1 phase. The cyclin-dependent kinase inhibitor p21(WAF1) causes cell arrest in G1 through inhibition of CDK complexes, which are required for the G1 to S transition (Xiong et al. 1993). p21(WAF1) may have additional roles in cell cycle and cancer, because it is able to inhibit DNA replication and repair, independently of its ability to inhibit CDK activity (Michieli et al., 1994). It has been reported that $\mathrm{p} 21(\mathrm{WAF} 1)$ may play a role in the differentiation of epithelial cells and act as a tumor-suppressor gene (Halevy et al., 1995 and Chen et al, 1995). p21(WAF1) immunoreactivity has been recently observed in human neoplastic tissues, where its expression is related to cell proliferation and differentiation (Doglioni et al., 1996). High p21(WAF1) expression could be related to normal or increased p53 function, and low p21(WAF1) expression could be related to p53 gene deletion or mutation. p21(WAF1) expression may reflect different p53 functional states. This idea is based on the observation that p21(WAF1) expression in human breast cancer is low when p53 is mutated (Bukholm et al., 1997).

One of the key endogenous substrates of CDK4 in G1 phase is the retinoblastoma protein (Rb). Its phosphorylation is an important step in the transition between the G1 and S phases of the cell cycle because sufficiently phosphorylated $\mathrm{Rb}$ releases a transcription factor E2F1 that drives cells into $\mathrm{S}$ 
phase (Slansky et al., 1996 ). A diverse body of evidence now indicates that $\mathrm{pRb}$ stands in the midst of G1/S cell cycle regulatory pathway that suffers disruption during the pathogenesis of very many human tumors. Disruption of the $\mathrm{pRb} / \mathrm{E} 2 \mathrm{~F} 1$ interaction could be achieved by $\mathrm{pRb}$ functional inactivation, viral oncoprotein binding, or CDK phosphorylation during tumor progression. As a direct consequence, E2F1 is liberated from control and the progression of cells into late G1 and S becomes uncontrolled. Therefore, drugs which restore $\mathrm{pRb}$ normal function are potential antitumor agents.

\section{Ubiquitin-mediated Protein Degradation}

Endogenous proteins are selectively targeted by the ubiquitin/proteasome system for degradation by means of a complex system of protein-protein recognition elements. Degradation of a protein via proteasomes occurs by two distinct and successive steps. First, the protein is conjugated to ubiquitin. In the second step, the $26 \mathrm{~S}$ proteasome recognizes the ubiquitin-conjugated protein, and degrades it. The ubiquitin system is in both cytosolic and nuclear, and has high selectivity for normal short-lived proteins and misfolded proteins (Kisselev, et al., 1999). Many cell cycle regulatory proteins, including p27 and c-myc have been shown to be phosphorylated, ubiquitinated, and degraded by the proteasome (Montagnoli et al., 1999; Gregory et al., 2000). Thus, the activity of the proteasome performs an important cell cycle regulatory function. 


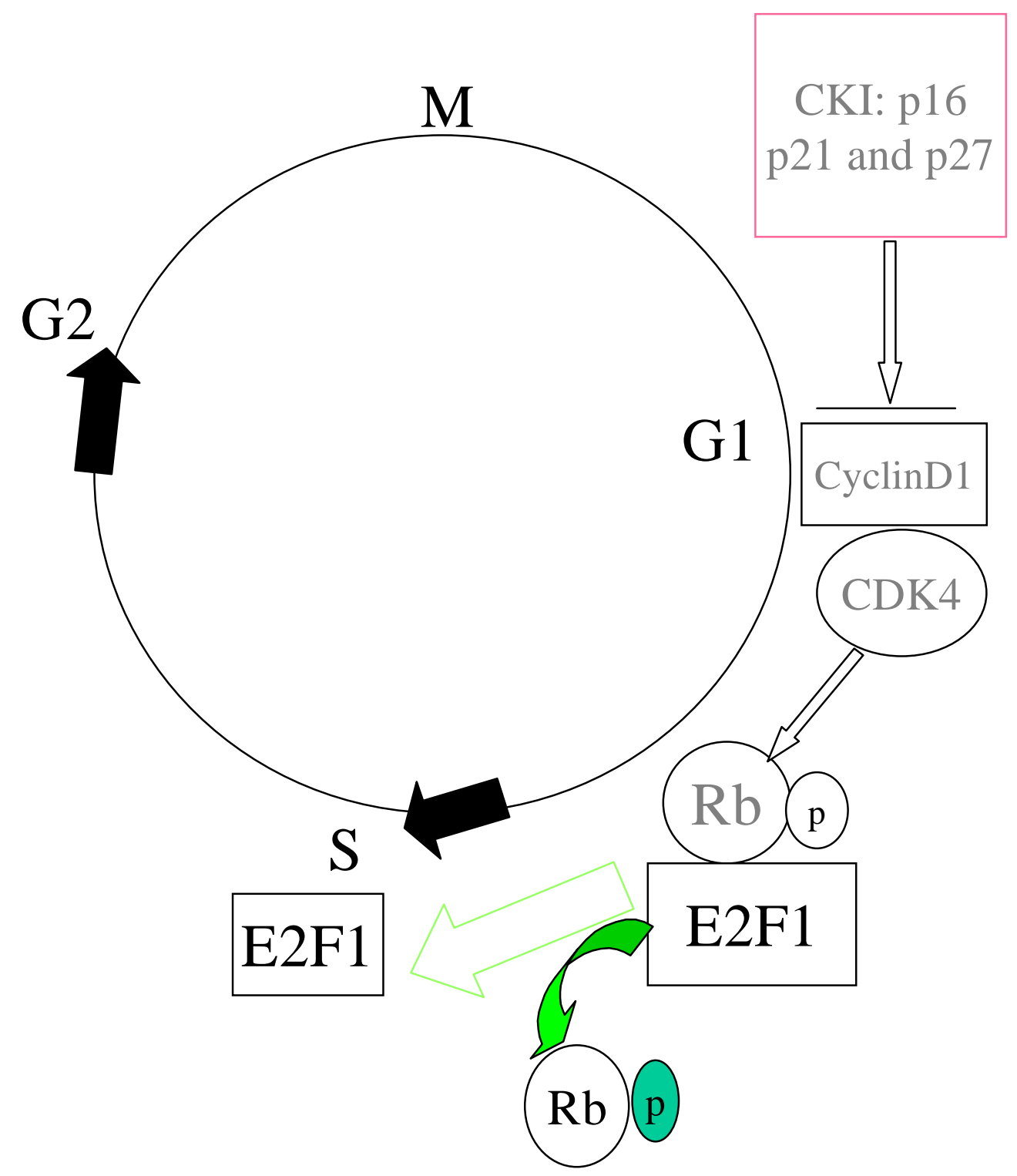

Figure 2. Cell Cycle Regulatory Proteins for G1 to S Phase Transition. Rb (retinoblastoma); CKI (cyclin dependent kinase inhibitor); CDK (cyclin dependent kinase); $\mathrm{p}$ (phosphorylation). 


\section{Apoptosis}

Apoptosis or programmed cell death is a major mechanism for maintaining cell homeostasis in normal development and adult life. It is also an important determinant of the response of tumors to chemotherapeutic agents. Morphological features of apoptosis include chromatin condensation, cell shrinkage, nuclear fragmentation and blebbing with the formation of membrane-bound apoptotic bodies. These events are the result of complex cellular biochemical pathways (Vaux et al., 1999). Disregulation of apoptosis has been identified in many human diseases and is recognized as an important event during carcinogenesis and in tumor progression. Thus, manipulation of apoptotic pathways is a promising approach for the treatment of various human cancers.

Activation of caspases is a central mechanism of apoptosis. Caspases are a family of cysteine proteases, which cleave specific substrates using a cysteine-aspartate recognition sequence. Caspases are synthesized as pro-enzymes and are activated by internal cleavage. Caspases are the executioners of cell death.

Apoptosis usually involves the release of cytochrome c from mitochondria by many different stimuli including tumor necrosis factor (TNF), chemotherapeutic and DNA-damaging agents (Reed 1997). Chemotherapeutic-induced cytochrome c release is caspase-independent in contrast to TNF, which is receptor-mediated apoptosis and depends on activation of caspase-8 (Sun et al., 1999). Activation of cytochrome c-caspase-9 pathway by chemotherapeutic agents leads to tumor cell apoptosis (Brown et al., 1999, and Tada-Oikawa et al., 1998). In the cytosol, cytochrome c combines with Apaf-1 in the presence of ATP to activate caspase-9, which in turn activates effector caspases such as caspase-3,-6 and -7 (Zou et al., 1997; Green et al., 1998). The activation of caspase-3 and subsequent degradative events are responsible for many of the biochemical and morphological changes associated with the apoptotic phenotype including DNA cleavage (Sun et al., 1999). Defects in this pathway which suppress apoptosis may contribute significantly to the development of breast cancer 
and resistance to chemotherapeutic agents. Chemotherapeutic resistance represents a major limitation in the ability of chemotherapy to cure cancer. Alteration in apoptotic-associated genes are often associated with chemotherapeutic resistance (Fisher 1994). The tumor suppressor genes p53 and pRb, the key regulators in DNA damage-induced apoptosis, are frequently mutated in human tumors (Thor et al; 1992). Overexpression of anti-apoptotic Bcl-2 family members has been detected in primary tumors and tumor cell lines (Lotem et al., 1993). Recently, loss of caspase-3 owing to 47-base pair deletion within exon 3 of the caspase-3 gene in MCF-7 cells has been reported (Reiner et al., 1998). Mutated caspase-3 leads to a block in DNA fragmentation of MCF-7 cells (Reiner et al., 1998). Caspase-3 deficiency is believed to contribute to chemotherapeutic resistance in many cancer cell lines (Prokop et al., 2000). Correction of these alterations could result in sensitization of the defective cells to chemotherapeutic agents (Bargou et al., 1996).

\section{Histone Deacetylase (HDAC)}

DNA is highly organized and packaged into the nucleus in eukaryotes (Wolffe 1995). This packaging and organization are achieved by DNA and DNA binding proteins including histones which form a complex structure referred to as chromatin. An average of 150 base pairs of DNA wrapped around a histone octamer, comprised of histones $\mathrm{H} 2 \mathrm{~A}, \mathrm{H} 2 \mathrm{~B}, \mathrm{H} 3$ and $\mathrm{H} 4$ forms the basic structural unit of the chromatin, the nucleosome (Kornberg 1974). Each nucleosome contains two H2As, two H2Bs, two $\mathrm{H} 3 \mathrm{~s}$, and two $\mathrm{H} 4 \mathrm{~s}$ in the core. Linker histone $\mathrm{H} 1$ appears to lie on the outer portion of the nucleosome. Repeating nucleosomes are assembled into a higher order chromatin structure.

Nucleosomes have both positive and negative effects on transcription (Durrin et al., 1991). The dynamic effects of nucleosomes on transcription may be due, in part, to the acetylation of lysine residues present in the hydrophilic amino-terminal portions (tails) of the core histones (Turner, 1991 and Davie et al., 1998). This acetylated state is maintained through the competing activities of histone 
acetyltransferases (HAT) and deacetylases (HDAC). HAT transfers the acetate from acetyl-CoA to neutralize the positively charged- $\varepsilon$-amino group of an unacetylated lysine residue. In contrast, deacetylation is achieved through the hydrolysis of the acetyl moiety, restoring a positive charge (Jeppesen et al., 1993). There is a general correlation between core histone acetylation and gene activity. Conversely, histone hypoacetylation leads to transcriptional repression.

To date, at least nine different mammalian HDACs were described, which are classified in to class I, class II, and Sir2 family. The class I proteins (HDAC1, HDAC2 and HDAC3) are homologou to the yeast transcriptional regulator $\mathrm{Rpd} 3$, bind to $\mathrm{E} 2 \mathrm{~F}$ and repress transcription through an association with pRb (Taunton, et al., 1996; Brehm, et al., 1998); the class II proteins (HDAC4, HDAC5, and HDAC6) are homologou to yeast HDA1 and form a second family of deacetylases that are specifically involved in cell differentiation (Verdel, et al., 1999; Grozinger, et al., 1999). The class II proteins localize to distinct nuclear bodies within the cell nucleus and only recently have been shown to interact with SMRT (silencing mediator for retinoid and thyroid receptor)/N-CoR (nuclear receptor corepressor) as result of transcriptional repression. TSA completely disrupted these nuclear bodies (Kao, et al., 2000). The Sir2 family depends on nicotinamide-adenine dinucleotide (NAD) (Imai, et al., 2000). Specific roles for these enzymes and their target genes remain to be clarified. Inhibition of HDAC activity results in the accumulation of acetylated histones $\mathrm{H} 2 \mathrm{a}, \mathrm{H} 2 \mathrm{~b}, \mathrm{H} 3$, and $\mathrm{H} 4$. As a result of $\mathrm{HDAC}$ inhibition, rather specific effects occur upon the transcription of a small subset of the genome (Van Lint, 1996). Evidence provided by DNA microarrays using malignant cell lines cultured with a HDAC inhibitor showed that a small (1-2\%) number of gene products is altered (Van Lint et al., 1996).

In MCF-7 cells, histone deacetylase 1 (HDAC1) is the most abundant enzyme in HDAC family and is mainly located in nuclear matrix (Hendzel et al., 1991). Histone H4 is the primary target of HDAC1 enzymatic activity (Chen et al., 1999), and this histone undergoes acetylation at lysine residues at 
multiple sites within the histone tails extending from the histone octamer of the nucleosome core (Davie et al., 1998).

\subsection{Disruption of HAT and /or HDAC activity and development of cancer}

Recent evidence suggests a relationship between alteration in chromatin structure by histone hyperacetylation or deacetylation and the development of cancer (Archer et al., 1999). Human $C B P$ participates as a coactivator in cyclic-AMP-regulated gene expression. Mutations in the CBP gene affect HAT activity, and are associated with leukemogenesis (Yang et al., 1996; Petrij et al., 1995). One of the functions of $\mathrm{pRb}$ is to recruit HDAC1 and suppress E2F activity, but the pRb pathway of G1-S cell cycle control is aberrantly altered in most cancers (Archer, et al., 1999). HDAC inhibitors have therapeutic potential because of their ability to elevate histone acetylation level and perhaps restore normal growth control upon tumor cells. Pharmacological inhibitors of HDAC modulate transcription, induce differentiation, and cause cancer cell apoptosis (Marks et al., 2000).

\subsection{Pharmacological HDAC Inhibitors}

Histone deacetylase inhibitors such as sodium butyrate (NaB), trapoxin (TPX), and trichostatin A (TSA), increase acetylated histones in many cell types (Yoshida et al., 1995). Unlike NaB which also has nonselective effects, TSA is thought to specifically inhibit HDAC (Kijima et al. 1993). For this reason, TSA has been used as a tool to study the consequences of histone acetylation in vivo or in vitro (Ogryzko et al., 1996).

The molecular structures for TPX and TSA are shown in Figure 3. The functional group of TSA responsible for the inhibition of HDAC is the hydroxamic acid moiety (Yoshida et al.,1990), which chelates the zinc ion in the active-site pocket of HDAC. TPX contains an epoxyketone structure at the end of the side chain of a constituent amino acid. The epoxyketone function group inserts and binds to the pocket of HDAC, leading to the irreversible inhibition of HDAC (Kijima et al., 1993). 
The characteristic cell response to HDAC inhibitors includes cell cycle arrest in G1, elevated p21(WAF1) expression, hypophosphorylation of $\mathrm{pRb}$, hyperacetylation of histones $\mathrm{H} 4$, cell differentiation and apoptosis (Yoshida et al., 1995; Sambucetti et al., 1999). Histone hyperacetylation by $\mathrm{NaB}$ and TSA is directly linked to the activation of p21(WAF1/Cip1) transcription by Sp1 and/or Sp3 transcription factor activation, which occurs in a p53-independent manner (Xiao et al., 1999). HDAC inhibitors such as TSA also synergize with retinoic acid to enhance differentiation of myeloid leukemia HL-60 cells (Janson 1997).

TSA demonstrated antiproliferative actions in a number of tumor cell lines. TSA has been named as a transcriptional therapeutic agent for neoplasia (Kosugi et al.,1999). A big concern of transcriptional therapy with TSA is its toxicity. Svensson et al. (1998) reported that TSA treatment in vitro caused malformation in embryos. However, a systematic analysis of the toxicology of TSA in adult mice and during embryonic development showed that TSA was not toxic to mouse embryos, and did not intervene with postnatal development (Nervi et al., 2001). Therefore, TSA might be a nontoxic or minimal toxic HDAC inhibitor for the transcriptional therapy of neoplasia. Most recently, FK228, (Nakajima et al., 1998), a synthetic HDAC inhibitor with antitumor activity, is under going clinical trial (phase I) at the National Cancer Institute (Frederick, MD) for cancer therapy. 

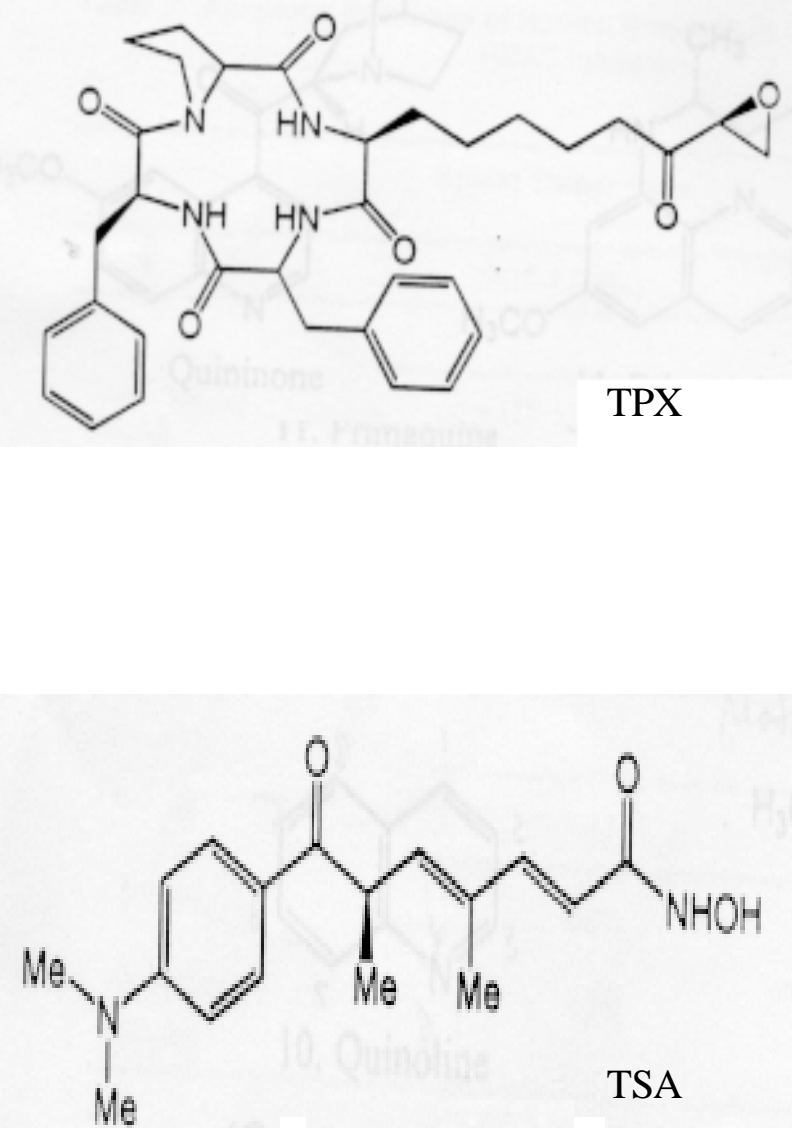

Figure 3. Structures of TPX and TSA 


\subsection{Drug Resistance and HDAC Inhibitors}

The chemotherapeutic agents are challenged by both intrinsic drug resistance and the development of acquired drug resistance during breast cancer treatment (Drewinko, et al., 1981). At the molecular level, at least three protein systems have been reported to be involved in drug resistance: the glucoseregulated protein (grp), the P-glycoprotein (Pgp), and the heat shock protein (hsp).

Cell stress conditions, such as glucose starvation, can be associated with drug resistance. Glucosestarved stress condition is not observed in normal tissues. This tumor specific condition commonly causes the glucose-regulated stress response of cancer cells (Shen, et al., 1987). Induction of grp leads to an increase in resistance to multiple anticancer drugs, such as doxorubicin, etoposide, and vincristine (Wallner et al, 1986; Shen, et al., 1987; Hughes, et al., 1989). The mechanism by which grp induces drug resistance is not clear. However, in mammalian cells the grps represent a subset of stress-induced proteins that were not associated with heat shock and thermotolerance (Shen, et al., 1987).

The second system implicated in drug resistance is the transmembrane Pgp encoded by the MDR (multidrug resistance) gene family (Gottesman, et al., 1988). Composed of two members (MDRl and $M D R 2$ ), only MDR1 seems to be functionally linked to development of the MDR phenotype (Roninson, et al., 1986). The acquisition of the MDR phenotype, defined as increased resistance against cytotoxic drugs, represents one of the major obstacles for chemotherapy of tumors and malignancies. One of the mechanisms that may account for MDR is the surface accumulation of Pgp. Pgp is involved in the transport of small molecules and mediates the efflux of drugs from cells, which is called the multidrug transporter (Germann et al., 1993). The MDR1 gene is subject to control by a variety of internal and external stimuli, including differentiation signals, hsp, cytokines, hormones and a variety of toxic insults (Ince et al., 1997). MDR1 mRNA levels are increased by heat shock, sodium arsenite, and cadmium chloride treatment but not by stresses that activate grp expression (Chin et al., 
1990). Tumor cells that overexpress Pgp are resistant to a wide range of caspase-dependent apoptotic inducers (Smyth et al., 1998); thus, new approaches to inhibit Pgp protein expression are needed and are clinically important.

Overexpression of Pgp can be circumvented by interrupting the transcriptional activation of the MDR1 gene. The proximal promoter of $M D R 1$ contained several regulatory regions, including an inverted CCAAT box at -82 to -73 and a GC element at -56 to -42 , both of which have been shown to be required for constitutive promoter activity (Jin, et al., 1998). Binding of Sp1 to the GC element activates the MDRl promoter in Drosophila cells (Cornwell, et al., 1993), while interaction of the trimeric transcription factor NF-Y with the CCAAT box has been implicated in constitutive regulation of the MDRl promoter in several cell lines ( Goldsmith, et al., 1993; Jin, et al., 1998). Recent studies have shown that the MDR1 gene can be more activated by HDAC inhibitors such as sodium butyrate (NaB), TSA and differentiating agents (Jin et al., 1998; Abolhoda et al.,1999). These agents stimulated the histone acetytransferase PCAF to bind with the MDR1 promoter as result of acetylattion of promoter-proximal histones following transcriptional activation (Mickley, et al, 1989; Jin, et al., 1998; Hu et al., 2000). The net effect needs to be determined; it is possible that Pgp protein function is blocked by TSA and NaB treatment.

The third stress-responsive system implicated in drug resistance is the heat shock protein system. Resistance to doxorubicin has been observed in human breast cancer cells with elevated hsp27. MDAMB-231 human breast cancer cells transfected with a plasmid containing the structural gene for human hsp27 expressed both thermoresistance and drug resistance (Oesterreich, et al.,1993). Hsp27 could be a very important mediator of chemoresistance. 


\section{Program Aims}

Quinidine is used as an anti-malarial and also as an anti-arrhythmic agent. Previous studies from our laboratory demonstrated that quinidine arrested cells in early G1 phase, and induced apoptosis in MCF-7 cells (Wang et al., 1998), but the biochemical mechanisms for the anti-proliferative effects of

quinidine are not well understood. To clarify the molecular mechanisms of the anti-proliferative activity of quinidine, we investigated the effects of quinidine on cell cycle regulatory proteins and histone acetylation . Based on effects of quinidine, a prototype quinoline derivative, on HDAC activity, histone $\mathrm{H} 4$ and apoptosis, we begin to explore whether all quinoline-based antimalarials have a similar profile of antitumor activities in human breast cancer cells. 


\section{MATERIALS AND METHODS}




\section{Chemicals}

Amodiaquin, chloroquine, etoposide, Oil Red O, quinidine, quinine, quinoline, quinolinic acid, and trichostatin A (TSA) were purchased from Sigma Chemical Company (St. Louis, MO). Calcium acetate was purchased from Fisher (Pittsburgh, PA). Mefloquine and Halofantrine Methylsulfate were provided by the National Cancer Institute (Bethesda, MD). Recombinant histone H4 protein (expression in E.coli, cat \#14-412) was purchased from Upstate Biotechnology (Lake Placid, NY).

\section{Tissue Culture}

Permanent cell lines derived from patients with breast carcinomas were used in these studies. MCF-7 cells, passage numbers 30 - 50, were maintained in Dulbecco's Modified Eagle's medium (DMEM) (BioWhittaker, Walkersville, MD) supplemented with $10 \%$ fetal bovine serum (FBS) (Hyclone Laboratories, Inc., Logan, Utah), and $40 \mathrm{ug} / \mathrm{ml}$ gentamicin. MCF-7-YAMA cells were obtained from Dr. Lahti (St. Jude's Children's Research Hospital, Memphis, TN). The cells were stably transformed with a plasmid expressing caspase-3. MCF-7 -YAMA cells were grown in DMEM supplemented with $10 \%$ FBS, and 500ug/ml geneticin. MDA-MB-468 cells were from the American Type Culture Collection (Rockville, MD). MDA-MB-468 cells lines were maintained in medium consisting of DMEM/F12 (1:1) (Life Technologies, Rockville, MD) supplemented with 10\% FBS, and 50units/ml of both penicillin and streptomycin. The cells were maintained at $37^{\circ} \mathrm{C}$ in a humidified atmosphere of $93 \%$ air/7\% $\mathrm{CO}_{2}$. After 4 or 5 days, cells became about $70-80 \%$ confluent and were passaged at a 1:5 ratio.

\section{Western Blotting}

Confluent cells were subcultured $\left(1 \times 10^{6}\right)$ in $100 \mathrm{~mm}^{2}$ dishes. Twelve hours after plating, cells were treated with drug. At specific time points, cell lysates were prepared according to Dr. J.R Davie's 
protocol (personal communication). The cells were harvested at the times indicated by scraping into harvesting buffer (1\% SDS and 10mM Tris-HCl, $\mathrm{pH} 7.4)$. Cell lysates were boiled for $5 \mathrm{~min}$, centrifuged in an Eppendorf microcentrifuge (14,000 rpm, 5 minutes) at $4^{\circ} \mathrm{C}$, and then the supernatants were collected. One tablet Complete ${ }^{\mathrm{TM}}$ (protease inhibitor cocktail, cat. \# 1836153, Roche Boehringer Mannheim, Indianapolis, IN) was dissolved in $1.5 \mathrm{ml}$ distilled $\mathrm{H}_{2} \mathrm{O} ; 2.5 \%(\mathrm{v} / \mathrm{v})$ of reconstituted protease inhibitor solution was added immediately to the supernatant. The protein concentration of the supernatant was determined using a BCA protein assay (Pierce, Rockford, IL) and bovine serum albumin as a standard unless otherwise noted. For Western blots, 5x SDS (sodium dodecyl sulfate)loading buffer $(3.15 \mathrm{mM}$ Tris- $\mathrm{HCl}, \mathrm{pH} 7.0,50 \%(\mathrm{v} / \mathrm{v})$ glycerol, $0.1 \%$ SDS (w/v), and 1\% (v/v) bromphenol blue) plus 2-mercaptoethanol (12.5ul of 2-mercaptoethanol per 100 ul 5x SDS-loading buffer) was added to the protein samples. The protein samples were heated in a sand bath for 5 min at $100^{\circ} \mathrm{C}$. Equal amounts of protein were loaded onto $10 \%$ SDS-polyacrylamide mini-gels. Colored molecular weight protein markers (RPN756, Amersham Pharmacia Biotech Inc., Piscataway, NJ) were used to indicate different protein molecular weight. Proteins were transferred to polyvinylidene difluoride membranes (PVDF, Novex, San Diego, CA) and blocked overnight at $4{ }^{0} \mathrm{C}$ using $3 \%$ nonfat milk blocking buffer (3g non-fat dry milk in $100 \mathrm{ml}$ of TBS $(20 \mathrm{mM}$ Tris- $\mathrm{HCl}, \mathrm{pH} 7.5,0.5 \mathrm{M} \mathrm{NaCl})$ and $0.05 \%(\mathrm{v} / \mathrm{v})$ Tween 20). Membranes were incubated for $3 \mathrm{~h}$ at room temperature with the following primary antibodies: mouse monoclonal anti-p21 (WAF1) (Ap-1, cat. \# OP64-100UG) from Calbiochem (Cambridge, MA), mouse monoclonal anti-epithelial glycoprotein (cat. \# MAB-4043) from Chemicon International (Temecula, CA) and anti-acetylated histone H4 antibody (rabbit polyclonal, cat.\# 06-598, Upstate Biotechnology, NY). The primary antibodies were diluted 1:500 in Western washing solution ( $0.1 \%$ non-fat dry milk, $0.1 \%$ albumin (chicken egg), $1 \%$ (v/v) FBS, 10\%(v/v)10xPBS (1.4 M NaCl, $0.02 \mathrm{M} \mathrm{KCl,} 0.08 \mathrm{M} \mathrm{Na}_{2} \mathrm{HPO}_{4} .7 \mathrm{H}_{2} \mathrm{O}$ and $15 \mathrm{mM} \mathrm{KH}_{2} \mathrm{PO}_{4}, \mathrm{pH} 7.0$ ) and $0.2 \%(\mathrm{v} / \mathrm{v})$ Tween-20). After washing three times with Western washing solution and then one time 
with TBS, the antigen-antibody complexes were incubated $1 \mathrm{~h}$ at room temperature with HRP (horseradish peroxidase)-conjugated secondary antibodies (rabbit IgG-HRP (SC-2004), and mouse IgG-HRP (SC-2005) from Santa Cruz Biotechnology) diluted 1:3000 in Western washing solution. After washing three times with TBS, antibody binding was visualized using enhanced chemiluminescence (SuperSignal West Pico, cat. \#1856136, Pierce, Rockford, IL) and autoradiography. The experiments were repeated at least three times.

\section{Histone extraction}

Confluent MCF-7 cells were plated at $6 \times 10^{6}$ (maximal cell number: $1 \times 10^{7}$ ) $/ \mathrm{T}-162$ flask in $20 \mathrm{ml}$ of 5\% FBS/DMEM. The cells then were grown in a humidified incubator chamber in $7 \% \mathrm{CO}_{2}$ at $37^{0} \mathrm{C}$ for $12 \mathrm{~h}$. MTS IC50 of each antimalarial was added into each flask and incubated for the times indicated. After that, the growth medium was removed. Following a quick rinse with ice-cold PBS, cells were scraped into $4 \mathrm{ml}$ of ice-cold lysis buffer $(10 \mathrm{mM}$ Tris $\mathrm{HCl}, 50 \mathrm{mM}$ sodium bisulfite, $1 \%$ Triton X-100 (v/v), $10 \mathrm{mM} \mathrm{MgCl}_{2}, 8.6 \%$ sucrose, $\mathrm{pH}$ 6.5) and nuclei released by Dounce homogenization (glass $\mathrm{T}$ type, five strokes). The nuclei were collected by centrifugation $(3,000 \mathrm{rpm}$, 10 minutes, SS-34 rotor) at $4^{0} \mathrm{C}$ and washed three times with the lysis buffer. Histones were extracted from the crude nuclear pellets using the procedure of Nakajima et al. (1998). The pellets were resuspended in $0.1 \mathrm{ml}$ of ice-cold sterile water using a vortex and concentrated $\mathrm{H}_{2} \mathrm{SO}_{4}$ to $0.2 \mathrm{M}$ was added. The preparation was incubated at $4^{0} \mathrm{C}$ for $1 \mathrm{~h}$, then centrifuged $(17,000 \mathrm{rpm}$, Sorvall SS-34 rotor) for 10 minutes at $4^{0} \mathrm{C}$. The supernatant containing the extracted histones was mixed with $10 \mathrm{ml}$ of acetone, and the precipitate obtained after an overnight incubation at $-20^{\circ} \mathrm{C}$ was collected and airdried. The acid-soluble histone fraction was dissolved in $50 \mathrm{ul} \mathrm{of} \mathrm{H}_{2} \mathrm{O}$, and stored at $-70^{0} \mathrm{C}$. 


\section{Cell Death ELISA ( enzyme-linked immunosorbent assay)}

Apoptotic death cells were measured with the use of the cell death ELISA kit (Roche Molecular Biochemicals, Indianapolis, IN). The assay is based on quantitative sandwich-enzyme-immunoassayprinciple using mouse monoclonal antibodies directed against DNA and histones, respectively. This allows the specific determination of mono- and oligonucleosomes that are released into the cytoplasmic fraction of cell lysates during the early stage of apoptosis.

Cells $\left(4.0 \times 10^{3}\right)$ were plated in each well of 96-well plates and treated with either drug in 5\%FBS/DMEM or 5\% FBS/DMEM alone (control cells) for 48 or $72 \mathrm{~h}$. Each treatment was performed in triplicate. To prepare cell cytoplasmic fractions, the supernatant which contains necrotic cell bodies was carefully removed by fast inversion of the plate. The attached cells were resuspended in $200 \mathrm{ul}$ lysis buffer, incubated for $30 \mathrm{~min}$ at room temperature. The lysate was centrifuged using a microtiter plate centrifuge (Sorvall GLC-2B General Laboratory centrifuge) at 200x $g$ for $10 \mathrm{~min}$, and then $20 \mathrm{ul}$ of the supernatant (cytoplasmic fraction) was transferred into the streptavidin coated cell culture grade microtiter plate (MTP) for analysis. A mixture of anti-histone-biotin and anti-DNA-POD (peroxidase) was added and incubated for 2 hours at room temperature. During the incubation periods, the antihistone antibody bound to the histone-component of the nucleosomes present in the cell lysate, and simultaneously fixed the immunocomplex to the streptavidin-coated MTP via its biotinylation. Additionally, the anti-DNA-POD antibody reacted with the DNA-component of the nucleosomes. After removal of unbound antibodies by a washing step, the amount of the nucleosomes was quantified by the POD retained in the immunocomplex. POD was determined spectrophotometrically using ABTS (2,2-Azino-di-3-ethylbenzthiazolin-sulfonat) as the substrate. The sample absorbances were measured at $405 \mathrm{~nm}$ in the microtiter plate reader (EL340 BIOKINETICS READER, Bio-Tek Instruments, Winooski, Vermont). 


\section{MTS Assay}

The MTS assay is based on the reduction of the yellow-colored-tetrazolium compound (MTS) by mitochondrial dehydrogenases of metabolically active cells to a blue formazan product which can be measured spectrophotometrically. It is a measurement of cell viability.

MCF-7 cells were plated at $4.0 \times 10^{3}$ cells/well in 96-well plates in 225 ul of 5\% FBS/DMEM. The cells then were grown in a humidified incubator chamber in $7 \% \mathrm{CO}_{2}$ at $37^{0} \mathrm{C}$ for $12 \mathrm{~h}$. Stock solution $(10 \mathrm{mM})$ of quinidine and other compounds were diluted in the appropriate medium immediately prior to use. Test agents were added at different concentrations into each well of the plate and incubated for 48 h. Cell proliferation was measured using a MTS assay kit (CellTiter 96 AQueous one solution assay, Promega, Madison, WI) according to the manufacturer's instructions. Briefly, the culture medium was removed from each well of the plate; 100ul of DMEM plus 5\% FBS were added into all wells of the plate; 20ul of CellTiter 96 AQueous One Solution were immediately pipeted into each well. The plate was incubated for $2 \mathrm{~h}$ at $37^{0} \mathrm{C}$ in a humidified $5 \% \mathrm{CO} 2$ atmosphere, and the absorbance was read at 490nm using the microtiter plate reader (Spectra Max 340PC). This assay is linear for 2.5 h.

Assays run in triplicate were repeated at least two times. Means \pm SE were given. The concentration of each agent that inhibited cell growth by 50\% (IC50) was determined in each case using nonlinear regression analysis to fit inhibition data to the appropriate dose-response curve (GraphPad Prism version 3.0; GraphPad Software, Inc., San Diego, CA).

\section{Ki67 Immunohistochemical Assay}

An immunohistochemical assay for $\mathrm{Ki} 67$ antigen was performed according to the protocol described by Wang et al (1998). MCF-7 cells were plated on $5 \times 5 \mathrm{~mm}^{2} 95 \%$ ethanol-washed glass coverslips in $35 \mathrm{~mm}^{2}$ dishes at 2x $10^{5}$ cells per dish in 5\% FBS/DMEM culture medium. After $12 \mathrm{~h}$, 
cells were treated with different antimalarials at the IC50 determined in the MTS assay for $48 \mathrm{~h}$. At that time point, cells were fixed in acetone:ethanol (50:50) on ice for $10 \mathrm{~min}$, and then washed with Dulbecco's phosphate-buffered saline (PBS (140 mM NaCl, $2 \mathrm{mM} \mathrm{KCl,} 80 \mathrm{mM} \mathrm{Na} 2 \mathrm{HPO}_{4} .7 \mathrm{H}_{2} \mathrm{O}, 1.5$ $\left.\mathrm{mM} \mathrm{KH} 2 \mathrm{PO}_{4}, \mathrm{pH} 7.0\right)$ )-0.15\% bovine serum albumin (BSA), fraction V (A-9647, Sigma) (PBS-BSA). Coverslips were incubated with peroxidase blocking solution ( $0.3 \%$ hydrogen peroxide in methanol) for 10 min. Cells then were rinsed with PBS-BSA, and incubated with $10 \%$ horse serum in PBS-BSA for 30 min. After incubation, primary antibody for Ki67 (MIB-1, cat \# M7240, Dako Corporation, Glostrup, Denmark) was diluted in PBS-BSA at 1:77 and added to the coverslips for 60 min. After rinsing with PBS-BSA, the coverslips were immediately incubated with second antibody (1:250 in PBS-BSA, biotinylated horse anti-mouse IgG, Vector Laboratories, Burlingame, CA) for $30 \mathrm{~min}$. Following washing with PBS-BSA, the coverslips were incubated with the avidin-biotin-peroxidase reagent (Vector Laboratories) for $30 \mathrm{~min}$. The coverslips were washed in PBS, and the antigenantibody complex was visualized using diaminobenzidine (Stable DAB, Research Genetics, Huntsville, AL), and then counterstained with Mayer's hematoxylin (Fisher Scientific, Pittsburgh, PA). Finally, coverslips were mounted using Permount (Fisher Scientific, Pittsburgh, PA). Ki67 negative cells were visualized by light microscopy (400x objective, Ortholux microscope, Ernst Leitz, Wetzlar, Germany).

Cells were individually assigned with negative or positive staining, and the Ki67 negative percentage of the cell population was determined by counting. In each coverslip, at least 500 cells were counted. 


\section{Oil Red Assay}

Lipid droplet accumulation, a classic differentiation marker, was measured in breast cancer lines using Oil Red O staining (Graham et al, 1988). Oil Red O stock solution (0.5\% Oil Red O in 98\% isopropanol) was prepared. MCF-7 cells were plated on 5x5 mm 95\% ethanol-washed glass coverslips in $35 \mathrm{~mm}^{2}$ dishes at $1 \times 10^{5}$ cells per dish. After cells were treated with drug or vehicle for 48 and $72 \mathrm{~h}$ respectively, cells were fixed in $10 \%$ formaldehyde and $0.2 \%$ calcium acetate in PBS for 3 minutes and then transferred to an Oil Red O staining solution for 10 minutes (Oil Red O stock solution diluted 6:4 in distilled water, and filtered through No.42 Whatman filter paper (Bancroft et al., 1984)). The slides were washed briefly in distilled water and then counterstained with Mayer's Hematoxylin solution (Fischer, Pittsburgh, PA) for $1 \mathrm{~min}$ at room temperature. After incubation, slides were washed in $0.4 \%$ $\mathrm{NH}_{4} \mathrm{OH}$, rinsed in distilled water, and then mounted using 50\% glycerol (50:50 glycerol/water (v/v)). The lipid accumulation was visualized by light microscopy (400x objective, Ortholux microscope, Ernst Leitz, Wetzlar, Germany).

Cells were individually assigned either as negative ORO denoting no lipid or less that 10 lipid droplets within a cell or positive ORO cells that had at least 10 lipid droplets per cell. The percentage of positive ORO cells was determined; at least 300 cells were counted .

\section{9. p21(WAF1) ELISA}

Cells were plated at the density $1 \times 10^{6}$ cells $/ 100 \mathrm{~mm}^{2}$ dish in $5 \%$ FBS/DMEM culture medium. After $12 \mathrm{~h}$, cells were exposed to each antimalarial at the MTS IC50 for $24 \mathrm{~h}$. The total cell p21(WAF1) protein levels were measured using a colorimetric assay (WAF1 ELISA, cat.\# QIA18, Oncogen, Boston, MA) according to the manufacturer's instructions. Briefly, the cells were harvested at the times indicated by scraping into harvesting buffer (1\% SDS and 10mM Tris- $\mathrm{HCl}, \mathrm{pH} 7.4)$. Cell lysates were boiled for $5 \mathrm{~min}$, and then centrifuged in an Eppendorf microcentrifuge (14,000 rpm, 5 minutes) 
at $4{ }^{0} \mathrm{C}$. The supernatants were collected. One tablet Complete ${ }^{\mathrm{TM}}$ (protease inhibitor cocktail, cat. \# 1836153, Roche Boehringer Mannheim, Indianapolis, IN) was dissolved in $1.5 \mathrm{ml}$ distilled $\mathrm{H}_{2} \mathrm{O} ; 2.5 \%$ $(\mathrm{v} / \mathrm{v})$ of reconstituted protease inhibitor solution was added immediately to the supernatant. The protein concentration of the supernatant was determined using a BCA protein assay (Pierce, Rockford, IL) and bovine serum albumin as a standard. Fifty ug of cell lysate was transferred into the streptavidin-coated cell culture grade microtiter plate (MTP) for analysis. One hundred ul of p21 (WAF1) antibody was added to each well, and incubated for $2 \mathrm{~h}$ at room temperature. Additionally, 100ul of 1X Streptavidin Conjugate (horseradish peroxidase) were pipetted into each well. After removal of unbound antibodies by a washing step, the amount of p21(WAF1) was determined spectrophotometrically with substrate solution. The samples were measured at 490nm in the microtiter plate reader (Spectra Max 340PC). Quantitation is achieved by the construction of a standard curve using known concentrations of WAF1. In each experiment, a p21(WAF1) antibody-antigen standard curve was performed (the samples were incubated for $20 \mathrm{~min}$ ). By comparing the absorbance obtained from a sample containing as unknown amount of WAF1 with that obtained from the standards, the concentration of WAF1 in the sample can be determined.

\section{Histone Deacetylase (HDAC ) Fluorescent Activity Assay}

The HDAC Fluorescent Activity Assay (Drug Discovery kit cat \# AK-500, BIOMOL Research Laboratories, Inc. Plymouth Meeting, PA) was used to screen drugs for the ability to directly inhibit HDAC activity. This assay system measures histone deacetylase activity present in a commercial HeLa (human cervical cancer cell line) cell nuclear extract, which is rich in HDAC activity. The potent HDAC inhibitor, trichostatin A $(0.4 \mathrm{uM})$, was used as a positive control.

The principle of this assay is follows. The HDAC substrate contains an acetylated lysine side chain. After incubation with the HeLa nuclear extract, HDAC-mediated deacetylation of the substrate 
sensitizes the substrate so that, upon addition of a developer agent, the deacetylated lysine becomes a fluorophore. Briefly, reactions were performed in $50 \mathrm{ul}$. Fifteen ul of diluted HeLa extract and $10 \mathrm{ul}$ of different concentrations of antimalarials were added into appropriate wells of the microtiter plate at room temperature; HDAC reactions were initiated by adding diluted substrate ( $25 \mathrm{ul})$ to each well and mixing thoroughly; the reactions were performed for $10 \mathrm{~min}$, and then the developer (50ul) was added into each well of the microtiter plate to stop the HDAC reactions. The plate was incubated at room temperature for $10 \mathrm{~min}$, and read in a microtiter-plate reading fluorimeter using an excitation at a wavelength in the range 350-380nm and emission in the range 440-460nm (CytoFluor, Muti-well Plate Read Series 4000, PerSeptive Biosystems, Farmingham, MA).

\section{Densitometric Analysis}

Autoradiograms of the Western immunoblots were scanned using ChemiImager software (Alpha Innotech Corporation, San Leandro, CA). The blots were adjusted for brightness and contrast, and the mean density for each band was analyzed using ChemiImager analysis program. In this program, a rectangle which was called as a object was drawn around the detected spot, the AUTO BACKGRD (the program function name) determined the average of the 10 lowest pixel values in each individual object and assigned that value to the background. This background value was unique for each object, and was subtracted from all the pixels in the object. Unless specified otherwise, the results shown in each case are representative of three independent experiments with similar findings. 


\section{Statistical Evaluation}

Data are expressed as the mean \pm SER (standard error), with the number of replicates indicated in the figure legends. One-way ANOVA (analysis of variance) followed by Bonferroni's t-tests were used to assess statistical significance of difference between control- and drug-treated samples. Differences among the means were considered different if $\mathrm{p}$ values less than 0.05 were obtained using the GraphPad Instat computer program (Intuitive Software for Science, San Diego, CA). 


\section{RESULTS}


1. Rapid Induction of Histone Hyperacetylation and Cellular Differentiation

in Human Breast Tumor Cell Lines Following Degradation

of Histone Deacetylase-1

Zhou, Q., Melkoumian, Z.K.,Lucktong, A, Moniwa, M., Davie, JR and Strobl JS 


\subsection{Introduction}

Histone deacetylase (HDAC) proteins comprise a family of related proteins that act in conjunction with histone acetyltransferase proteins to modulate chromatin structure and transcriptional activity via changes in the acetylation status of histones. Histones $\mathrm{H} 3$ and $\mathrm{H} 4$ are the principal histone targets of HDAC enzymatic activity, and these histones undergo acetylation at lysine residues at multiple sites within the histone tails extending from the histone octamer of the nucleosome core. The association of HDAC proteins with $\mathrm{mSin} 3, \mathrm{~N}-\mathrm{CoR}$ or SMRT and other transcriptional repressors has led to the hypothesis that HDAC proteins function as transcriptional co-repressors (Davie et al., 1998). The spectrum of genes that show alterations in gene transcription rates in response to decreased HDAC activity is quite restricted (Van Lint et al., 1996). Yet, small molecule inhibitors of the enzyme histone deacetylase (HDAC) such as trichostatin A (TSA), superoylanilide hydroxamic acid (SAHA), trapoxin, and phenylbutyrate cause major alterations in cellular activity including the induction of cellular differentiation and apoptosis (Medina et al., 1997; Richon et al.; 1998; Sambucetti et al., 1999). Trichostatin A, SAHA and trapoxin stimulate histone acetylation by acting as direct inhibitors of HDAC enzyme activity (Yoshida et al., 1999). Trichostatin A, SAHA and trapoxin possess lysine-like side-chains and act as chemical analogs of lysine substrates. Molecular models based upon the X-ray crystal structure of an HDAC-like protein indicate that trichostatin A and SAHA can bind within the active site of the HDAC enzyme and interact with a zinc metal ion within the catalytic pocket that is critical for enzymatic activity (Finnin et al., 1999). Trapoxin is an irreversible HDAC enzyme inhibitor (Kajima et al., 1993).

Much remains to be learned about the biochemical events subsequent to HDAC inhibition that lead to cell cycle arrest, cellular differentiation, and apoptosis. However, a spectrum of biological responses characteristic of HDAC inhibitors has emerged, including cell cycle arrest in G1, elevated p21/WAF1 expression, hypophosphorylation of retinoblastoma protein ( $\mathrm{pRb}$ ), hyperacetylation of histones, 
particularly $\mathrm{H} 3$ and $\mathrm{H} 4$, and apoptosis. Histone hyperacetylation is directly linked to the activation of p21 transcription and is p53-independent (Sambucetti et al., 1999). This observation provides an important link between HDAC inhibition and cell cycle arrest because p21/WAF1 plays a critical role in causing G1 cell cycle arrest via inhibition of the G1 cyclin-dependent kinase family (Xiong et al., 1993). Overexpression of p21/WAF1 has also been associated with apoptosis, but the mechanism of p21/WAF1-induction of apoptosis requires further investigation (Sheikh et al., 1995).

Cancer therapy that targets the activity of genes or gene products controlling cell cycle progression, differentiation and apoptosis is a promising new strategy. Because HDAC inhibitors regulate the cell cycle and cause both cellular differentiation and apoptosis, they comprise an interesting group of compounds with potential for development into a new category of clinically significant anti-tumor agents. Single, key protein targets for "gene-regulatory chemotherapy" are difficult to identify due to the existence of parallel, functionally overlapping signaling cascades. For this reason, use of cancer therapies that target multiple intracellular signaling pathways, such as observed with the HDAC inhibitors, is an intriguing approach that addresses the problem of redundancy in growth signaling pathways. In this regard, the HDAC inhibitor phenylbutyrate was recently shown to have clinical antitumor activity (Warrel et al., 1998).

Quinidine is a natural product therapeutic agent originally used as an anti-malarial and as an antiarrhythmic agent. Previous studies with human breast tumor cell lines demonstrated that quinidine (90 $\mathrm{uM})$ is an anti-proliferative agent as well. Quinidine arrested cells in early G1 phase, and induced apoptosis by $72-96 \mathrm{hr}$ in MCF-7 cells (Wang et al., 1998), but the biochemical basis for the antiproliferative effect of quinidine was not well understood. To clarify the molecular mechanisms of the anti-proliferative activity of quinidine, we investigated the effects of quinidine on histone acetylation and cell cycle regulatory proteins. In this report, we show that quinidine causes hyperacetylation of histone $\mathrm{H} 4$, downregulation of HDAC1 protein levels, and cellular differentiation in a panel of human 
breast tumor cell lines. We conclude that quinidine is a novel differentiating agent that stimulates histone hyperacetylation as a result of HDAC1 protein degradation.

\subsection{Methods}

\section{Cell culture}

Permanent cell lines derived from patients with breast carcinomas were used in these studies. MCF-7 cells, passage numbers 40 - 55, MCF-7-ras (Kasid et al., 1985), T47D, MDA-MB-231, and MDA-MD-435 cells were maintained in Dulbecco's Modified Eagle's medium (DMEM) (BioWhittaker, Walkersville, MD) supplemented with 10\% heat-inactivated fetal bovine serum (FBS) (Hyclone Laboratories, Inc., Logan, Utah), 2mM glutamine, and $40 \mathrm{ug} / \mathrm{ml}$ gentamicin. Experiments were performed in this medium supplemented with 5\% FBS. The cells were maintained at $37 \mathrm{C}$ in a humidified atmosphere of $93 \%$ air/7\% $\mathrm{CO}_{2}$. After six days, cells became about $70-80 \%$ confluent and were passaged at a 1:5 ratio $(\mathrm{MCF}-7)$ or at a 1:10 ratio (all others). Normal human mammary epithelial cells (HMEC) were obtained from Clonetics, San Diego, CA were grown according to directions of the suppliers. Cells were grown from frozen stocks and used for 1-3 passages. Quinidine, TSA, and all trans-retinoic acid were purchased from Sigma Chemical Company (St. Louis, MO). The cell permeant proteasome inhibitors, MG-132 and lactacystin, were purchased from Calbiochem-Novabiochem (San Diego, CA).

\section{Growth inhibition assays}

Growth inhibition by cell numbers was assayed by plating cells in $35 \mathrm{~mm}^{2}$ dishes $\left(1-1.5 \times 10^{5}\right)$ containing DMEM/ 5\% FBS plus quinidine $(90 \mathrm{uM})$. Viable cells were counted using a hemacytometer and trypan blue $(0.02 \%)$ exclusion was used as an indicator of viability. Cell growth 
was also monitored in a 96-well plate format using the One Solution Cell Proliferation Assay (Promega, Madison, WI), that is based upon metabolic bioreduction of a tetrazolium compound (Owen's reagent) to a colored formazan product that absorbs light at $490 \mathrm{~nm}$. The plating density for the 96-well dishes (cells/well) was varied depending upon the relative growth rates of the cell lines as follows: HMEC (2000), MCF-7 (1000), MDA-MB-231 (500), T47D (1500), and MCF-7ras (500). The One Cell Proliferation Assay Reagent was added to each well and incubated for $2 \mathrm{~h}$ at $37^{\circ} \mathrm{C}$. Absorbance (490 nm) was read using a Molecular Devices PC340 (Sunnyvale, CA).

\section{Microscopic Imaging}

Cells were plated $\left(1 \times 10^{5}\right)$ on sterile coverslips in $35 \mathrm{~mm}^{2}$ dishes, and grown for $96 \mathrm{~h}$ in DMEM / 5\% FBS supplemented with either $10 \mathrm{uM}$ all-trans retinoic acid (in $0.01 \%$ ethanol) or $90 \mathrm{uM}$ quinidine (in $\mathrm{H}_{2} 0$ ). Control cells were grown in medium containing a final concentration of $0.01 \%$ ethanol. The presence of ethanol had no effect upon lipid droplet accumulation compared to cells grown in DMEM / $5 \%$ FBS. Cells were fixed in $3.7 \%$ formaldehyde - PBS, rinsed in PBS, then treated briefly with $0.4 \%$ Triton X-100 in PBS. After rinsing three times in PBS, the cells on coverslips were incubated for 30 $\min$ at $37^{\circ} \mathrm{C}$ with a primary antibody to cytokeratin $18(1: 1$ dilution, provided by Dr. Guillaume van Eys, Maastricht University), rinsed and incubated $\left(30 \mathrm{~min} / 37^{\circ} \mathrm{C}\right)$ with Texas Red conjugated secondary antibody (goat anti-mouse IgG, Sigma). Alternatively, cells were incubated with fluoresceinphalloidin ( $5 \mathrm{ug} / 0.1 \mathrm{ml}$, Sigma) in the dark for $40 \mathrm{~min}$ at room temperature, rinsed and incubated for 5 min (room temperature) with the fluorescent lipid stain, Nile Red (1:10,000 dilution of a $1 \mathrm{mg} / \mathrm{ml}$ acetone solution, Sigma) (Greenspan et al., 1985 and Toscani et al., 1990). All coverslips were rinsed in PBS, and mounted with Fluoromount - G containing 2.5\% N-propyl galate. Images were obtained using a Zeiss Axiovert $100 \mathrm{M}$ confocal microscope (63 X objective). 


\section{Immunoblotting:}

Cells were harvested from confluent T-75 flasks and subcultured $\left(1 \times 10^{6}\right)$ in $100 \mathrm{~mm}^{2}$ dishes. On subcultivation, this confluent population of cells (85\% in G1) synchronously proceeded through the cell cycle. To prepare whole cell lysates, the cells were harvested at the times indicated by scraping into ice-cold buffer (50 mM Tris-HCl, $0.25 \mathrm{M} \mathrm{NaCl}, 0.1 \%$ (v/v) Triton X-100, 1mM EDTA, $50 \mathrm{mM}$ $\mathrm{NaF}$ and $0.1 \mathrm{mM} \mathrm{Na} \mathrm{VO}_{4}, \mathrm{pH}$ 7.4). Protease inhibitors (protease inhibitor cocktail, Roche Molecular Biochemicals, Indianapolis, IN) were added immediately. Cell lysates were centrifuged in an Eppendorf microcentrifuge $(14,000 \mathrm{rpm}, 5 \mathrm{~min})$ at $4{ }^{0} \mathrm{C}$, and the supernatants used in immunoblotting experiments.

Histones were prepared from cells grown at a density of $1 \times 10^{7} / \mathrm{T}-162$ flask. To harvest the cells, the flasks were placed on ice, and the growth medium removed. Following a quick rinse with ice-cold PBS, cells were scraped into $1 \mathrm{ml}$ of ice-cold lysis buffer $(10 \mathrm{mM}$ Tris $\mathrm{HCl}, 50 \mathrm{mM}$ sodium bisulfite, $1 \%$ Triton $\mathrm{X}-100(\mathrm{v} / \mathrm{v}), 10 \mathrm{mM} \mathrm{MgCl}_{2}, 8.6 \%$ sucrose, $\mathrm{pH}$ 6.5) and nuclei released by Dounce homogenization. The nuclei were collected by centrifugation $(3,000 \mathrm{rpm}, 10 \mathrm{~min}, \mathrm{SS}-34$ rotor) and washed three times with the lysis buffer. Histones were extracted from the crude nuclear pellets using the procedure of Nakajima et al. (1998). The pellets were resuspended in $0.1 \mathrm{ml}$ of ice-cold sterile water using a vortex and concentrated $\mathrm{H}_{2} \mathrm{SO}_{4}$ to $0.4 \mathrm{~N}$ was added. The preparation was incubated at $4^{0} \mathrm{C}$ for $1 \mathrm{~h}$, then centrifuged $(17,000 \mathrm{rpm}, 10 \mathrm{~min}$, Sorvall SS-34 rotor). The supernatant containing the extracted histones was mixed with $10 \mathrm{ml}$ of acetone, and the precipitate obtained after an overnight incubation at $-20^{\circ} \mathrm{C}$, was collected and air-dried. The acid-soluble histone fraction was dissolved in $50 \mathrm{ul}$ of $\mathrm{H} 2 \mathrm{O}$, and stored at $-70^{\circ} \mathrm{C}$.

The protein concentration of the whole cell lysate supernatants or histone preparations was determined using the BCA protein assay (Pierce, Rockford, IL) and bovine serum albumin as a standard. Equal amounts of protein were loaded onto SDS - polyacrylamide gels. Molecular weights 
of the immunoreactive proteins were estimated based upon the relative migration with colored molecular weight protein markers (Amersham Life Science Inc., Arlington Heights, IL). Proteins were transferred to polyvinylidene difluoride membranes (PVDF) (Novex, San Diego, CA) and blocked at $4^{0} \mathrm{C}$ using $5 \%$ nonfat milk blocking buffer (1M glycine, $1 \%$ albumin (chicken egg), 5\% nonfat dry milk and 5\% FBS) overnight. The membranes were incubated with primary antibodies for $3 \mathrm{~h}$ at room temperature. The antibody sources were as follows: mouse monoclonal anti-p27 (F-8,SC-1641), rabbit polyclonal anti-CDK4 (C-22), goat polyclonal anti-HDAC1 (N-19,SC-6299), all from Santa Cruz Biotechnology (Santa Cruz, CA), mouse monoclonal anti-pRb (14001A) from PharMingen (San Diego, CA), mouse monoclonal anti-cyclin D1 (NCL-cyclin D1, \#113105) from Novocastra (Burlingame, CA), and mouse monoclonal anti-p16 (Ap-1), p21 (WAF1,Ap-1), p53 (Ap-6) from Calbiochem (Cambridge, MA) and anti-acetylated histone H4 antibody (1:500, rabbit polyclonal, Upstate Biotechnology, NY). The primary antibodies were diluted at 1:500 in Western washing solution $(0.1 \%$ non-fat dry milk, $0.1 \%$ albumin (chicken egg), $1 \%$ FBS, $0.2 \%(v / v)$ Tween-20, in PBS, $\mathrm{pH}$ 7.3). The antigen-antibody complexes were incubated for $1 \mathrm{~h}$ at room temperature with horseradish peroxidase (HRP)-conjugated secondary antibodies (goat IgG-HRP (SC-2020), rabbit IgG-HRP (SC2004) or mouse IgG-HRP (SC-2005) from Santa Cruz Biotechnology) at a final dilution of 1:3000 in Western washing solution. After washing three times with Tris-buffered saline (TBS: $10 \mathrm{mM}$ Tris$\mathrm{HCl}, \mathrm{pH} 7.5,0.5 \mathrm{M} \mathrm{NaCl})$ and $0.05 \%(\mathrm{v} / \mathrm{v})$ Tween 20 , antibody binding was visualized using enhanced chemiluminescence (SuperSignal West Pico, Pierce) and autoradiography.

\section{In vitro HDAC activity assay}

Quinidine-HCl was added to a chicken erythrocyte cellular extract, which contained HDAC activity, at concentrations of $90 \mathrm{uM}$ (Saunders et al., 1999). HDAC assays were performed as described in Hendzel et al. (1991). Briefly, the cellular extract was incubated with 500 ug acid-soluble 
histones isolated from $\left[{ }^{3} \mathrm{H}\right]$ acetate-labeled chicken erythrocytes for $60 \mathrm{~min}$ at $37^{0} \mathrm{C}$. Reactions were terminated by addition of acetic acid/ $\mathrm{HCl}$ to a final concentration of $0.12 \mathrm{~N} / 0.72 \mathrm{~N}$. Released [ $\left.{ }^{3} \mathrm{H}\right]-$ acetate was extracted using ethyl acetate and quantified by scintillation counting. Samples were assayed three times, and the non-enzymatic release of label was subtracted to obtain the reported values.

\subsection{Results}

\subsubsection{Hyperacetylation of histone $\mathrm{H4}$}

Antibodies that recognize acetylated forms of histone $\mathrm{H} 4$ have been used as a probe for agents that cause histone hyperacetylation. (Schmodt et al., 1999). In Western blot experiments, we compared the ability of quinidine to cause hyperacetylation of H4 in MCF-7 cells with that of TSA, an established HDAC inhibitor, known to inhibit proliferation in MCF-7 cells (Sun et al., 1999). H4 acetylation in response to TSA was rapid (within $0.5 \mathrm{~h}$ ) (Figure 4B) and reached a maximum around $12 \mathrm{~h}$. Some level of $\mathrm{H} 4$ acetylation persisted in the TSA treated cells for $48 \mathrm{~h}$. In cells treated with quinidine (Figure 4A) detectable H4 acetylation was slightly delayed and could be seen at $2 \mathrm{~h}$ but not $1 \mathrm{~h}$ of treatment. H4 acetylation was maximal between 12 and $24 \mathrm{~h}$, but then sharply fell to an undetectable level at $48 \mathrm{~h}$. Hyperacetylation of $\mathrm{H} 4$ was a transient response to both agents. Acetylated $\mathrm{H} 4$ is present in MCF-7 cells but under the conditions of Western blotting and immunochemical staining was not detected in control cells (data not shown).

HDAC1 is expressed in MCF-7 cells, and this enzyme contributes to the control of histone deacetylation rates (Saunders et al., 1999). Quinidine caused the rapid disappearance of HDAC1 from MCF-7 cells. HDAC1 protein levels in quinidine treated cells were reduced after 15-20 minutes compared with control cells, and HDAC1 protein was undetectable between 30 minutes and 6 hours 
Figure. 4. Histone Hyperacetylation in MCF-7 Cells. (A) Histones were extracted from cells grown in the presence of $90 \mathrm{uM}$ quinidine for $0.5,1,2,6,12$, or $24 \mathrm{~h}$; histones (20 ug/lane) were electrophoresed in $15 \%$ polyacrylamide gels containing $1 \%$ SDS, and assayed for the presence of acetylated $\mathrm{H} 4$ by immunoblotting. (B) Histones were extracted from cells grown in the presence of $300 \mathrm{nM}$ TSA for $0.5,6,12,24$ or $48 \mathrm{~h} ; 20 \mathrm{ug}$ of histone/lane were electrophoresed and analysed for acetylated histone $\mathrm{H} 4$ by immunoblotting. (C,D) HDAC1 protein in cell lysates was prepared from control MCF-7 cells at $0.5,9,12,24$ or $48 \mathrm{~h}$, control groups were treated with distilled $\mathrm{H}_{2} \mathrm{O}(\mathrm{C})$ or cells treated with $300 \mathrm{nM}$ TSA $0.5,12,24$ or $48 \mathrm{~h}$, control groups were treated with $0.1 \%$ DMSO (D); $50 \mathrm{ug}$ protein/lane were electrophoresed in $12 \%$ polyacrylamide gels containing $1 \%$ SDS, and assayed for HDAC1 protein by immunoblotting. (E,F) HDAC1 protein in whole cell extracts from cells grown in the presence of $90 \mathrm{uM}$ quinidine for (E) 15,20, $30 \mathrm{~min}$ or 9,12, 24 or $48 \mathrm{~h}$ or $(\mathrm{F}) 0.5,1,2$, or $6 \mathrm{~h}$; extracts were electrophoresed (50 ug protein/lane) and assayed for HDAC1 protein by immunoblotting. 
A

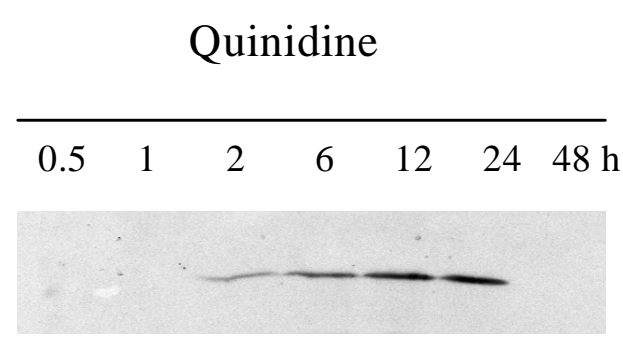

C

\begin{tabular}{|c|c|c|c|c|}
\hline & & & & \\
\hline 0.5 & 9 & 12 & 24 & $48 \mathrm{~h}$ \\
\hline
\end{tabular}

E

Control Quinidine

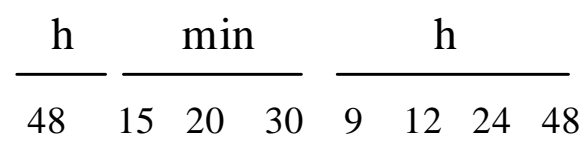

B

\section{TSA}

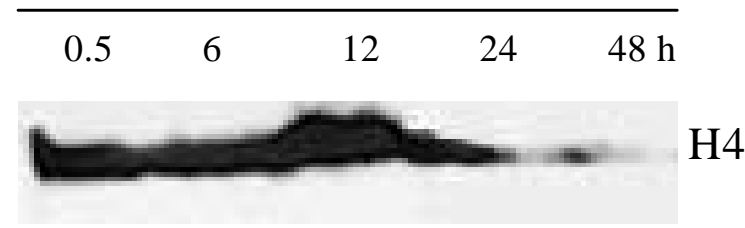

D

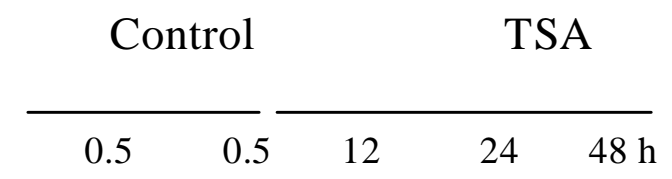

HDAC1

F

\begin{tabular}{|c|c|c|c|c|c|c|c|}
\hline \multicolumn{3}{|c|}{ Control } & & \multicolumn{4}{|c|}{ Quinidine } \\
\hline 0.5 & 1 & 2 & 6 & 0.5 & 1 & 2 & $6 \mathrm{~h}$ \\
\hline
\end{tabular}


(Figure 4E and 4F). Partial restoration of HDAC1 protein occurred beginning at $9 \mathrm{~h}$ of treatment, but even after 48 h, HDAC1 levels in quinidine-treated cells were still less than control cells. Levels of HDAC1 protein in control MCF-7 cells were relatively constant during this time (Figure 4C). TSAtreated MCF-7 cells also showed reduced levels of HDAC1 protein as early as 30 minutes after drug addition, and the reduced HDAC1 protein level was maintained through $48 \mathrm{~h}$ (Figure 4D). The data indicate that loss of HDAC1 protein might contribute to the $\mathrm{H} 4$ acetylation response to both TSA and quinidine. However, HDAC1 protein levels were never reduced by TSA below the level of detection as was observed with quinidine. In light of the more extensive $\mathrm{H} 4$ acetylation response to TSA than quinidine, we conclude that the direct inhibition of HDAC1 catalytic activity by TSA remains an important component of the $\mathrm{H} 4$ acetylation response in vivo. In addition, the time course of the HDAC1 response to quinidine and TSA differ. In response to quinidine, there is initially a more marked decrease in HDAC1 protein levels but a more rapid recovery. TSA treatment caused a sustained reduction in HDAC1 protein levels through $48 \mathrm{~h}$.

To determine if the rapid loss of HDAC protein in the presence of quinidine were mediated through the $26 \mathrm{~S}$ proteasome pathway, MCF-7 cells were treated simultaneously for $30 \mathrm{~min}$ with quinidine and MG-132 (30 uM), an inhibitor of the 26S proteasome. Cells treated with $90 \mathrm{uM}$ quinidine showed a complete loss of HDAC1 protein which was prevented when MG-132 and quinidine were added simultaneously (Figure 5A). Treatment with the solvent, DMSO, or MG-132 in solvent (0.1\%) caused a modest reduction in the level of HDAC1 protein. These reductions in HDAC1 did not elicit a detectable stimulation of $\mathrm{H} 4$ acetylation, and we suggest that other HDAC enzymes present in MCF-7 cells, insensitive to DMSO, could compensate for the lost HDAC1 in the maintenance of deacetylated histone H4. This action of quinidine on HDAC1 protein was not reflected in a general decrease in cellular protein content (Wang et al., 1998), nor were all cell cycle regulatory proteins down-regulated in MCF-7 cells in the presence of quinidine (e.g., p21/WAF1 and p53 protein, Figure 6). Additional 
Figure 5. Protection of HDAC1 protein by proteasome inhibitors. (A) MCF-7 cells were released from confluency and subcultured in normal growth medium supplemented with $30 \mathrm{uM}$ MG-132 in 0.1\% DMSO, $90 \mathrm{uM}$ quinidine plus $0.1 \% \mathrm{DMSO}$ or $0.1 \%$ DMSO alone as indicated. Cells were harvested after $30 \mathrm{~min}$, and Western blot analysis of HDAC1 protein was performed as detailed in methods. (B) MCF-7 cells were cultured as described above, or with lactacystin (3 uM in $0.1 \%$ DMSO) except were harvested after $24 \mathrm{~h}$, and analyzed for the presence of immunoreactive acetylated histone $\mathrm{H} 4$. 

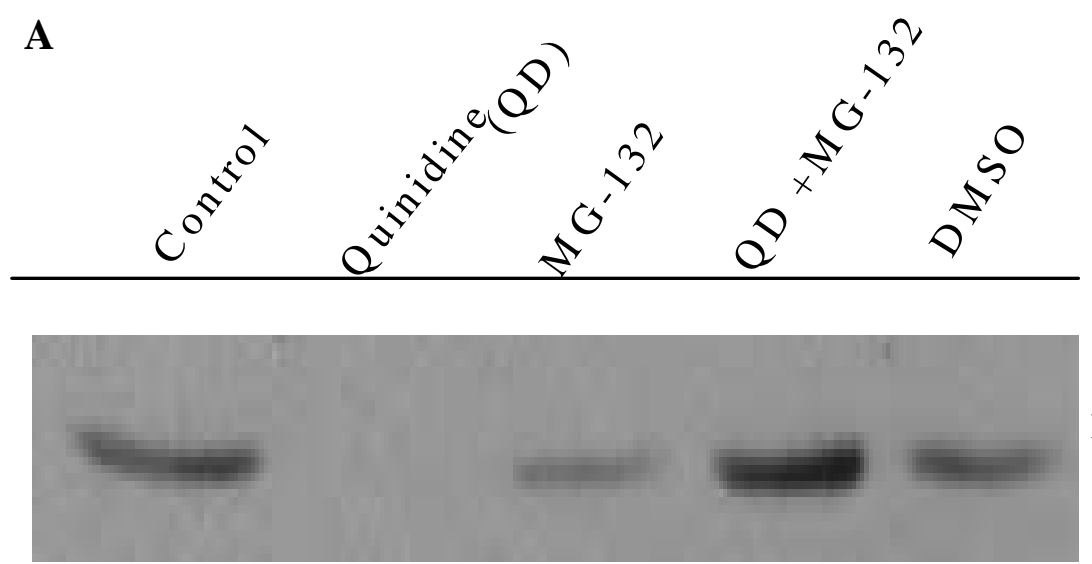

H D A C 1

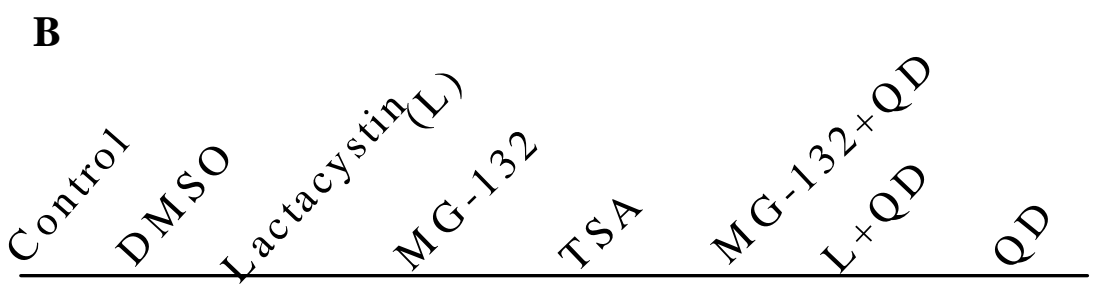


studies are required to define the spectrum of proteins affected by quinidine in a proteasome-sensitive manner. Quinidine (90 or $250 \mathrm{uM}$ ) did not inhibit the activity of the isolated chicken erythrocyte HDAC1 enzyme in vitro (data not shown) suggesting that quinidine caused histone hyperacetylation by eliciting a rapid and transient loss of HDAC1 protein without a direct inhibition of the HDAC enzyme. The suppression of HDAC protein levels in MCF-7 cells was accompanied by a decrease in HDAC enzyme activity in the cell extracts. Histone acetylation and depressed HDAC1 protein levels persisted for approximately $48 \mathrm{~h}$ in the presence of quinidine. When MCF-7 cells were exposed to quinidine for $24 \mathrm{~h}$ in the presence of either MG-132 or lactacystin, there was no detectable $\mathrm{H} 4$ acetylation (Figure 5B). These results support the idea that quinidine-induced loss of HDAC1 protein is involved in the $\mathrm{H} 4$ acetylation response via a proteasomal-sensitive pathway.

\subsubsection{G1 phase cell cycle regulatory profile in MCF-7 cells}

G1 cell cycle arrest is characteristic of HDAC inhibitors, and reports of alterations in several cell cycle proteins in cells exposed to HDAC inhibitors, particularly, the elevation of the p21/WAF1 protein are numerous (Kim et al., 1999; Saito et al., 1999; Sowa et al., 1999). It was of interest to determine whether p21/WAF1 and other key cell cycle regulatory proteins such as the retinoblastoma protein $(\mathrm{pRb})$ and the $\mathrm{G} 1$ phase cyclin-dependent kinase activator, cyclin D1 were targets of quinidine action in MCF-7 cells. Western blotting analysis showed that by $12 \mathrm{~h}$, the levels of p21/WAF1 were increased in response to quinidine treatment approximately 11-fold, and this elevated level of protein expression persisted through $48 \mathrm{~h}$. A small, less than 2-fold increase in p27 levels was observed in cells exposed to quinidine for $24-48 \mathrm{~h}$, while levels of p16 were not increased (Figure 6). Quinidine treatment decreased cyclinD1 and CDK4 protein levels by $24 \mathrm{~h}$ of treatment (Figure 7), indicating that the CKI inhibitor, p21/WAF, as well as an important G1 phase target of p21/WAF1, the cyclin D1 / CDK4 complex, are early targets of quinidine in MCF- 7 cells. This profile of activity is consistent 
Figure 6. G1 cell cycle proteins in MCF-7 cells. Cells released from confluency were plated into control medium or medium containing 90 uM quinidine. Whole cell lysates were prepared 12, 24 or 48 $\mathrm{h}$ after plating and assayed by immunoblotting for the CKIs , p21/WAF1 (n=3), p27 (n=1), p16 (n=3) and p53 ( $\mathrm{n}=3)$ after electrophoresis of 50 ug protein/lane through 12\% SDS-polyacrylamide gels. Rb protein was immunoprecipitated from 500 ug of whole cell lysate protein using an antibody that recognizes phosphorylated and non-phosphorylated $\mathrm{pRb}$ (Liu, et al., 1999). This entire immunoprecipitate was electrophoresed in a 7.5\% SDS-polyacrylamide gel and immunoblotted using this same antibody. Results shown are typical of two independent analyses. 
Control Quinidine

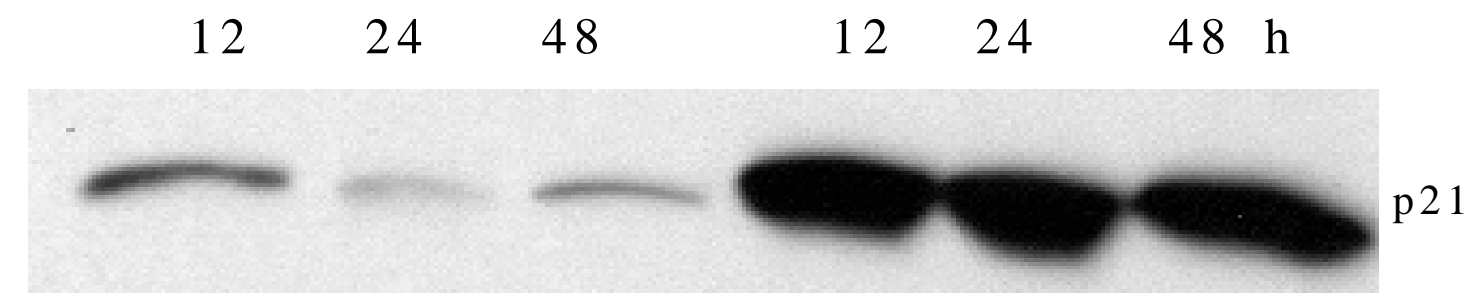

p 53
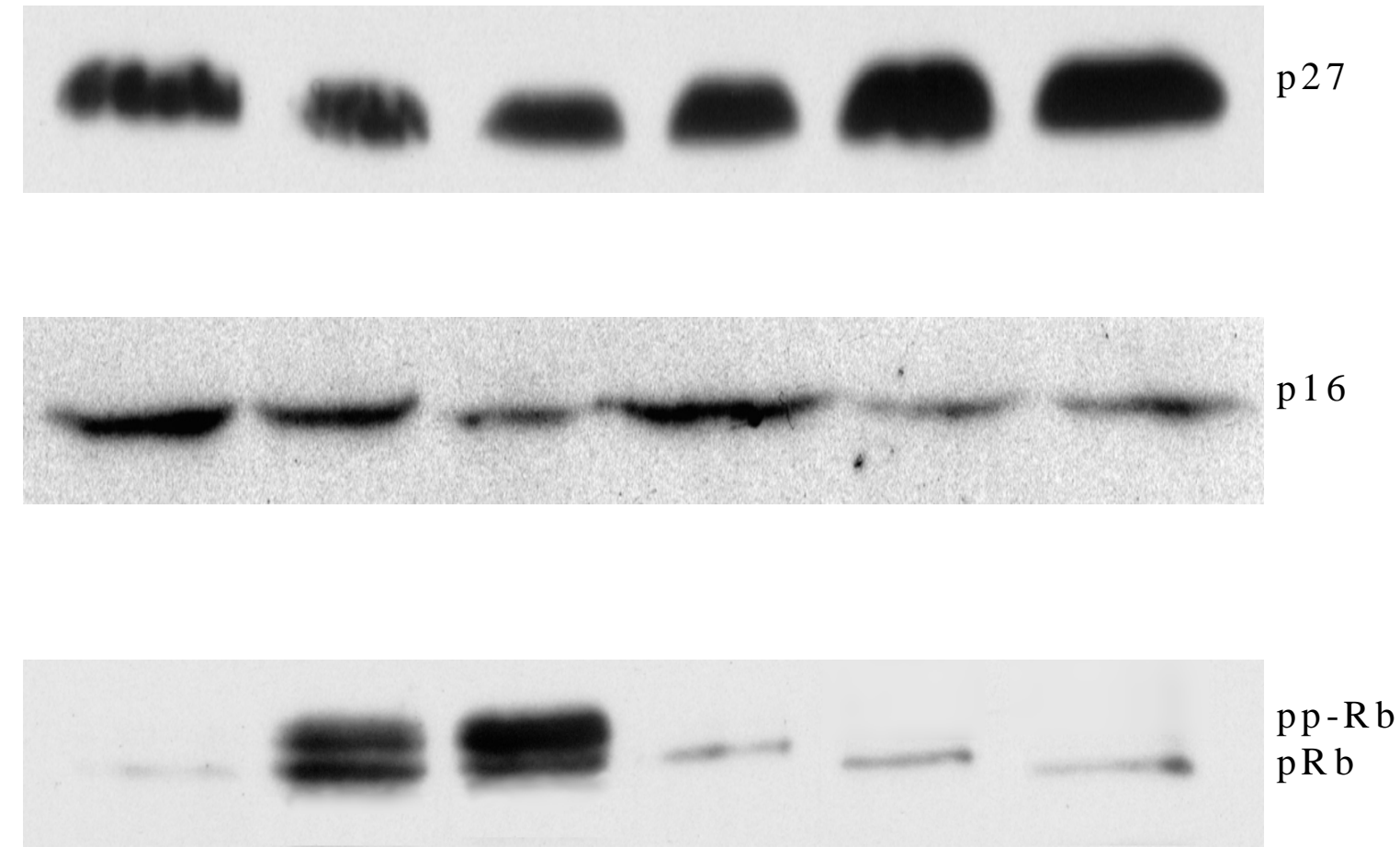
Figure 7. Cyclin D - CDK4 in MCF-7 cells. Confluent MCF-7 cells were subcultured in control medium or medium containing $90 \mathrm{uM}$ quinidine. Whole cell lysates were prepared 0.5, 12, 24 and $48 \mathrm{~h}$ after subculture. Equal protein aliquots (50ug/lane) were electrophoresed in $12 \%$ SDS-polyacrylamide gels, and assayed for cyclin D1 and CDK protein levels by immunoblotting. Results shown are representative of three independent experiments. 


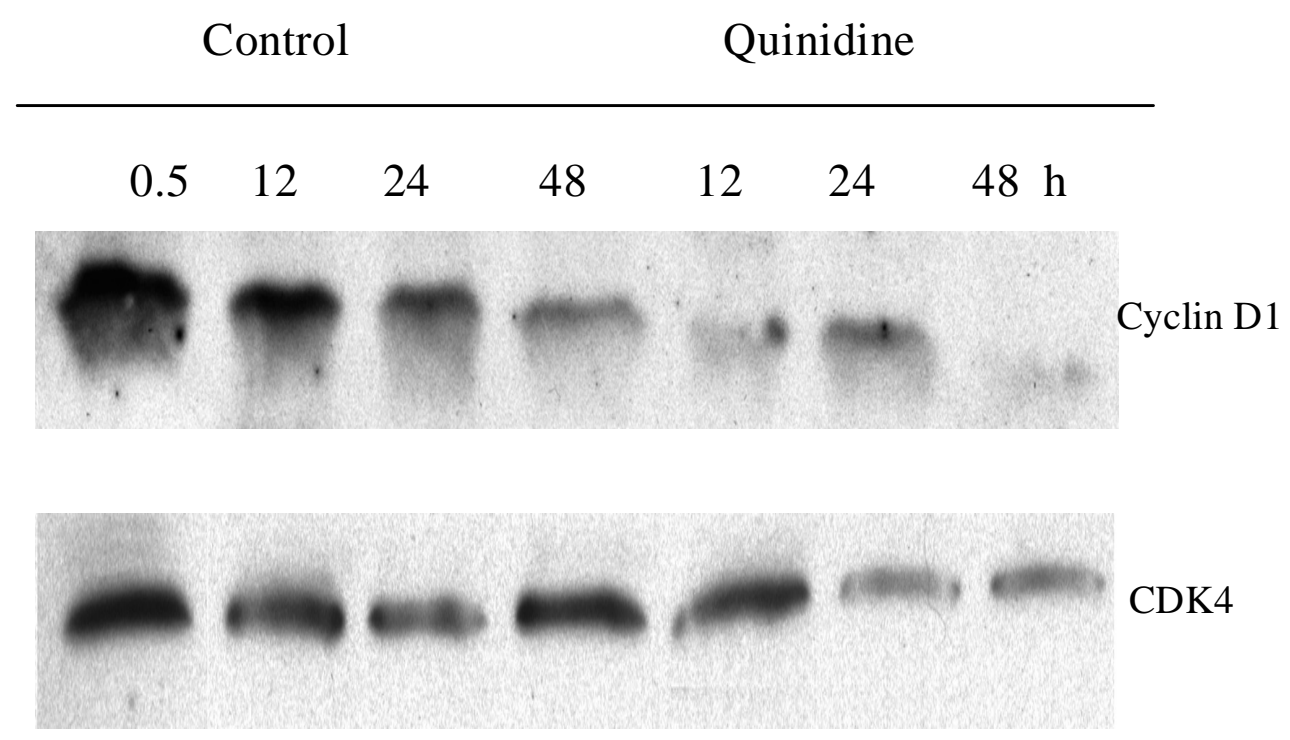


with the observed cell cycle arrest of quinidine-treated MCF-7 cells in mid-G1 phase (Wang et al., 1998).

In MCF-7 cell extracts probed using anti-Rb antibodies, two separate but closely migrating bands were distinguishable. The upper band contained more highly phosphorylated $\mathrm{pRb}$ and the lower band, unphosphorylated or hypophosphorylated $\mathrm{pRb}$. Control cells showed a faint $\mathrm{pRb}$ signal at $12 \mathrm{~h}$, typical of cells in early G1 phase, and increased expression of both phosphorylated and unphosphorylated $\mathrm{pRb}$ at 24 and $48 \mathrm{~h}$. Quinidine treated MCF-7 cells had no detectable hyperphosphorylated pRb at any time point examined, and total levels of $\mathrm{Rb}$ protein failed to increase with progression through $\mathrm{G} 1$ phase as seen in the control, proliferating cells (Figure 6). The decrease in Rb phosphorylation level was predictable based on the increase in p21/WAF1 and decreased levels of both cyclin D1 and CDK4 (Figure 7). In addition, Nakanishi et al. (Nakanishi et al., 1999) showed that p21/WAF1 can bind Rb protein and block its phosphorylation. However, the actions of quinidine upon p21/WAF1 and cyclinD/CDK4 activity do not explain why the levels of total Rb protein were so low. Reductions in the cellular content of phosphorylated $\mathrm{Rb}$ protein in MCF-7 cells by quinidine is an important additional level of cell cycle control that effectively attenuates progression of cells out of G1 phase, and has been reported in other tumor cell lines in response to HDAC inhibition (Levine et al., 1997). In Figure 8 we show data suggesting that the $26 \mathrm{~S}$ proteasome pathway regulates the total pRb content. MCF-7 cells incubated for $24 \mathrm{~h}$ in MG-132 or MG-132 plus quinidine had more total pRb than cells incubated with quinidine alone. Thus, quinidine promoted the loss of both HDAC1 and pRb, and inhibition of the $26 \mathrm{~S}$ proteasome pathway restored the levels of both of these proteins to that seen in the untreated cells. We have no direct evidence that quinidine promotes the proteasomal degradation of either protein. We hypothesize that quinidine may direct degradation of HDAC1 by the proteasome or, alternatively, quinidine might stimulate the proteasomal degradation of other regulatory factor(s) that act to maintain $\mathrm{HDAC} 1$ and $\mathrm{pRb}$ protein levels. 
Figure 8. Proteasome inhibitor modulates retinoblastoma protein levels. Confluent MCF-7 cells were subcultured in the presence of $90 \mathrm{uM}$ quinidine, $30 \mathrm{uM}$ MG-132, or quinidine + MG-132 for 24 $\mathrm{h}$, then harvested, and whole cell extracts (100ug/lane) were analyzed for $\mathrm{pRb}$. A Coomassie blue stained protein is shown as the loading control. 

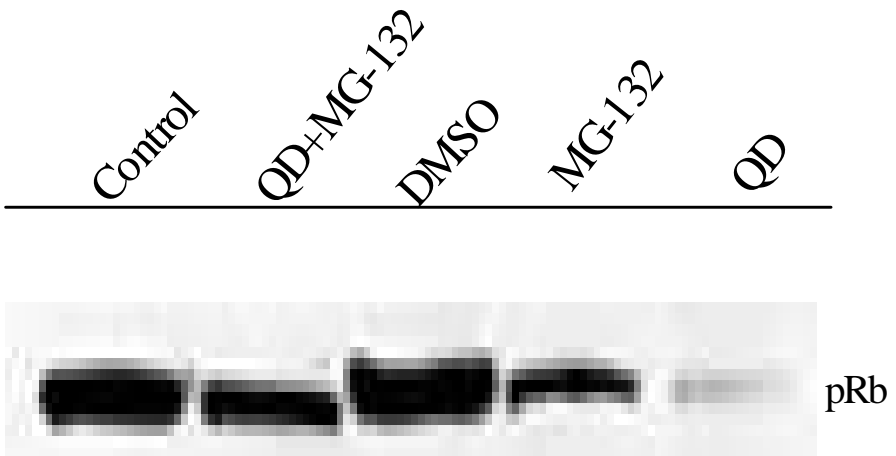

110KD 
MCF-7 cells express wild-type p53 protein. Normal p53 is a short-lived protein that is maintained at low levels, but in response to cell stress or DNA damage, p53 is stabilized and accumulates in the nucleus where it functions as a transcription factor inducing p21, G1 cell-cycle arrest and apoptosis (Levine et al., 1997). Wild-type p53 down-regulates pRb levels in MCF-7 cells (Ameyar et al., 1997). Although Saito et al. (Saito et al., 1999) showed that p53 is not required for pRb downregulation by HDAC inhibitors in all cell lines, quinidine-treated MCF-7 cells have elevated p53 levels (5-7-fold) (Figure 6). Thus, p53 could contribute to the maintenance of the G1 cell cycle arrest in MCF-7 by sustaining p21/WAF1 protein levels and suppressing pRb protein levels.

\subsubsection{Growth arrest and cellular differentiation in human breast tumor cell lines}

In contrast to MCF-7 cells, human breast tumor cell lines T47D, MDA-MB-231 and MDA-MB435 express p53 proteins with distinct point mutations (Nieves-Neira et al., 1999). To test for a requirement of p53, this panel of human breast tumor cell lines was exposed to quinidine, and the effects of quinidine on cell growth were compared (Figure 9). The data shown are viable cell numbers/well, bioreductive metabolism/well, or both. In all four cell lines growth was suppressed in a concentration-dependent fashion between 10 and $90 \mathrm{uM}$ quinidine, and maximal growth inhibition was observed at $\sim 90 \mathrm{uM}$ quinidine (data not shown). These data showed that growth suppression by quinidine is a p53-independent response. It is interesting that quinidine was not overtly cytotoxic in HMEC, a line of normal human mammary cells (Stampfer et al., 1993).

Evidence that quinidine elicited cellular differentiation in MCF-7 human breast tumor cells in conjunction with the inhibition of cell growth was obtained using maximally effective concentrations of quinidine or retinoic acid (data not shown). Antibodies directed against cytokeratin 18 (Stingl et al., 1998) were used to probe the organization of the cytoskeleton (Figure 10). In these studies, all-trans retinoic acid (10 uM) was used to compare the differentiation response (Jing et al., 1996). Control 
Figure 9. Growth of human breast cell lines in quinidine. MCF-7, MDA-MB-231, T47D, MCF7ras tumor cells and normal HMEC were replica plated in 96-well plates in control medium (open symbols) or medium containing $90 \mathrm{uM}$ quinidine (solid symbols). Cell growth as monitored using the MTS assay is shown with solid lines. Results shown are the average of quadruplicates in one experiment. Quinidine had no effect on MTS metabolism in the MCF-7ras cell line (data not shown). Viable cell counts/dish of replica plated MCF-7, MDA-MB-231, T47D and MCF-7ras tumor cells and normal HMEC cells in $35 \mathrm{~mm}^{2}$ dishes in control medium (open symbols) and medium containing 90 $\mathrm{uM}$ quinidine (solid symbols) is indicated with the dashed lines. The MTS data are the result of single experiments conducted in quadruplicate for all the cell lines. The cell number (growth curve data) represent the mean and S.E. of three independent experiments for the MCF-7, T47D and MDA-231 cell lines performed in duplicate dishes (MCF-7, T47D) or single dishes (MDA-231) for each experiment. MCF-7ras data are the mean ( \pm range) of two experiments performed in duplicate dishes. HMEC data are from one experiment performed in single dishes. Data taken from Zhou, et al., 2000 as performed by Dr. Zaroui Melkoumian. 

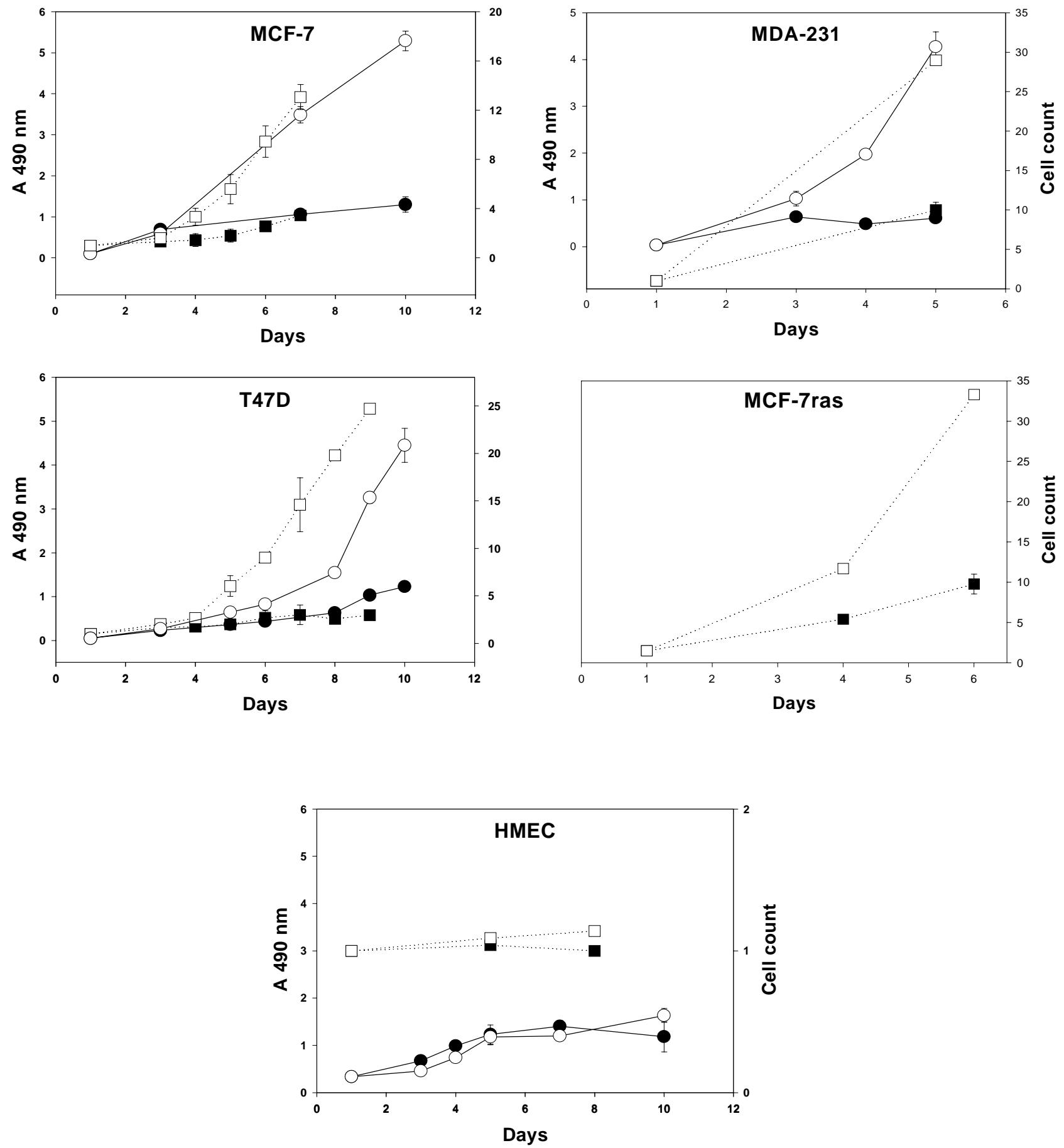
MCF-7 cells showed expression of cytoplasmic cytokeratin 18 in a disorganized fashion. Cells that were treated for $96 \mathrm{~h}$ with retinoic acid showed an increase in the intensity of the cytokeratin 18 staining and relocalization of cytokeratin 18 throughout the nucleus as well as the cytoplasm. In contrast, cytokeratin 18 staining occurred in a highly organized pattern in MCF-7 cells treated with quinidine for $96 \mathrm{~h}$ and the cells adopted a shape and nuclear localization more typical of columnar epithelium.

Lipid droplets are found in the cytoplasm of normal mammary epithelium (Halm et al., 1990), and cytoplasmic lipid droplet accumulation occurs in a variety of differentiating cell systems. Induction of differentiation in human breast cancer cell lines by oncostatin M (Douglas et al., 1998), the HER2/neu kinase inhibitor, emodin (Zhang et al., 1995), overexpression of c-erbB-2 (Giani, etal., 1998) the vitamin D analog, 1-alpha-hyroxyvitamin D5 (Mehta et al., 2000), the HDAC inhibitor, sodium butyrate (Bacus et al., 1990) and retinoic acid (Bacus et al., 1990) is accompanied by the accumulation of cytoplasmic lipid droplets. We utilized a fluorescent stain, Nile Red to monitor lipid droplet formation in mammary tumor cells in response to quinidine. The cells were counterstained with fluorescein-phalloidin that binds actin filaments to assay for changes in the actin cytoskeleton (Figure 11). The distribution of actin in four human breast tumor cell lines, MCF-7, T-47D, MDA-MB-231, and MDA-MB-435 is seen clearly in the control cells. Three of these lines show strong nuclear staining of actin characteristic of transformed cells, while the fourth, MDA-MB-435, shows more cytoplasmic actin. In all cases except MDA-MB-435, the presence of quinidine did not significantly alter the actin cytoskeleton. Lipid droplet accumulation was weak or absent in the control cell lines, and increased by retinoic acid and quinidine. Lipid droplet accumulation was more marked in all four cell lines treated with quinidine than with retinoic acid. These data demonstrate that induction of a more differentiated phenotype is a general response of human mammary tumor cells to quinidine. 
Figure 10. Cytokeratin 18 in MCF-7 cells. Cells were replica plated $\left(2 \times 10^{5}\right)$ on sterile coverslips in $35 \mathrm{~mm}^{2}$ dishes in medium containing $0.01 \%$ ethanol (control), $10 \mathrm{uM}$ retinoic acid, or $90 \mathrm{uM}$ quinidine and grown for 96 hs. Cytokeratin 18 detection using a Texas red tagged secondary antibody is shown using confocal microscopy. Data shown are typical fields representative of two independent experiments. Data taken from Zhou, et al., 2000 as performed by Dr. Zaroui Melkoumian. 


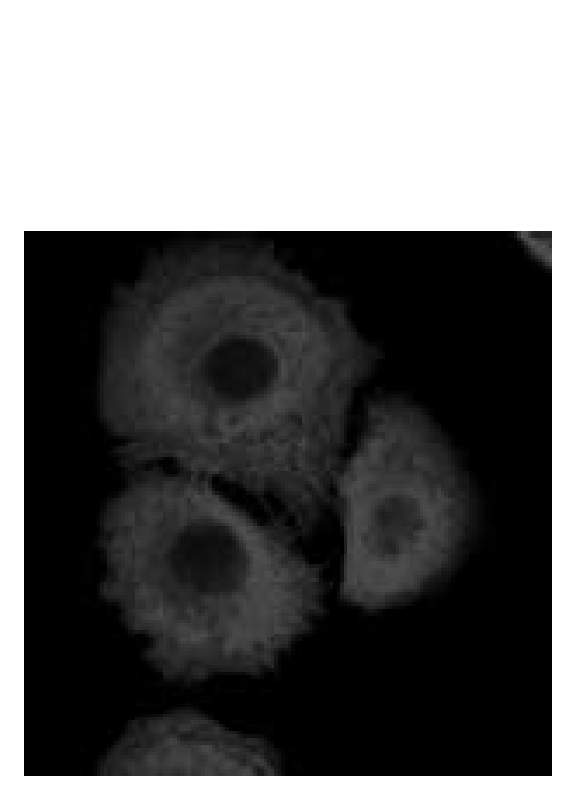

Control

MCF-7

Cytokeratin 18

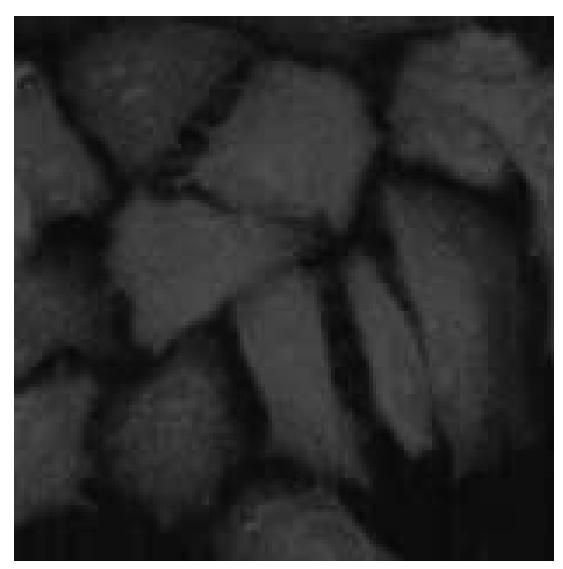

Retinoic Acid

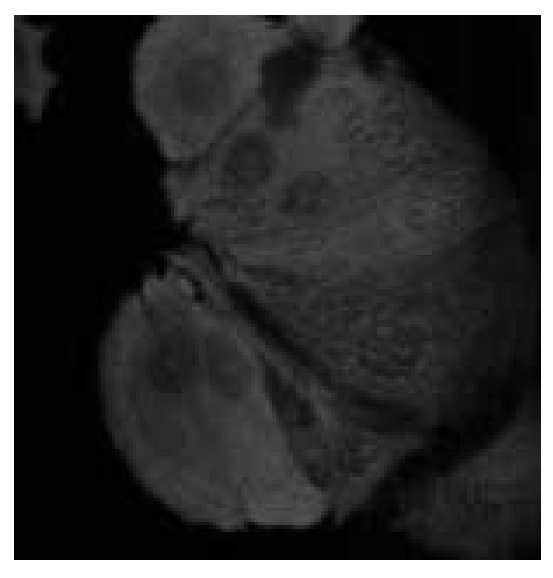

Quinidine 
Figure 11. Lipid accumulation as an index of cellular differentiation in human breast tumor cell lines. MCF-7, T47D, MDA-MB-231 and MDA-MB-435 cells were replica plated $\left(0.8-3 \times 10^{5}\right)$ on sterile coverslips in $35 \mathrm{~mm}^{2}$ dishes in medium containing $0.01 \%$ ethanol (control), $10 \mathrm{uM}$ retinoic acid ( $0.01 \%$ ethanol) or $90 \mathrm{uM}$ quinidine (in water). Cells were fixed, permeabilized and then incubated sequentially with fluorescein-phalloidin to identify actin filaments and Nile Red to identify lipid droplets after $96 \mathrm{~h}$. Images were obtained by confocal microscopy. The results are typical of three experiments conducted in each cell line. Data taken from Zhou, et al., 2000 as performed by Ann Lucktong. 

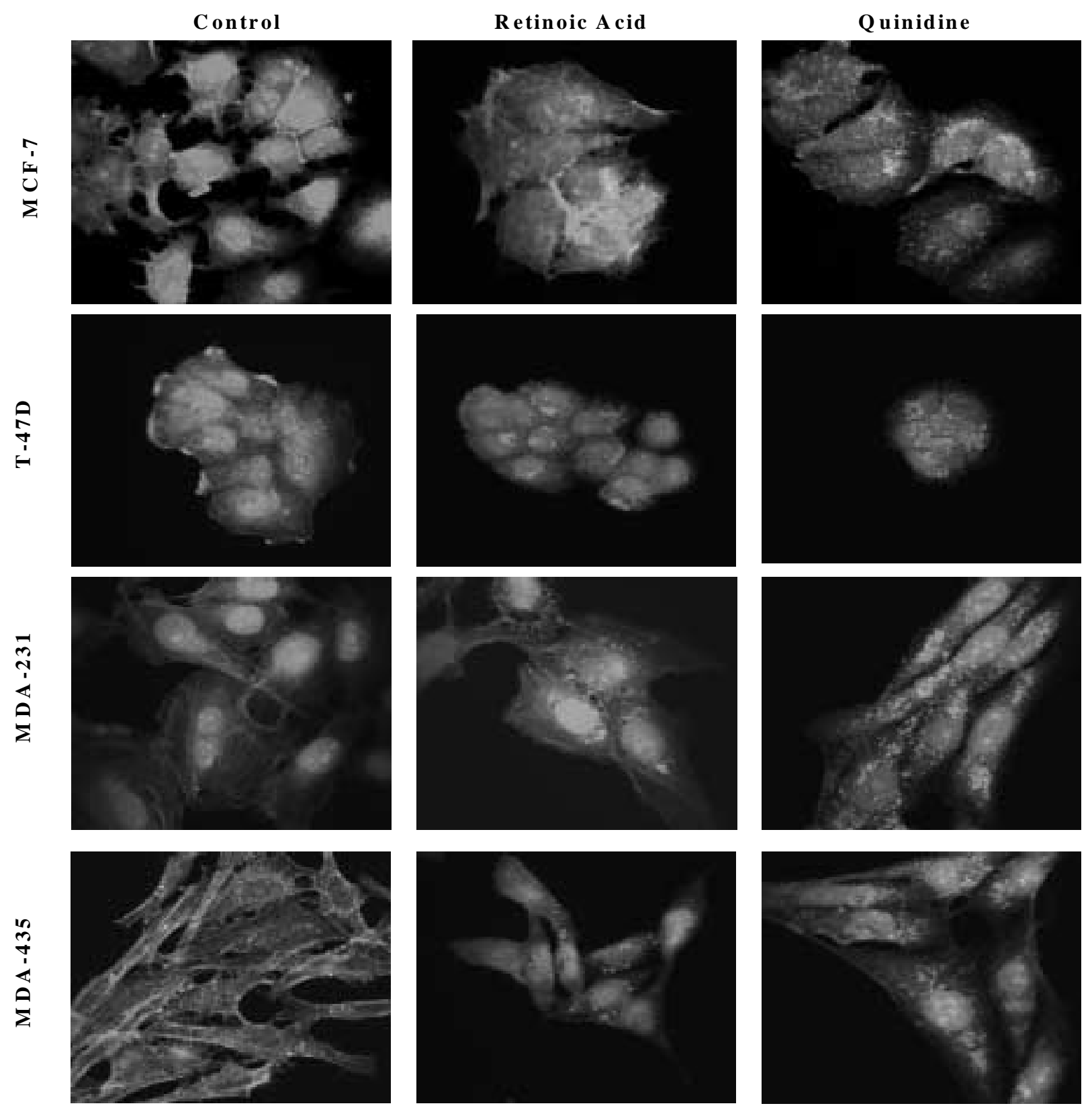


\subsubsection{Hyperacetylation of histone $\mathrm{H} 4$ in mammary tumor cell lines by quinidine}

To determine whether differentiation and histone acetylation were linked, we investigated the histone $\mathrm{H} 4$ acetylation status of quinidine treated MCF-7, MCF-7ras, T47D and MDA-MB-231. All four cell lines were incubated for $24 \mathrm{~h}$ in the presence or absence of quinidine, and then histones were extracted for immunoblotting. Figure 12 shows that histone H4 was hyperacetylated in all cell lines treated with quinidine. Control cells contained no hyperacetylated histone H4. 
Figure 12. Histone $\mathbf{H} 4$ hyperacetylation in human breast tumor cell lines. MCF-7, MDA-MB231, T47D and MCF-7ras tumor cells were replica plated ( 1 x $10^{7} / \mathrm{T}-162$ flask) in control medium $(\mathrm{C})$ or medium containing $90 \mathrm{uM}$ quinidine (Q). Histones were extracted from the cells after $24 \mathrm{~h}$, and 20ug/lane of histone proteins were electrophoresed in 15\% SDS-polyacrylamide gels. Immunoblotting was performed to detect acetylated histone $\mathrm{H} 4$. 


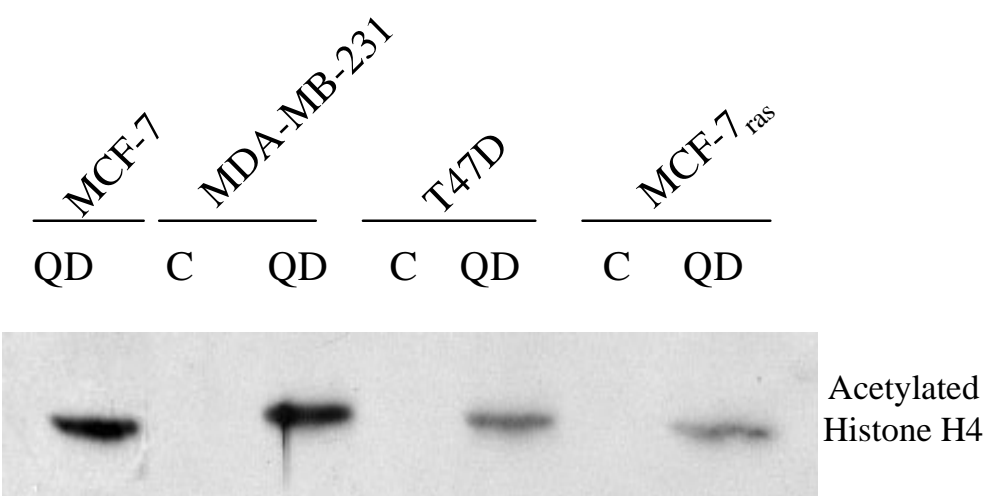


Table 1. Summary of effects of quinidine on cell cycle proteins in MCF-7 cells. Protein signals were analyzed from autoradiographic signals on X-ray film using Molecular Dynamic Research Densitometer. These signals were estimated as fold changes due to the limitation of the X-ray film sensitivity. Quantitation of signal density for each the cell cycle regulatory protein expression is shown as fold induction of the protein by quinidine treatment over the control group. “+” indicates increase in protein level; “-” indicates decrease in protein level. Data are presented as the mean \pm SER of values from typical experiment. 
Table 1. Summary of Effects of Quinidine on Cell cycle Regulatory Proteins in MCF-7 Cells

\begin{tabular}{|c|c|c|c|}
\hline Proteins & $12 h$ & $24 h$ & $48 h$ \\
\hline P21(n=4) & $11.2 \pm 1.1$ & $9.2 \pm 1.8$ & $9.3 \pm 1.2$ \\
\hline P53(n=3) & $6 \pm 0.2$ & $5 \pm 0.3$ & $7.4 \pm 0.5$ \\
\hline P27(n=1) & 1.2 & & 3.2 \\
\hline Cyclin D1(n=3) & $-5.6 \pm 0.3$ & $-2 \pm 0.4$ & $-4.0 \pm 0.7$ \\
\hline CDK4(n=3) & $-1.1 \pm 0.5$ & $-3.5 \pm 0.4$ & $-4.0 \pm 0.2$ \\
& & & $-15 \pm 0.4$ \\
\hline & & & \\
\hline & & & \\
\hline & & & \\
\hline & & & \\
\hline & & & \\
\hline
\end{tabular}




\subsection{Discussion}

Quinidine-induced histone H4 hyperacetylation in MCF-7 human breast carcinoma cells can be attributed to the rapid elimination of HDAC1 protein, a response that was blocked by MG-132 and lactacystin, two inhibitors of proteasome-mediated proteolysis. HDAC1 protein was undetectable within 30 min after the addition of quinidine to the medium of MCF-7 cells, and hyperacetylated histone $\mathrm{H} 4$ appeared between 1 and $2 \mathrm{~h}$. Levels of HDAC1 protein were completely suppressed between 0.5 and $6 \mathrm{~h}$, and during this time $\mathrm{H} 4$ acetylation levels increased. $\mathrm{H} 4$ acetylation was maintained at 12 and $24 \mathrm{~h}$, despite the partial restoration of HDAC1 protein at these same time points. These data indicate that quinidine induced reductions in HDAC1 protein levels are unlikely to fully explain the regulation of $\mathrm{H} 4$ acetylation state in MCF-7 cells by quinidine. Additional HDAC enzymes or effects upon histone acetylation rates could possibly play a role as well.

An earlier study showed that over this initial $48 \mathrm{~h}$ period, $80 \%$ of the MCF-7 cell population had shifted into G0, a quiescent state marked by the absence of Ki67 antigen immunoreactivity (Wang et al., 1998). Cellular differentiation manifested as the accumulation of lipid droplets and a reorganization of the cytokeratin 18 cytoskeleton was evident after this initial $48 \mathrm{~h}$ period. Quinidine exhibited all the responses typical of known HDAC inhibitory drugs, with the exception that quinidine had no direct inhibitory effect upon HDAC1 enzymatic activity. We conclude from the current studies that quinidine is a novel differentiating agent that causes histone hyperacetylation, in part, by physical elimination of HDAC1 protein rather than the inhibition of HDAC enzymatic activity.

Histone $\mathrm{H} 4$ hyperacetylation and induction of cellular differentiation by quinidine were seen in a panel of human breast tumor cell lines that were selected for study on the basis of their diversity of genetic backgrounds. The differentiation response to quinidine was independent of the estrogen receptor (ER) status. Cell lines representative of ER-positive and ER-negative human breast carcinoma 
cells were induced to differentiate in the presence of quinidine. The ER status of the estrogen receptor positive cell lines is MCF-7 (ER-alpha, ER-beta), T47D (ER-alpha and ER-beta), and MDA-MB-231 (ER-beta). MDA-MB-435 cells expressed very low levels of ER-beta (Fuqua et al., 1999; Vladusic et al., 2000). MCF-7 and T47D cells display an epithelial morphology and show similarities with mammary ductal and luminal epithelial cells, respectively (Jin et al., 1996; Soule etal., 1973). MDAMB-231 exhibit an elongated cellular morphology which is also typical of MDA-MB-435 cells. Our results demonstrate that quinidine is a differentiation agent in both types of mammary tumor cells.

HDAC inhibitors reverse the transformed phenotype of NIH3T3ras cells, and this property has been used successfully as a screening assay for the identification of new HDAC inhibitors (Jones et al.; 1997; Sweeney et al., 1998). Quinidine elicited a more differentiated phenotype in MCF-7ras cells, an MCF-7 cell derivative produced by stable transformation with v-Ha-ras, thus demonstrating that quinidine, like other HDAC inhibitors, can reverse an H-ras induced phenotype.

Quinidine induced differentiation independently of wild-type p53. The ability of quinidine to cause differentiation of p53 mutant cell lines is consistent for a role of histone hyperacetylation in the response. HDAC inhibitors typically induce a p53-independent activation of p21/WAF1 gene expression (Sambucetti et al., 1999; Saito et al., 1999). Growing MCF-7 and T47D cells express p21/WAF1 protein in moderate to low levels (Sheikh et al., 1994), and quinidine raised p21/WAF1 protein levels in MCF-7 cells approximately 11-fold within $12 \mathrm{~h}$. Although p21/WAF1 was reported to be low to undetectable in MDA-MB-231, p21/WAF1 was detected in Western analyses of both MDA-MB-231 and T47D cells in a p53-independent fashion in response to serum deprivation, adriamycin, etoposide (Sheikh et al., 1994; Futamura et al., 1995), and quinidine (data not shown). These data support the idea that the p21/WAF1 gene is present, but inactive in growing MDA-MB-231 cells. Since histone hyperacetylation of the p21/WAF1 gene occurs in response to HDAC inhibitors, it 
might be involved in the pathway of p53-independent activation of p21/WAF1 gene expression (Sambucetti etal., 1999).

The processes of cellular differentiation and cell cycle progression are interdependent. G1 arrest is a necessary but insufficient condition for differentiation in numerous cell types including leukemic cells, keratinocytes, colonic epithelium, and muscle cells. In all of these cells, induction of p21/WAF1 protein and G1 cell cycle arrest occurred prior to differentiation (Itazaki et al., 1990; Chang et al., 1999; DiCunto et al., 1998; Evers et al., 1996; Freemerman et al. 1997; Missero et al., 1996; Matsumura et al., 1997), and was generally independent of p53. We hypothesize that the differentiated state can be viewed as a cellular response to G1 arrest, requiring a change in gene expression profile and suppression of cell death pathways. The response of MCF-7 breast tumor cells to quinidine is consistent with this model.

To begin to understand how quinidine might elicit G1 arrest of MCF-7 cells, we have focused on the action of quinidine as a potassium channel blocking agent. Quinidine enters cells and inhibits cardiac potassium channels by binding to the intracellular face of the ion pore (Yeola et al., 1996). Although the location of the quinidine binding site on the ATP-sensitive potassium channel is unknown, quinidine is freely permeable across membranes and inhibits the ATP-sensitive potassium channels whether it is applied to the external or internal surface of a lipid membrane bilayer (Watson et al., 1996).

In the presence of quinidine, MCF-7 cells accumulate at a position $12 \mathrm{~h}$ into $\mathrm{G} 1$ phase (Wang et al., 1998). This position, defined by cell cycle arrest and release experiments, precedes the lovastatin arrest point by 5-6 h, and is clearly distinct from the restriction point described by Pardee (Pardee et al., 1974) near the G1/S transition. The present work showed that quinidine treatment caused elevated levels of p53 and p21/WAF1 protein by $12 \mathrm{~h}$ (Figure 6), the point within G1 where MCF-7 cells arrest in response to quinidine (Wang et al., 1998). When p53 and p21/WAF1 proteins were assayed before 
$12 \mathrm{~h}, \mathrm{p} 53$ was undetectable, and p21 was first detected after $8 \mathrm{~h}$ of quinidine treatment (data not shown), suggesting a p53-independent induction of p21/WAF1 occurred prior to arrest in G1. Cdk4 and cyclin D1 protein levels were also reduced, as was cdk4 activity as demonstrated by the abundance of hypophosphorylated Rb protein. Based upon our observations in MCF-7 cells, we conclude that p21/WAF1 protein levels become elevated prior to the G1 arrest in response to quinidine, and could initiate the G1 arrest. Hypophosphorylated Rb protein is prominent in quinidine-treated MCF-7 cells and this could act to sustain the G1 state by preventing the transition into S phase. The G1 arrest induced by quinidine in MCF-7 cells was correlated with the blockade of ATP-sensitive potassium channels in MCF-7 cells (Wang et al. 1998; Woodfork et al., 1995; klimatcheva et al., 1999). Direct evidence for the involvement of potassium ions in the G1 arrest was provided using valinomycin a potassium-selective ionophore to stimulate a G1 - S phase transition in the presence of quinidine (Wang et al., 1998).

In summary, quinidine, a drug that is used therapeutically in the treatment of malarial infections and cardiac arrhythmia, was shown to be useful as an inducer of cellular differentiation in human breast tumor epithelial cells. Quinidine caused histone $\mathrm{H} 4$ hyperacetylation and cellular differentiation in human breast tumor cells following the rapid loss of HDAC1 involving a proteasome-dependent pathway. Additional experiments are needed to determine how the action of quinidine upon ATPsensitive potassium channels initiates the molecular events underlying the differentiation response. 
2. Effects of Antimalarials on Cell Growth, Differentiation and Apoptosis in Human Breast Cancer Cells 


\subsection{Introduction}

Quinidine, a quinoline antimalarial, is a growth inhibitor of breast cancer cells, which may be useful for adjunct therapy of human breast cancer. We have shown that inhibition of MCF-7 cell growth in response to quinidine involves cell cycle arrest in G1/G0 phase followed by apoptotic cell death (Wang et al., 1998). Quinidine induces a variety of changes within the nucleus, including elevated p21(WAF1) protein and hyperacetylation of histone H4 (Zhou et al., 2000). Overexpression of the cyclin-dependent kinase inhibitor p21(WAF1) by quinidine might be through a process that involves activation of tumor suppressor gene p53. We also reported that antiproliferative actions of quinidine might involve activation of proteasome pathway, which, in part, degrades HDAC1 protein without directly inhibiting HDAC activity (Zhou et al., 2000). Quinidine is a novel HDAC inhibitor, and bears potential as new antitumor drug because of its ability to induce p21(WAF1) protein and to trigger differentiation and apoptosis. Quinidine also caused a decrease in cyclin D1 protein expression (Zhou et al., 2000). This is relevant to the potential use of quinidine in cancer therapy, because cyclin D1 has been strongly associated with proliferation and carcinogenesis in the mammary gland (Buckley et al, 1993).

We hypothesized that effects of quinidine on HDAC and apoptotic response were generalizable to quinoline antimalarials. To test this hypothesis, we screened quinoline antimalarials, including amodiaquin, chloroquine, halofantrine, mefloquine, primaquine, quinine, quinoline and quinolinic acid, for the ability to inhibit tumor cell growth. In this study, the main work is to determine if quinoline antimalarials exert their growth regulatory effects on MCF-7 cells via common mechanisms which involve cell cycle arrest, differentiation, apoptosis, and induction of hyperacetylated histone H4 without directly inhibiting HDAC activity. The selection of these molecular targets is based on the fact that they are the major contributors, possibly causative, to the mechanisms of breast cancer cell death. 
The long-term goal of these studies is to obtain structure-activity information that will enable us to predict unique chemical structures with greater potency.

The molecular mechanisms by which quinidine induces apoptosis have been postulated including inhibition of anti-apoptotic Bcl-2 protein, and increase in cytochrome c release, which are a central coordinating events in apoptosis (Zhou and Strobl, 2000). However, the mechanism of quinidineinduced apoptosis still remains to be clarified.

One cell cycle-related gene implicated in quinidine action is $\mathrm{pRb}$. The histone deacetylase HDAC1 physically interacts and cooperates with $\mathrm{pRb}$, and there is evidence that this complex is a key element in the control of proliferation and differentiation (Magnaghi-Jaulin et al., 1998). Quinidine treatment leads to $\mathrm{pRb}$ hypophosphorylation, and this is likely to be involved in the mechanisms underpinning quinidine inhibition of cell proliferation. We probed whether $\mathrm{pRb}$ status modulates quinidine-induced apoptosis. MDA-MB-468 cells, pRb deficient breast carcinoma cells were used for this work. In the current study, we also determined whether caspase-3 might influence the apoptotic responses of MCF7 cells to quinidine treatment. 


\subsection{Results}

\subsubsection{Effects of TSA on cell growth and HDAC activity}

Trichostatin A (TSA), a specific and potent inhibitor of HDAC, inhibits cell growth, blocks cell cycle progression in G1 phase, induces differentiation, and causes apoptosis in many breast cancer cell lines (Vigushin et al, 2001, Kim et al; 2000 and Furumai et al, 2001). TSA is the most well studied HDAC inhibitor, and its effects on cell cycle, HDAC activity, and p21(WAF1) reporter gene expression have been published (Kosugi et al., 1999 and Furumai et al., 2001). Yet, interpretation of these data is confusing because the concentration of TSA in published reports varies from low nanomolar to micromolar concentrations. We have reported that $300 \mathrm{nM}$ TSA causes hyperacetylation of histone H4 by $12 \mathrm{~h}$ in MCF-7 cells (Zhou et al., 2000). The TSA concentration-response in MCF-7 cells for several end -points are now reported in the following study; we compared the concentrationresponse effects of TSA on cell viability and HDAC activity in MCF-7 cells.

The MTS assay at $48 \mathrm{~h}$ of TSA exposure shows that TSA induced a concentration-dependent decrease in MCF-7 cell growth (Figure 13A). The MTS IC50 value of TSA is 35nM in MCF-7 cells. The IC50 value of TSA for HeLa HDAC activity is $8.4 \mathrm{nM}$ (Figure 13B).

\subsubsection{Effects of TSA on Ki67 antigen and p21(WAF1) protein in MCF-7 cells}

Ki67 is a nuclear protein that is expressed in all phases of the cell cycle (Van et al., 1989). The absence of Ki67 protein from cells is a marker that cells have exited the cell cycle (Van et al., 1989). The percentage of Ki67 negative cells in the TSA-treated cell population is an indication that TSA causes cell cycle exit. About a 5-fold increase in Ki67 negative cells was observed after 48 h TSA treatment compared to control group (Figure 14A).

Transcription of $\mathrm{p} 21(\mathrm{WAF} 1)$ and $\mathrm{p} 21(\mathrm{WAF} 1)$ protein levels have been shown to be increased by TSA (Yoshida et al., 1999 and Kim et al., 2000). p21(WAF1) has also been shown to play an 
A

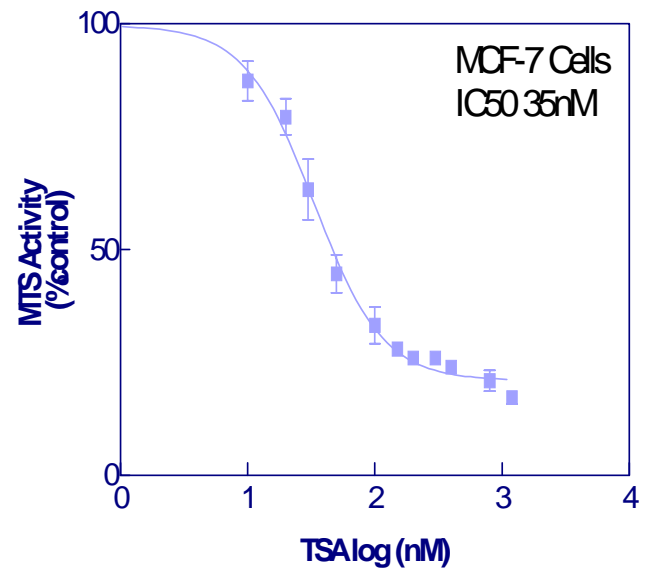

B

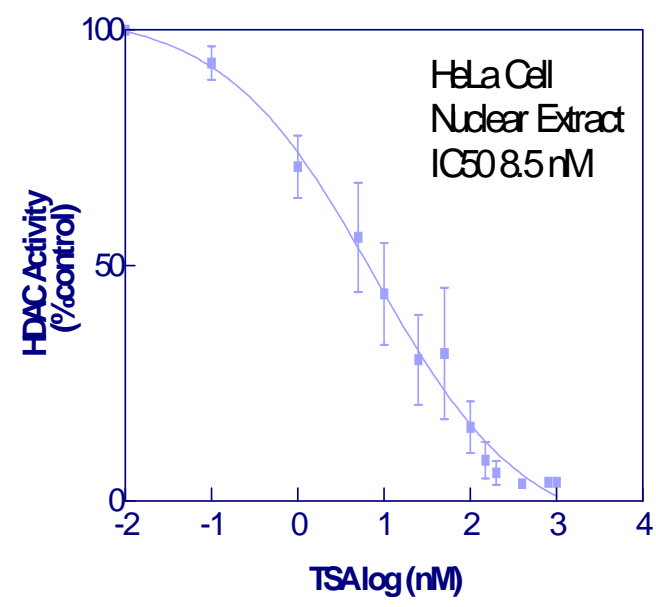

Figure 13. Effects of TSA on cell growth and HDAC activity in human carcinoma cells. (A) TSA inhibited MCF-7 cells growth. MCF-7 cells ( 4000 cells/well) were plated in 96-well plates; $12 \mathrm{~h}$ after plating, cultures were treated with indicated concentrations of TSA. Total cells were determined after $48 \mathrm{~h}$ of treatment using the MTS assay. Cell growth was presented as percentage of vehicle control (0.01\% DMSO). Data are mean \pm SER of two independent assays performed in quadruplicate. (B) Effect of TSA on HDAC activity of HeLa cell nuclear extracts. The assay is described in Materials and Methods. The enzyme activity was expressed as a percentage of the control. Data represent mean \pm SER of three independent experiments. 

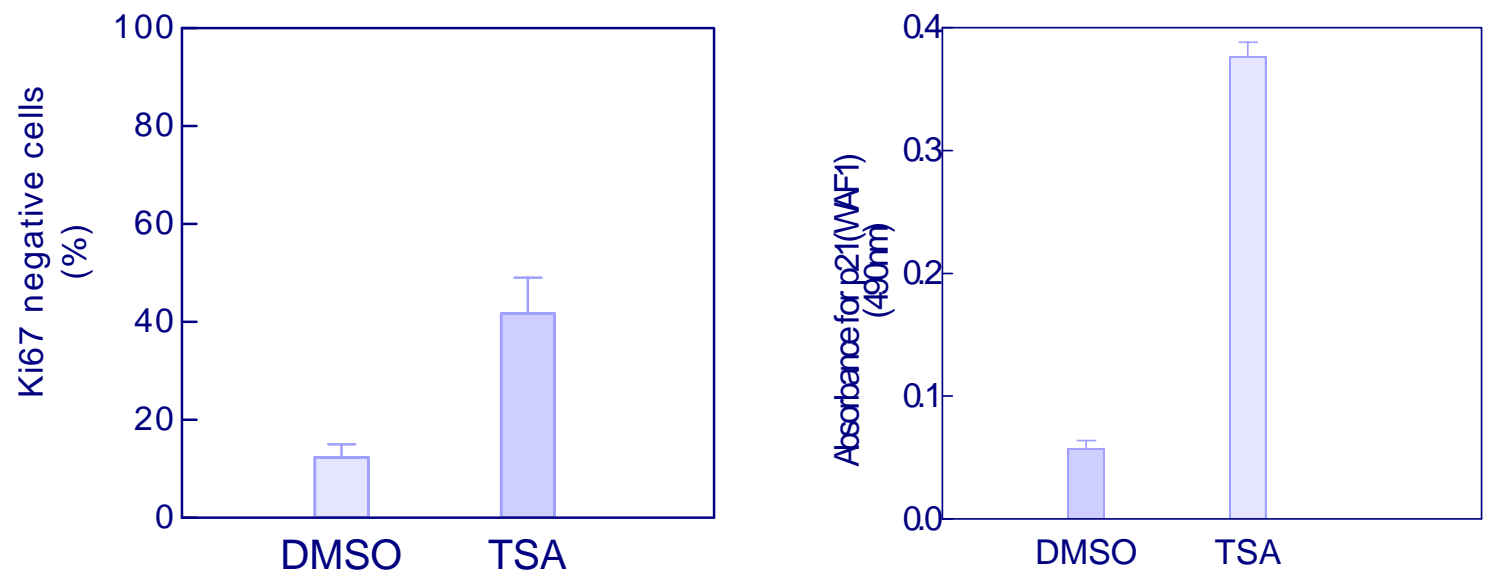

Figure 14. Effects of TSA on Ki67 negative cell population and p21(WAF1) in MCF-7 cells. (A) MCF-7 cells were plated $\left(2 \times 10^{5}\right)$ in $35-\mathrm{mm}^{2}$ dishes on sterile glass coverslips and grown in DMEM plus 5\%FBS. Cells were treated with solvent (0.01\% DMSO), or TSA 35nM for $48 \mathrm{~h}$. Cells were stained for Ki67 immunoreactivity. The bar (the mean \pm SER) represents the percentage of Ki67 negative cells in each treatment group. Data are from two independent experiments in which 500 cells per experiment condition were counted. (B) $\mathrm{MCF}-7$ cells were plated at a density of $1 \times 10^{6}$ cells $/ 100$ $\mathrm{mm}^{2}$ dish. Cells were cultured in DMEM with 5\% FBS and at $80 \%$ confluency were treated with solvent $(0.01 \%$ DMSO), or TSA 35nM for $24 \mathrm{~h}$. Cell lysate was obtained at the indicated time points. Proteins (50ug) from the cell lysates were assayed for p21(WAF1) protein using an ELISA kit. Data are the mean \pm SER of two independent experiments. 
important role in G1 to G0 cell cycle transition and differentiation (Xiong et al., 1993; Doglioni et al., 1996). To determine whether p21(WAF1) is regulated in MCF-7 cells by TSA, the levels of p21(WAF1) in control and TSA-treated MCF-7 cells were examined using a p21(WAF1) ELISA. p21(WAF1) protein levels increased 5-fold in MCF-7 cells exposed 35 nM TSA for 24 h (Figure 14B).

\subsubsection{Induction of differentiation by TSA in MCF-7 cells}

The effect of TSA on cell differentiation was determined by ORO staining. As seen in Figure 15, lipid droplets accumulated in the cytoplasm around the nucleus in MCF-7 cells exposed to 35 nM TSA for 48 h. Lipid droplets were still present up to $72 \mathrm{~h}$ after TSA addition (data not shown). Figure 16 shows that 20,30, and $40 \mathrm{nM}$ of TSA treatment significantly increased cytosolic accumulation of lipid droplets in MCF-7 cells compared to control cells $(\mathrm{p}<0.05)$. Collectively, these results indicate that induction of p21(WAF1) protein, G0 transition ( loss of Ki67 antigen expression), and differentiation (lipid droplet accumulation) occurred in MCF-7 cells treated with a TSA concentration that reduces MTS activity by $50 \%$.

\subsubsection{Effect of TSA on apoptosis in MCF-7 cells}

Apoptotic cell death was quantitated in MCF-7 cells following treatment with TSA using a cell death ELISA that measures soluble DNA-histone complexes generated during cell apoptosis. MCF-7 cells treated with increasing concentrations of TSA for $72 \mathrm{~h}$ exhibited a concentration-dependent increase in the number of soluble DNA-histone complexes, but the MTS IC50 for TSA (35nM) did not increase DNA-histone complex formation (Figure17). We conclude that the MTS IC50 TSA was sufficient to cause differentiation but not apoptosis, and the induction of 
Figure 15. Induction of differentiation by TSA treatment in MCF-7 cells for 48 h. (A) and (B) Cells $\left(1 \times 10^{5}\right.$ cells per $35 \mathrm{~mm}^{2}$ culture dish) were grown on coverslips treated with solvent only (0.01\% DMSO), or TSA $35 \mathrm{nM}$ for $48 \mathrm{~h}$; cells were stained with Oil Red $\mathrm{O}$ and counterstained with hematoxylin as described in “Materials and Methods". Cells were visualized using light microscopy (x400). (C) Data are presented as percentage of ORO positive cells in solvent and treatment groups. The data are from three experiment in which 300 cells per treatment were counted. *, $\mathrm{p}<0.05$ for TSA treatment versus control group using paired t-tests. 
MCF-7 Cells (48 h)

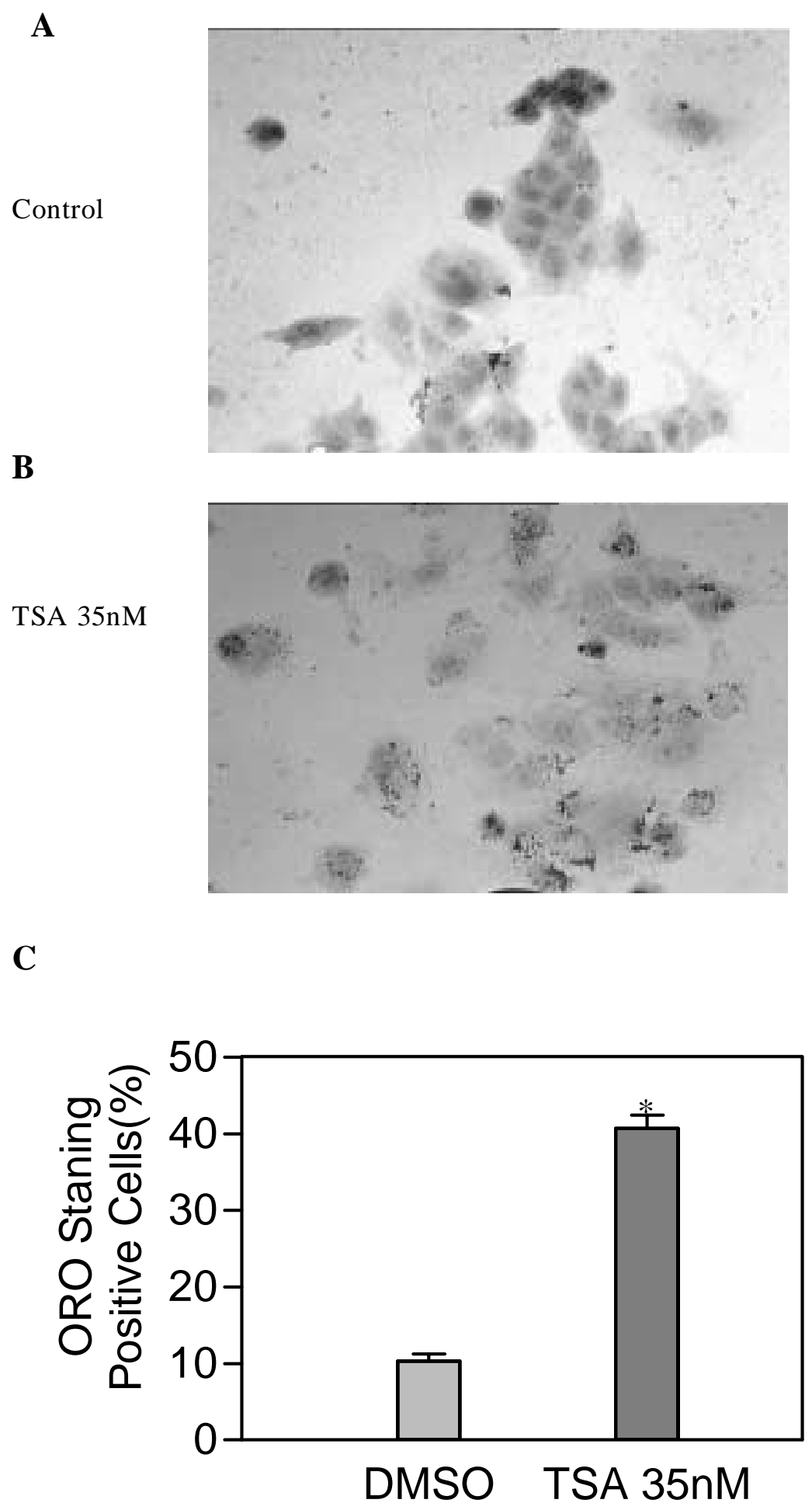




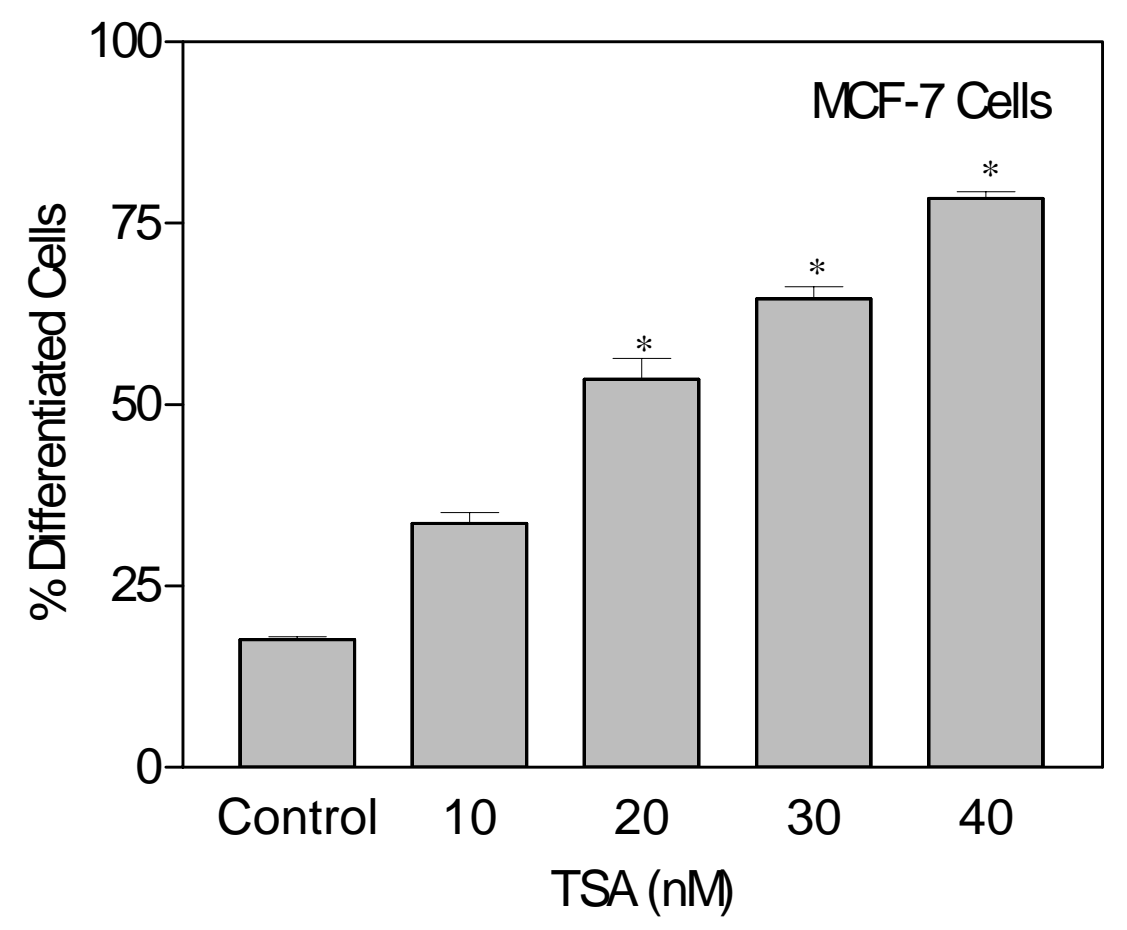

Figure 16. Induction of differentiation by TSA in MCF-7 cells. Cells $\left(2 \times 10^{5}\right.$ cells per $35 \mathrm{~mm}^{2}$ culture dish) were cultured with $0.01 \% \mathrm{DMSO}$, or increasing concentrations of TSA for $39 \mathrm{~h}$, at which time the lipid droplets were determined as an indicator of terminal differentiation using Oil Red O staining. The data are presented as the percentage of Oil Red O positive cells for each treatment. Data are mean \pm SER of three independent assays. *, $\mathrm{p}<0.05$ for TSA treatment versus control group using ANOVA followed by Bonferroni's ttests. 


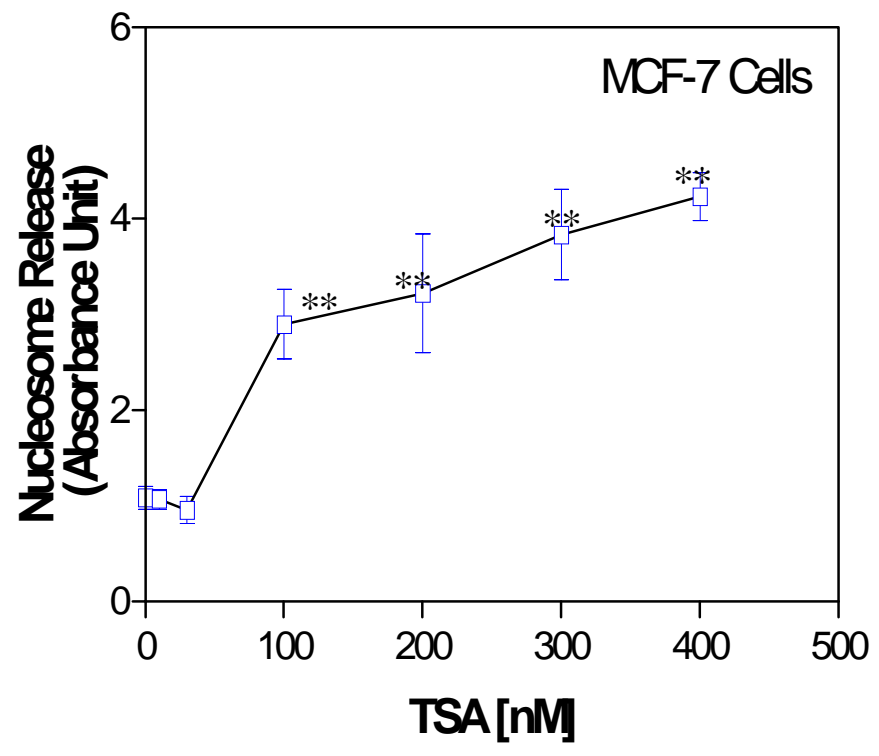

Figure 17. Nucleosome release in the cytoplasm of MCF-7 cells treated with TSA. MCF-7 cells (4000 cells/well in a 96-well plate) were incubated for $72 \mathrm{~h}$ with increasing concentrations of TSA. Cells were lysed, and mono- and oligonucleosome levels were determined by cell death detection ELISA. The release of nucleosomes of each sample was monitored by the absorbance at $405 \mathrm{~nm}$. Data are mean \pm SER of three independent experiments, each performed in triplicate. ${ }^{* *}, \mathrm{p}<0.01$ for TSA treatment versus control group using ANOVA followed by Bonferroni's t-tests. 
differentiation was effected at a lower threshold concentration than that required for induction of apoptosis in the MCF-7 cell line.

\subsubsection{Antimalarials inhibit MTS metabolism in MCF-7 cells}

Quinidine is known to inhibit cell proliferation in MCF-7 cells (Wang et al., 1998; Zhou et al., 2000). To compare the effects of other antimalarials on cell growth of MCF-7 cells, we determined the cell growth arrest upon treatment with antimalarial drugs using the MTS assay. The IC50 after $48 \mathrm{~h}$ was calculated for each drug (Figure 18A). Mefloquine and primaquine were the most potent cell growth arrest agents, and quinidine was least potent agent in this assay. As shown in Figure 18B, there was an initial loss of about $60 \%$ of the cell population by chloroquine treatment for $60 \mathrm{~h}$. Quinoline, quinidine and quinine caused growth arrest (no change in cell number) within $60 \mathrm{~h}$.

MTS reduction activity could be affected within $4 \mathrm{~h}$ (Berridge, et al., 1993). To study whether antimalarials effect early changes in mitochondrial dehydrogenase in MCF-7 cells, the MTS IC50 of each antimalarial was added to MCF-7 cells for 2 or 6 h. Figure 19 indicates that only primaquine treatment significantly inhibited the activity of mitochondial dehydrogenase at times up to $6 \mathrm{~h}$ compared to control group $(\mathrm{p}<0.05)$. No significant changes in mitochondial dehydrogenase were detected in MCF-7 cells treated with the other tested compounds for 2 or $6 \mathrm{~h}$. MTS IC50 of antimalarials did not affect cell viability within $2 \mathrm{~h}$ (Figure 20).

\subsubsection{Hyperacetylation of histone $\mathrm{H} 4$ by antimalarials in MCF-7 cells}

To analyze the effects of quinoline ring-containing antimalarial drugs on histone acetylation, Western blot assays were performed to detect acetylation of histone H4 in MCF-7 cells exposed to MTS IC50 of each antimalarial compound. Quinidine, quinine, and chloroquine possess a quinoline base ring structure and a tertiary amine side chain. Since quinidine causes hyperacetylation of histone 
Figure 18. Antimalarials inhibit MCF-7 cell growth. (A) Antimalarials Inhibit MTS Metabolism in MCF-7 cells. MCF-7 cells were grown in the presence of increasing concentrations of each compound for $48 \mathrm{~h}$, and cell viability was estimated using the MTS assay. The IC50 value for each agent was determined using nonlinear regression analysis to fit the inhibition data. The results are the average of at least two independent experiments carried out in quadruplicate, and are presented as the means \pm SER of the percentage of untreated, control cells. The IC50 value for each compound is shown in the table. Typical or a complete concentration response curve for each compound is shown in Appendix 1. (B) Effects of antimalarials on cell growth. MCF-7 cells $\left(5 \times 10^{5}\right)$ growing in $60 \mathrm{~mm}^{2}$ dishes in 5\% FBS/DMEM were treated with concentrations of antimalarials corresponding to $50 \%$ inhibition of MTS activity as measured at $48 \mathrm{~h}$. After $60 \mathrm{~h}$ incubation with antimalarials or solvent alone, viable cells that excluded trypan blue were counted using hemacytometer. Data are the mean of $n=3 \pm$ SER independent experiments. Abbreviations: AQ (amodiaquin), CL (chloroquine), ETOH (ethanol), HF (Halofantrine), MQ (Mefloquine), QA (quinolinic acid), QL (quinoline), QD (quinidine), PQ (primaquine), and QN (quinine). 
A

Summary of IC50 ( $\log$ uM) for Antimalarial Drugs on MIS

Metabolismin MCF-7 Cells

\begin{tabular}{|c|c|c|c|c|c|c|c|c|c|}
\hline & & & & & & & & & \\
Compound & $\mathrm{MQ}$ & $\mathrm{PQ}$ & $\mathrm{AQ}$ & $\mathrm{HF}$ & $\mathrm{QA}$ & $\mathrm{CL}$ & $\mathrm{QN}$ & $\mathrm{QL}$ & $\mathrm{QD}$ \\
\hline $\mathrm{IC50}(\log \mathrm{uM})$ & 0.48 & 0.52 & 0.84 & 1.03 & 1.46 & 1.483 & 1.6 & 1.79 & 2.04 \\
$(\mathrm{SER})$ & $(0.162)$ & $(0.13)$ & $(0.073)$ & $(0.089)$ & $(0.125)$ & $(0.157)$ & $(0.08)$ & $(0.3)$ & $(0.3)$ \\
$\mathrm{N}$ & 3 & 4 & 2 & 2 & 2 & 5 & 3 & 2 & 4 \\
$\mathrm{uM}$ & 3.0 & 3.4 & 7.0 & 11.0 & 28.0 & 33.0 & 40.0 & 62.0 & 110.0 \\
\hline
\end{tabular}

B

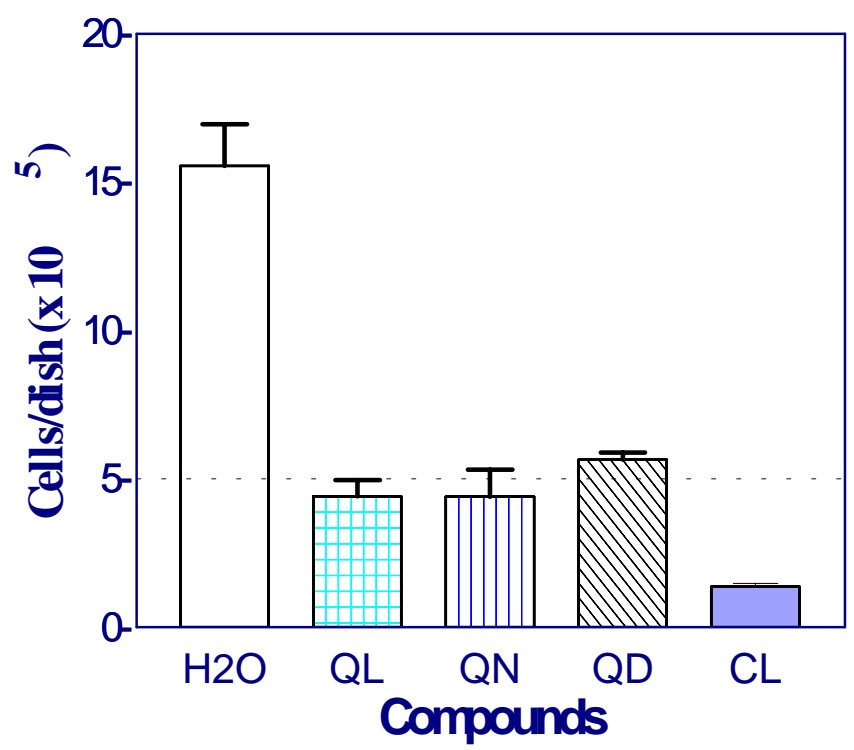


Figure 19. Effects of antimalarials and TSA on MTS metabolism in MCF-7 cells. MCF-7 cells were grown in the presence of MTS IC50 of each compound for $2 \mathrm{~h}$ (A) or 6 h (B), and cell mitochondria metabolism was estimated using the MTS assay. The results are the average of one experiment carried out in quadruplicate, and are presented as the means \pm SD. The microtiter plates were incubated with MTS for $1 \mathrm{~h}$ at $37{ }^{0} \mathrm{C}$, and the absorbance was read at $490 \mathrm{~nm}$ using the microtiter plate reader. *, $\mathrm{p}<0.05$ for compound treatment versus control group using ANOVA followed by Bonferroni's t-tests. 
A

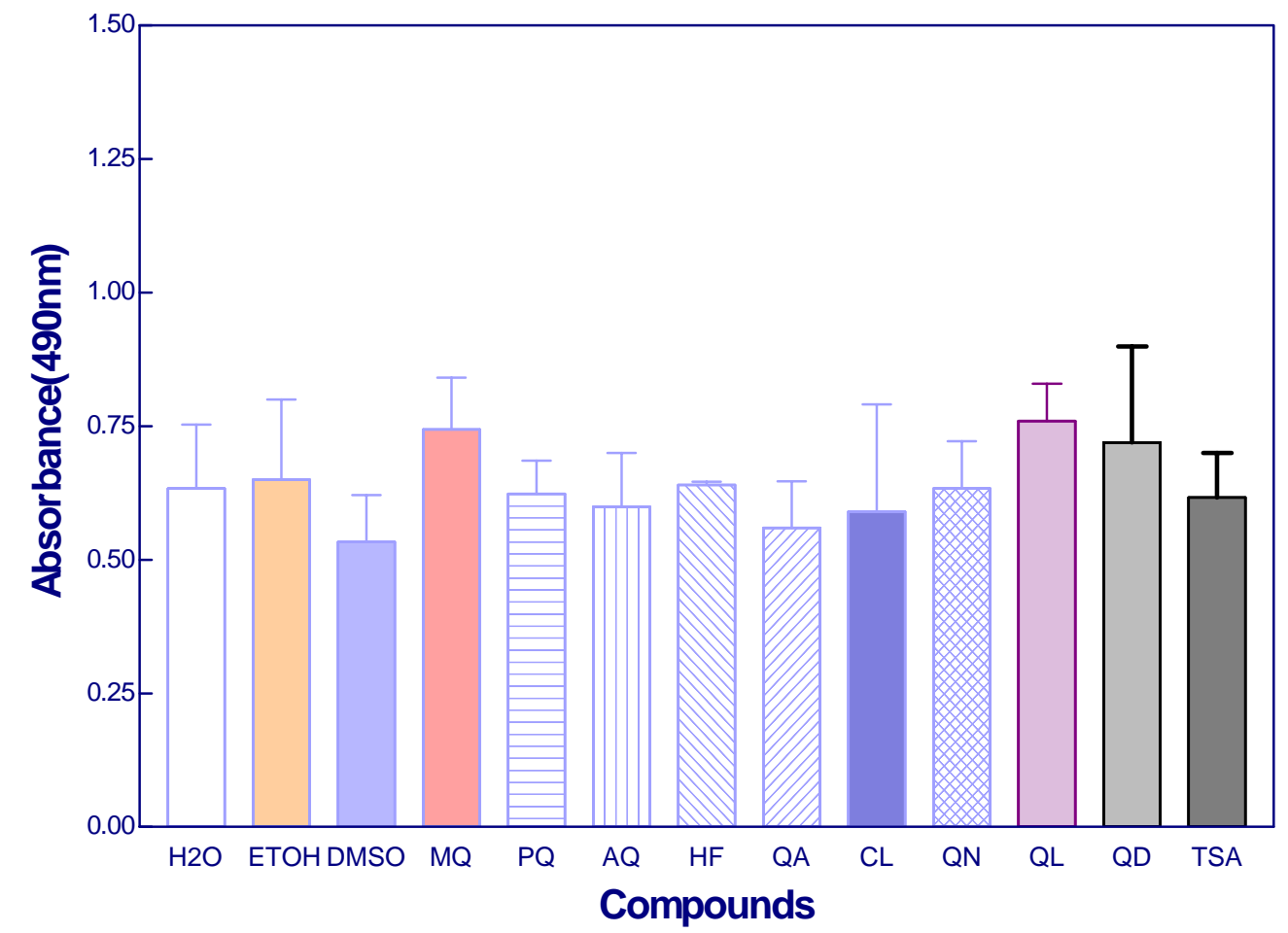

B

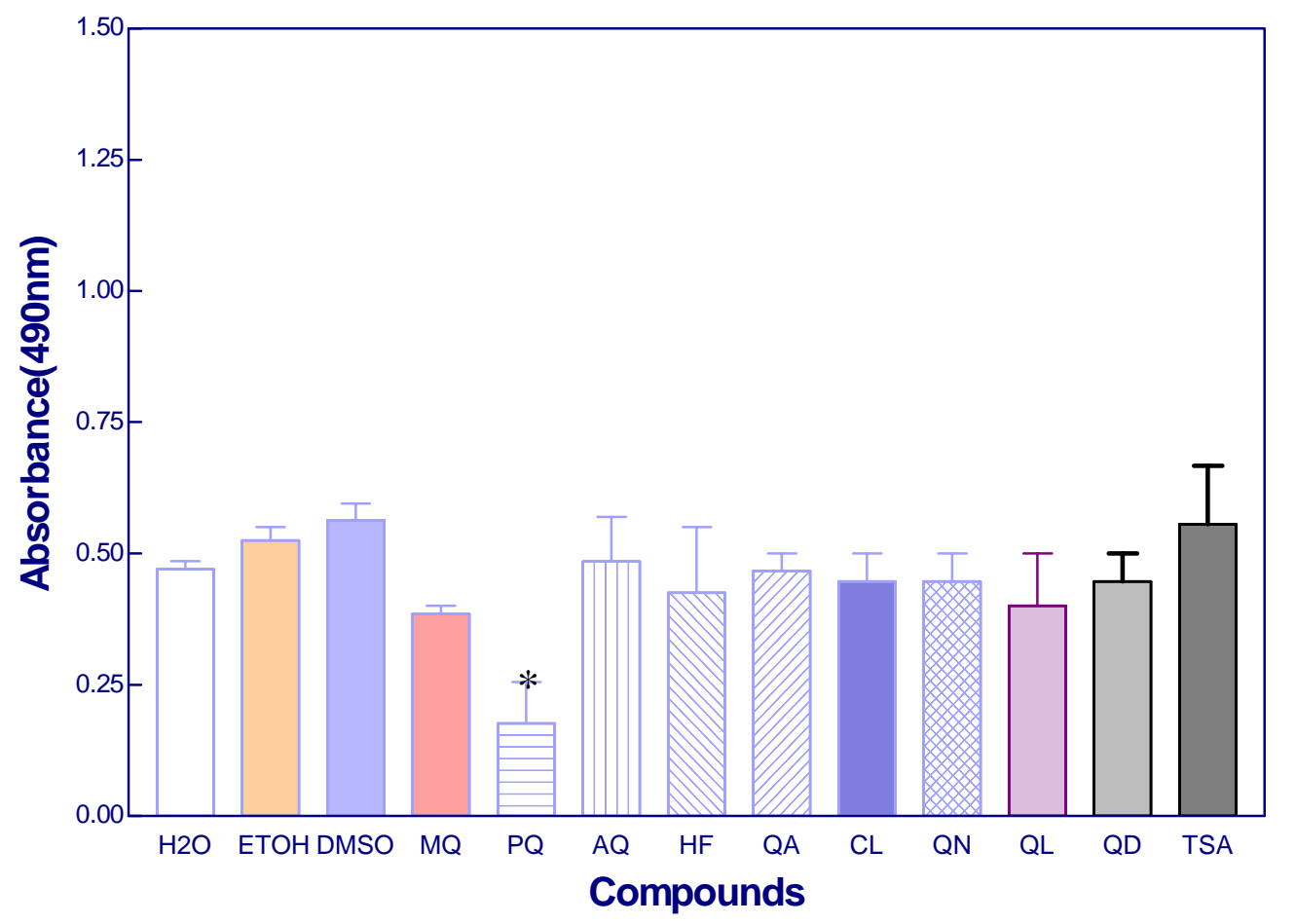




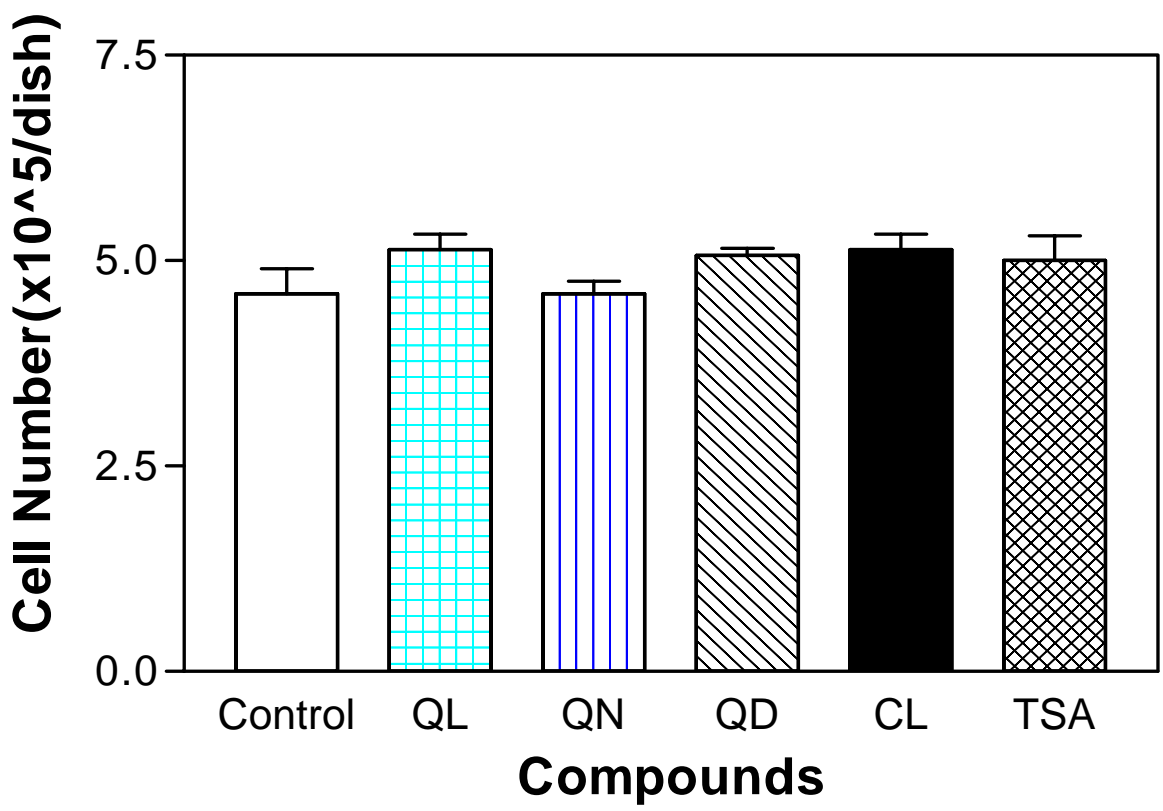

Figure 20. Effects of antimalarials and TSA on cell viability. MCF- 7 cells $\left(5 \times 10^{5}\right)$ were growing in $60 \mathrm{~mm}^{2}$ dishes in 5\% FBS/DMEM, and treated with concentrations of antimalarials corresponding to 50\% inhibition of MTS activity as measured at $48 \mathrm{~h}$. After $2 \mathrm{~h}$ incubation with each compound or distilled $\mathrm{H}_{2} \mathrm{O}$ alone (control), viable cells that excluded trypan blue were counted using hemacytometer. Data are the mean of $n=3 \pm S E R$ independent experiments. 
Figure 21. Hyperacetylation of histone $\mathrm{H4}$ by antimalarials in MCF-7 Cells. Histones were extracted from cells grown either in the presence of compound or solvent control (distilled $\mathrm{H}_{2} \mathrm{O}$ or $0.1 \%$ ethanol) for 12 or $24 \mathrm{~h}$. Histone proteins were electrophoresed in $10 \%$ SDS-polyacrylamide gels, and assayed for the presence of acetylated $\mathrm{H} 4$ by immunoblotting. (A) Cells were treated with either MTS IC50 of antimalarials or $0.1 \%$ ethanol (control) for $24 \mathrm{~h}$. Recombinant histone H4 proteins (20ug) were used as the negative control for acetylated histone $\mathrm{H} 4$ antibody. (B) Cells were treated with either amodiaquin $10 \mathrm{uM}$ or distilled $\mathrm{H}_{2} \mathrm{O}$ (control) for $24 \mathrm{~h}$. (C) Cells were treated with quinidine, primaquine, or halofantrine for $24 \mathrm{~h}$. (D) Cell were treated with 0-, 10-, 50-, and $90 \mathrm{uM}$ of quinine for $12 \mathrm{~h}$. (E) Summary of effects of antimalarials on acetylation of histone H4 protein in MCF-7 cells. "+", agent induced acetylated histone H4; “-”, agent did not cause induction of acetylated histone H4. 
A H4 HF MQ PQ QL CL QA Control

B

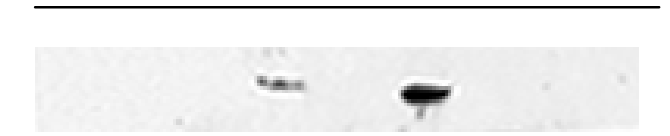

B Control AQ (10uM)

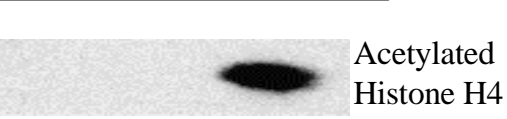

C

\begin{tabular}{|c|c|c|c|c|c|}
\hline QD & & PQ & ETOH HF QD & $\mathrm{HF}$ & QL \\
\hline $0 \quad 90$ & 1 & $5 \mathrm{uM}$ & $0.1 \% \quad 11 \quad 110$ & 11 & $62 \mathrm{uM}$ \\
\hline-0 & & - & - & - & \\
\hline
\end{tabular}

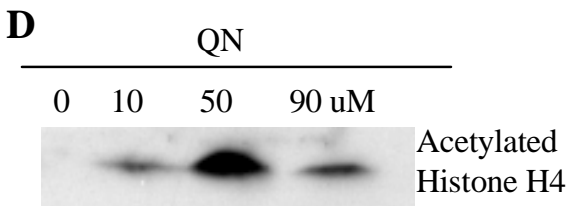

E

\begin{tabular}{|l|c|c|c|c|}
\hline Antimalarials & Test 1 & Test 2 & Test 3 & Total N \\
\hline $\mathrm{CL}$ & $+(30 \mathrm{uM})$ & $+(33 \mathrm{uM})$ & $+(33 \mathrm{uM})$ & 3 \\
\hline $\mathrm{QD}$ & $+(90 \mathrm{uM})$ & $+(110 \mathrm{uM})$ & $+(110 \mathrm{uM})$ & 3 \\
\hline $\mathrm{QN}$ & $+(50 \mathrm{uM})$ & $+(40 \mathrm{uM})$ & $+(90 \mathrm{uM})$ & 3 \\
\hline $\mathrm{PQ}$ & $+(5 \mathrm{uM})$ & $+(3.4 \mathrm{uM})$ & $+(3.4 \mathrm{uM})$ & 3 \\
\hline $\mathrm{AQ}$ & $+(10 \mathrm{uM})$ & $+(7 \mathrm{uM})$ & & 2 \\
\hline $\mathrm{MQ}$ & $-(3 \mathrm{uM})$ & & & 1 \\
\hline $\mathrm{HF}$ & $+(11 \mathrm{uM})$ & $+(11 \mathrm{uM})$ & & 2 \\
\hline $\mathrm{QL}$ & $-(62 \mathrm{uM})$ & $-(62 \mathrm{uM})$ & & 2 \\
\hline $\mathrm{QA}$ & $-(28 \mathrm{uM})$ & & & 1 \\
\hline
\end{tabular}


H4, we hypothesized that these antimalarials might be the same or related. Quinoline antimalarial compounds lacking a tertiary amine side chain (quinoline or quinolinic acid) were used as negative control to test this hypothesis.

As shown in Figure 21, 4-alkylamino substituted qunolines (chloroquine and amodiaquin), and an 8-amino substituted quinoline (primaquine) induced hyperacetylation of histone $\mathrm{H} 4$ in MCF-7 cells treated with their MTS IC50. Hyperacetylation of histone H4 was also observed in cells treated with halofantrine, quinidine and its stereoisomer quinine. Those are 4-amino substituted quinoline ring compounds containing a quinuclidine ring, and have structural parallels with amodiaquin and chloroquine. Mefloquine, quinoline and quinolinic acid that lack alkylamino-substituted quinoline rings did not increase acetylated histone $\mathrm{H} 4$ level. The data indicates that alkylamino-substituted quinoline ring might be important for acetylation of histone $\mathrm{H} 4$.

\subsubsection{Effect of quinoline antimalarial drugs on HDAC activity in vitro}

The effect of quinoline antimalarials on HDAC activity in vitro was assessed using a fluorescent enzyme assay. Histone deacetylases came from HeLa cells. As shown in Figure 22, none of antimalarials we tested inhibited HDAC activity compared to control ( $p>0.05)$. TSA was used as a positive control in these assays. IC50 TSA, 8.5nM, significantly inhibited in vitro HDAC activity compared to control $(\mathrm{p}<0.05)$.

\subsubsection{Effects of antimalarials on Ki67 antigen in MCF-7 cells}

We analyzed the effects of antimalarials on the cell cycle of the MCF-7 cells by performing Ki67 immunohistochemical staining. MCF-7 cells were treated with each antimalarial (MTS IC50) for 48 h. We observed that the percentage of Ki67 negative immunoreactive cells. Chloroquine, quinidine, quinine, -treated cell populations showed highly significant increases $(\mathrm{p}<0.01)$ (Figure 23). Moreover, 
an increase in the percentage of Ki67 negative cells also was observed in amodiaquin $(\mathrm{p}<0.05)$. This result indicates that amodiaquin, chloroquine, quinidine as well as quinine caused cells to enter G0 phase. No significant changes in the percentage of Ki67 negative cells were detected after treatment of MCF-7 cells with the other listed antimalarials $(p>0.05)$. We conclude that only a subset of quinoline antimalarials stimulates exit of MCF-7 cells from the cell cycle. 
A

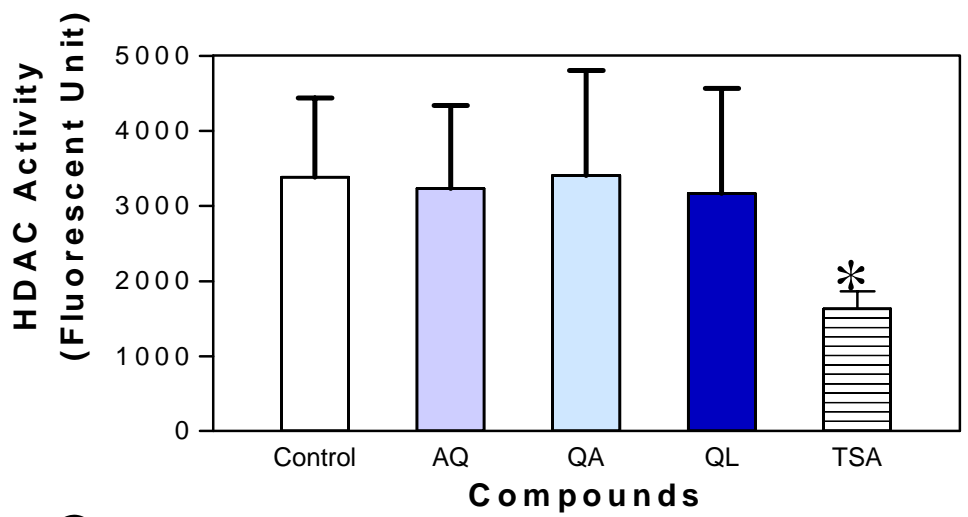

B

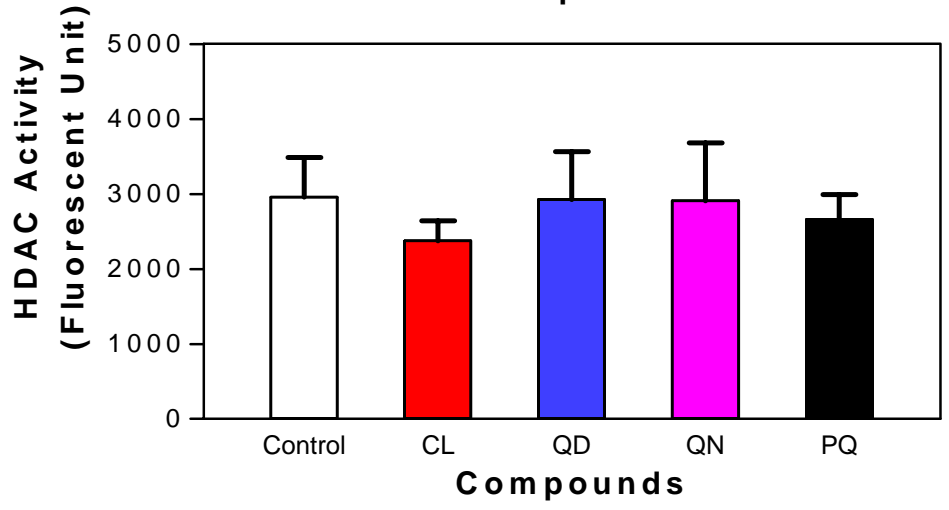

C

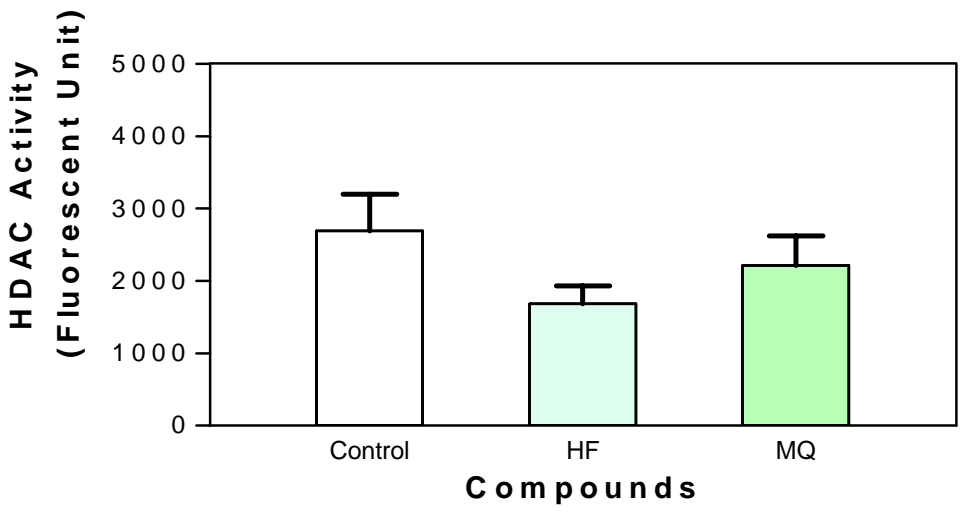

Figure 22. Effect of antimalarials on HDAC activity in HeLa cell nuclear extracts. Assay was performed using MTS IC50 of each compound as described in "Materials and Methods". In panel A and $\mathrm{B}$, control groups were treated with distilled $\mathrm{H}_{2} \mathrm{O}$; in panel $\mathrm{C}$, the control group was treated with $0.1 \%$ ethanol. Data represent the average of three different experiments, each performed in triplicate; bars, SER. *, $\mathrm{p}<0.05$ for compound treatment versus control group using ANOVA followed by Bonferroni's t-tests. 


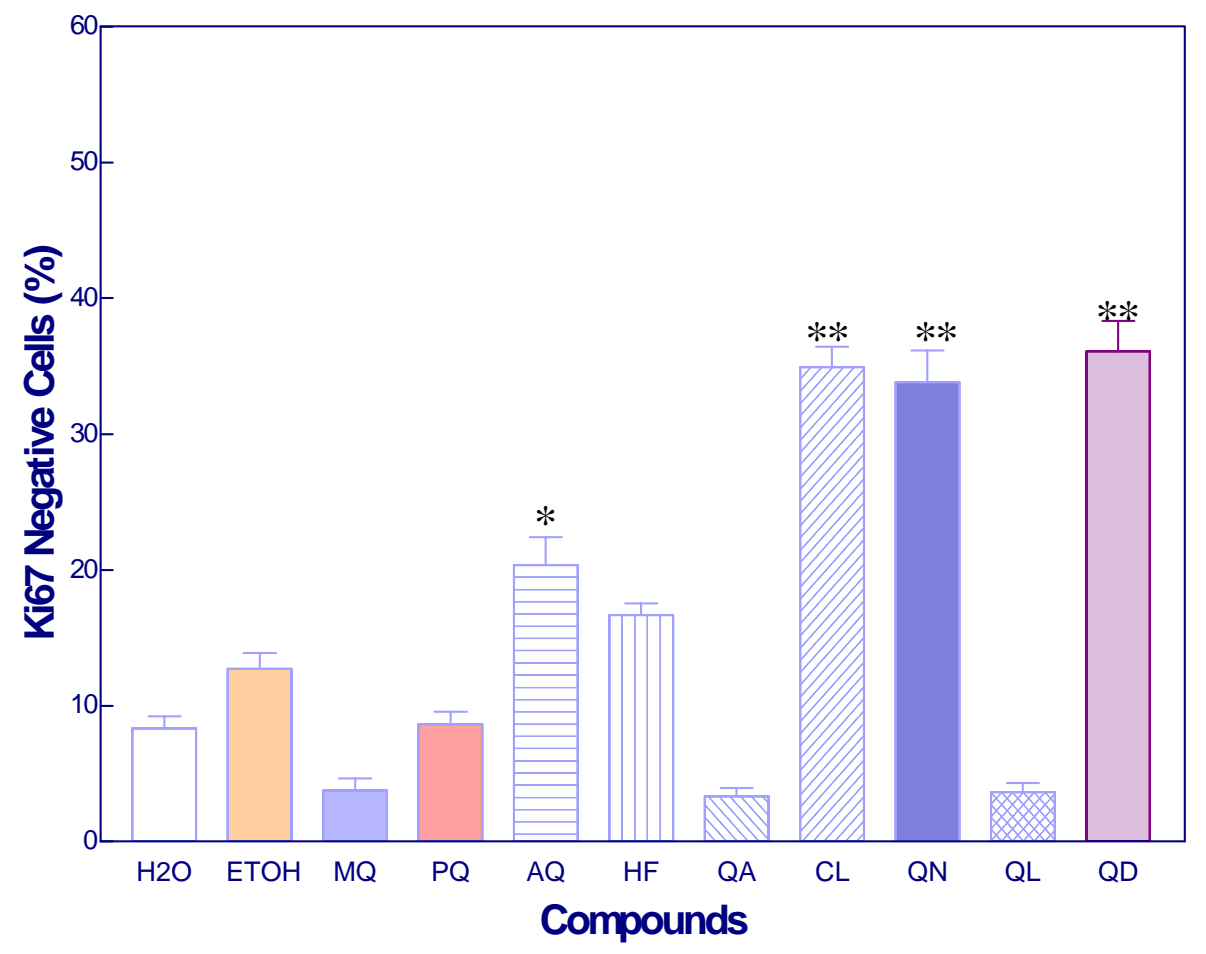

Figure 23. Ki67 expression in MCF-7 cells after treatment with antimalarials. MCF-7 cells were plated $\left(2 \times 10^{5}\right)$ in $35-\mathrm{mm}^{2}$ dishes on sterile glass coverslips and grown in 5\% FBS/DMEM. Cells were treated with vehicles (distilled $\mathrm{H}_{2} 0$, or $0.1 \%$ ethanol), or the MTS IC50 of each compound for $48 \mathrm{~h}$. Halofantrine and mefloquine were dissolved in 95\% ethanol; other listed antimalarials were dissolved in distilled $\mathrm{H}_{2} \mathrm{O}$. Cells were stained for $\mathrm{Ki} 67$ immunoreactivity as previously described by Wang et al. 1998. The bars represent the percentage of Ki67 negative cells in each treatment group. Data are the mean of $n=3 \pm$ SER independent experiments in which 300 cells per experiment condition were counted. *,p<0.05; **,p<0.01 for compound versus control group using ANOVA followed Bonferroni's t-tests. 


\subsubsection{Effects of antimalarials on p21(WAF1) protein in MCF-7 cells}

Because p21(WAF1) is rarely mutated in human cancer cells, induction of p21(WAF1) by drugs might be an important molecular target for anticancer therapy. We examined the effect of antimalarials on changes in p21(WAF1) protein. As shown in Figure 24, a p21(WAF1) ELISA was used to test if p21(WAF1) protein expression increased in MCF-7 cells exposed to quinoline antimalarial drugs for $24 \mathrm{~h}$. In our experiments, each drug was used at the MTS IC50. Protein p21(WAF1) was increased in chloroquine and quinidine treated cells, but not either in quinoline or other tested antimalarials. Trichostatin A (TSA) was used as a positive control for these experiments. Transcription of p21(WAF1) and p21(WAF1) protein levels have been shown to be increased by TSA (Kim et al., 2000). Western blot analysis was performed on MCF-7 cell extracts to confirm the changes in p21(WAF1) protein in response to the antimalarials ( comparison shown in Figure 25A). The results from Western blot analysis are consistent with the results by ELISA (Figure 25C). Amodiaquin, halofantrine, mefloquine, primaquine, quinolinic acid and quinoline did not increase p21(WAF1) protein levels (Western blot data not shown). Chloroquine caused a 10-15 fold elevation in p21(WAF1) levels in MCF-7 cells at $24 \mathrm{~h}$. The p21(WAF1) response to chloroquine exceeded that of

the potent histone deacetylase inhibitor, TSA. Quinidine elevated p21(WAF1) levels 4-5 fold, approximately the same as TSA, but neither quinine nor amodiaquin raised p21(WAF1) protein.

\subsubsection{Effect of antimalarials on lipid droplet accumulation in MCF-7 cells}

The effects of quinidine and other listed quinoline compounds on lipid accumulation were compared using ORO staining. The percentage of MCF-7 cells with lipid droplets in cells exposed to MTS IC50 of compounds for $48 \mathrm{~h}$ is shown in Figure 26 Quinidine (110uM) caused positive ORO staining in $65 \%$ of MCF-7 cells by $48 \mathrm{~h}$. Fifty percent ORO positive cells was achieved by and quinidine (110uM) and quinine (40uM), 


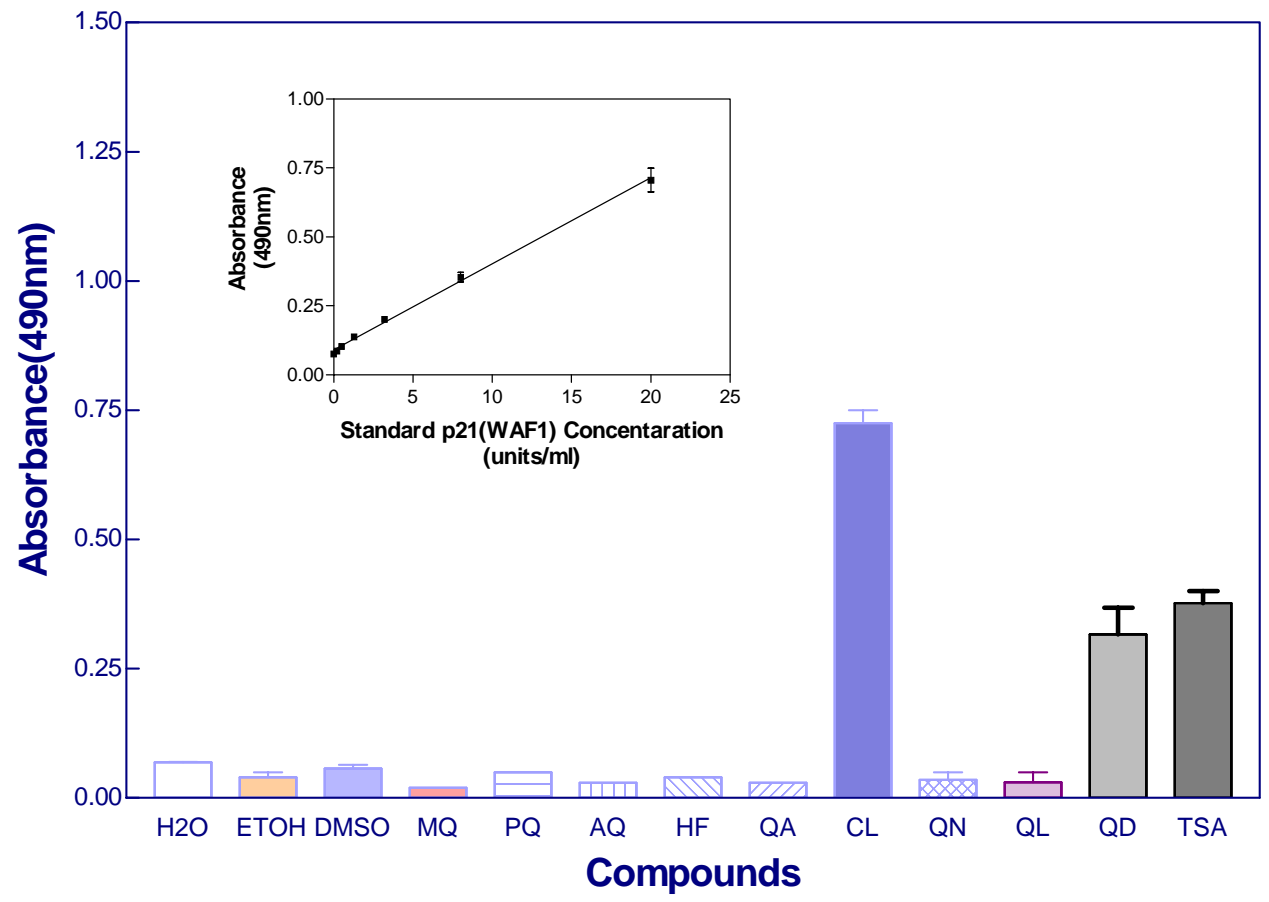

Figure 24. Effect of antimalarials and TSA on expression of p21(WAF1) protein in MCF-7 cells. Cells were plated at a density of $1 \times 10^{6}$ cells $/ 100-\mathrm{mm}^{2}$ dish. Twelve hours after plating, cells were treated with solvent (distilled $\mathrm{H}_{2} \mathrm{O}$, or $0.01 \%$ DMSO) or MTS IC50 of each compound for 24 h. p21(WAF1) protein levels were measured by p21(WAF1) ELISA kit according to the manufacturer's protocol (Oncogen). Each bar represents the mean $\pm \mathrm{SEM}$ of two independent experiments. 
Figure 25. Effect of antimalarials on p21(WAF1) protein expression in MCF-7 cells.

(A) Proteins (50ug) from the cell lysates (same lysate as p21(WAF1) ELISA) were separated by $12 \%$ SDS-polyacrylamide gel electrophoresis and analyzed with Western blotting using mouse monoclonal antibody for p21(WAF1) as detailed in "Materials and Methods". (B) The signal density for each band in Western blot analysis was quantitated by densitometric analysis. (C) Comparison the results from p21(WAF1) ELISA and Western blot analysis. The ' $\mathrm{W}$ ' bar represents the fold increase which is the signal density in drug treatment group divided by the signal density in solvent control using Western blot; the 'E' bar represents the fold increase which is the absorbance obtained from drug treatment group divided by the absorbance obtained from solvent control using p21(WAF1) ELISA . 


\section{H2O QL QN QD CL TSA DMSO}

A

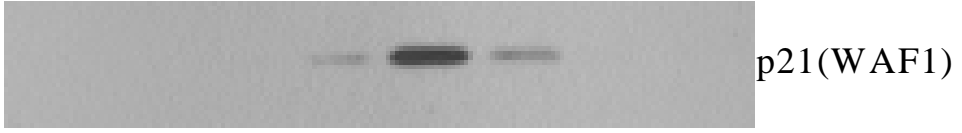

B

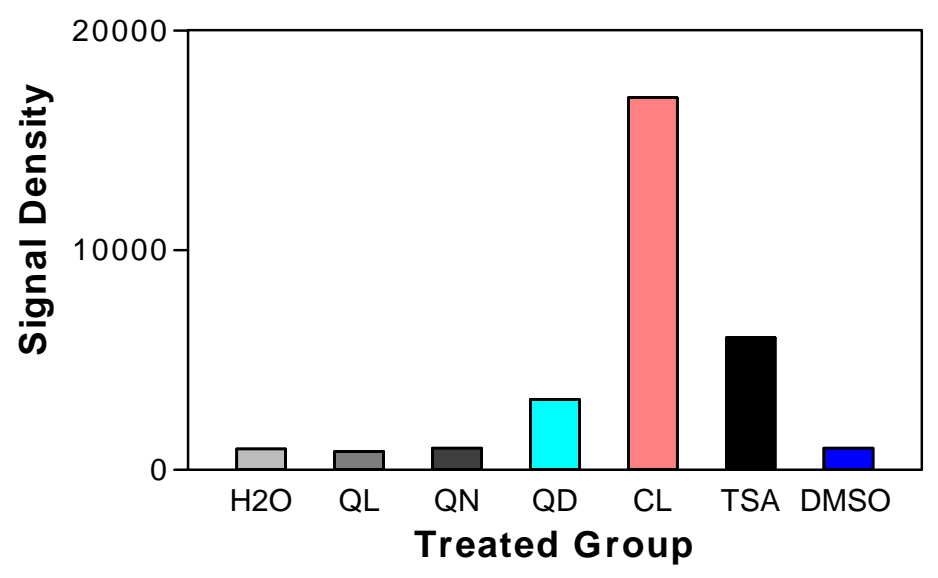

C

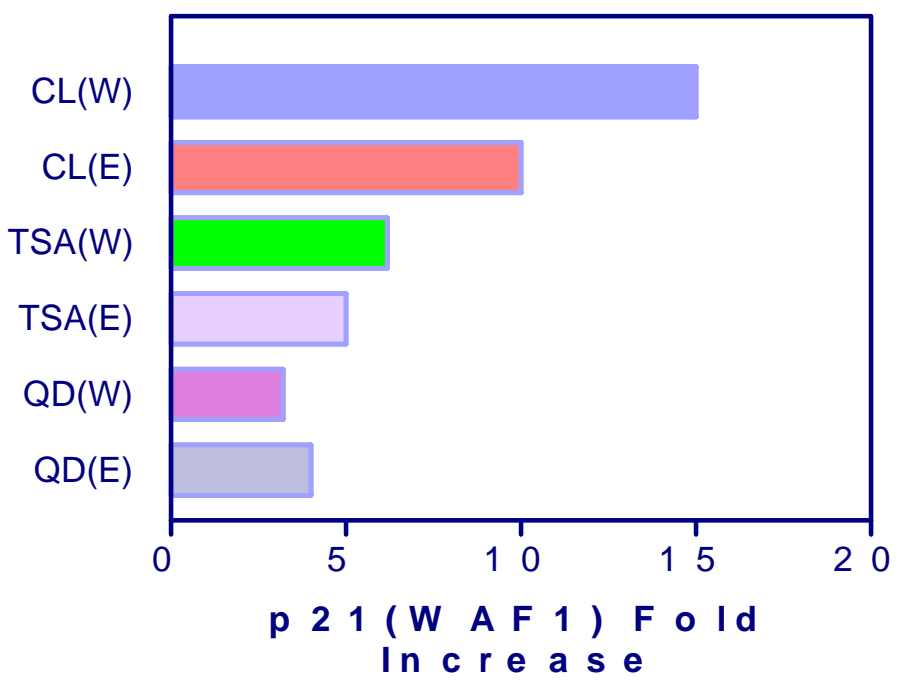




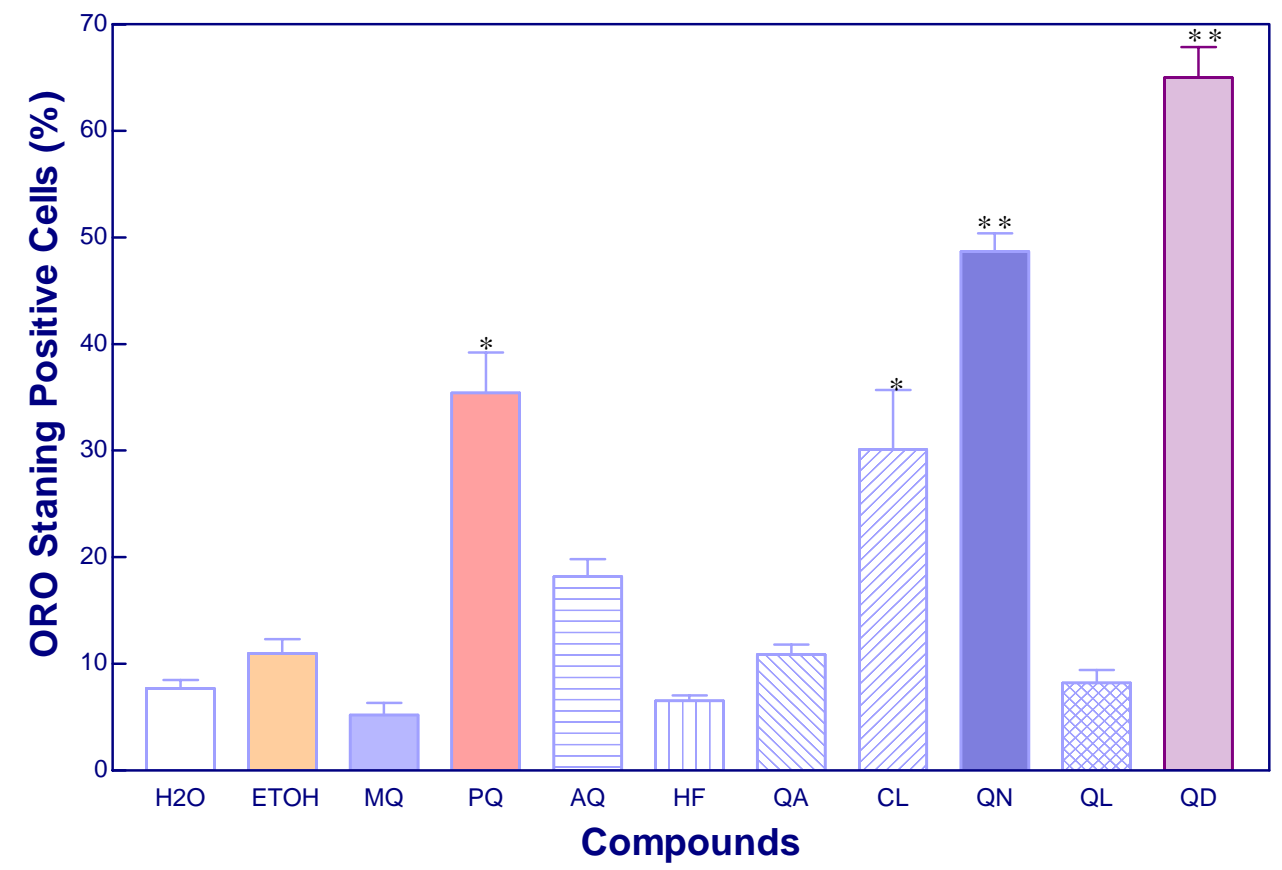

Figure 26. Effect of antimalarials on lipid droplet accumulation in MCF-7 cells. Cells were plated $\left(2 \times 10^{5}\right)$ in $35-\mathrm{mm}^{2}$ dishes on sterile glass coverslips and grown in DMEM plus $5 \%$ FBS. Cells were treated with solvent (distilled- $\mathrm{H}_{2} 0$, or $0.1 \%$ ethanol), or MTS IC50 of each compound for $48 \mathrm{~h}$; halofantrine (HF) and mefloquine (MQ) were dissolved in $95 \%$ ethanol; other listed antimalarials were dissolved in distilled $\mathrm{H}_{2} \mathrm{O}$. Cells were stained with Oil-Red O; and counterstained with hematoxylin. The data were presented as percentage of ORO positive cells in each treatment group. Data are the mean of $n=3 \pm$ SER independent experiments in which 300 cells per treatment were counted. *, p<0.05; **, $\mathrm{p}<0.01$ for compound versus control group using ANOVA followed by Bonferroni's t-tests. 
primaquine $(4 \mathrm{uM})$ and chloroquine $(33 \mathrm{uM})$ also stimulated lipid accumulation (40\% and $30 \%$ of ORO-positive cells respectively). Quinidine (90uM), quinine (90uM) and primaquine (10uM) induced positive ORO staining in 79-89\% of MCF-7 cells by 72 h (Johnson and Strobl et al., 1999). Quinidine (110uM) treated MCF-7 cells for $72 \mathrm{~h}$ show a more intense increase in accumulation of lipid droplets compared with $48 \mathrm{~h}$ treatment (data not shown). These data suggest that quinidine was the most effective compound stimulating lipid droplet accumulation, followed by quinine, primaquine and chloroquine. Other quinolines tested were inactive as differentiating agents in this assay ( $<10 \%$ OROpositive).

\subsubsection{Effect of quinoline antimalarials on apoptosis in MCF-7 cells}

To determine whether apoptotic cell death may be a contributing factor for antimalarial-induced decreases in MTS metabolism, we quantified the release of nucleosomes into the cytoplasm of MCF-7 cells using a photometric enzyme immunoassay. Etoposide, a DNA-damaging agent, was used as the positive control. Etoposide causes a double-strand breakage of DNA by forming a complex with the enzyme, topoisomerase II. Quinolinic acid and quinoline, compounds that contain only quinoline ring structure, did not change nucleosome release as compared with controls $(\mathrm{p}>0.05)$. Similarly, amodiaquin, mefloquine and primaquine treatments failed to induce apoptosis in MCF-7 cells (Figure 27). Clearly, quinoline-induced apoptosis was observed with chloroquine, quinidine and halofantrine treatment. Induction of apoptosis by these three agents was dependent on their concentrations. A statistically significant increase in apoptotic activity was observed after 48 or $72 \mathrm{~h}$ of treatment with 90, 110, 200 and 250uM quinidine in MCF-7 cells compared with control $(\mathrm{p}<0.05)$. These data are consistent with previous reports that quinidine induced apoptosis as evidenced by nuclear morphological changes (nuclear collapse) of the MCF-7 cells by $72 \mathrm{~h}$ using Hoechst 33342 staining of DNA (Wang et al., 1998). Chloroquine-treated cells (33uM) for $48 \mathrm{~h}$ exhibited an increase 
Figure 27. The apoptotic response to antimalarias in MCF-7 cells. MCF-7 cells (4000 cells/well in 96-well plate) were grown for $48 \mathrm{~h}$ in the presence of increasing concentrations of agents. Cells were evaluated for apoptosis by the histone-DNA cell death detection kit as described in "Materials and Methods". Data are the mean \pm SER of three independent experiments. One asterisk indicates a $\mathrm{p}$ value of $<0.05$ for compound vs. control using ANOVA followed by Bonferroni's t-tests. 

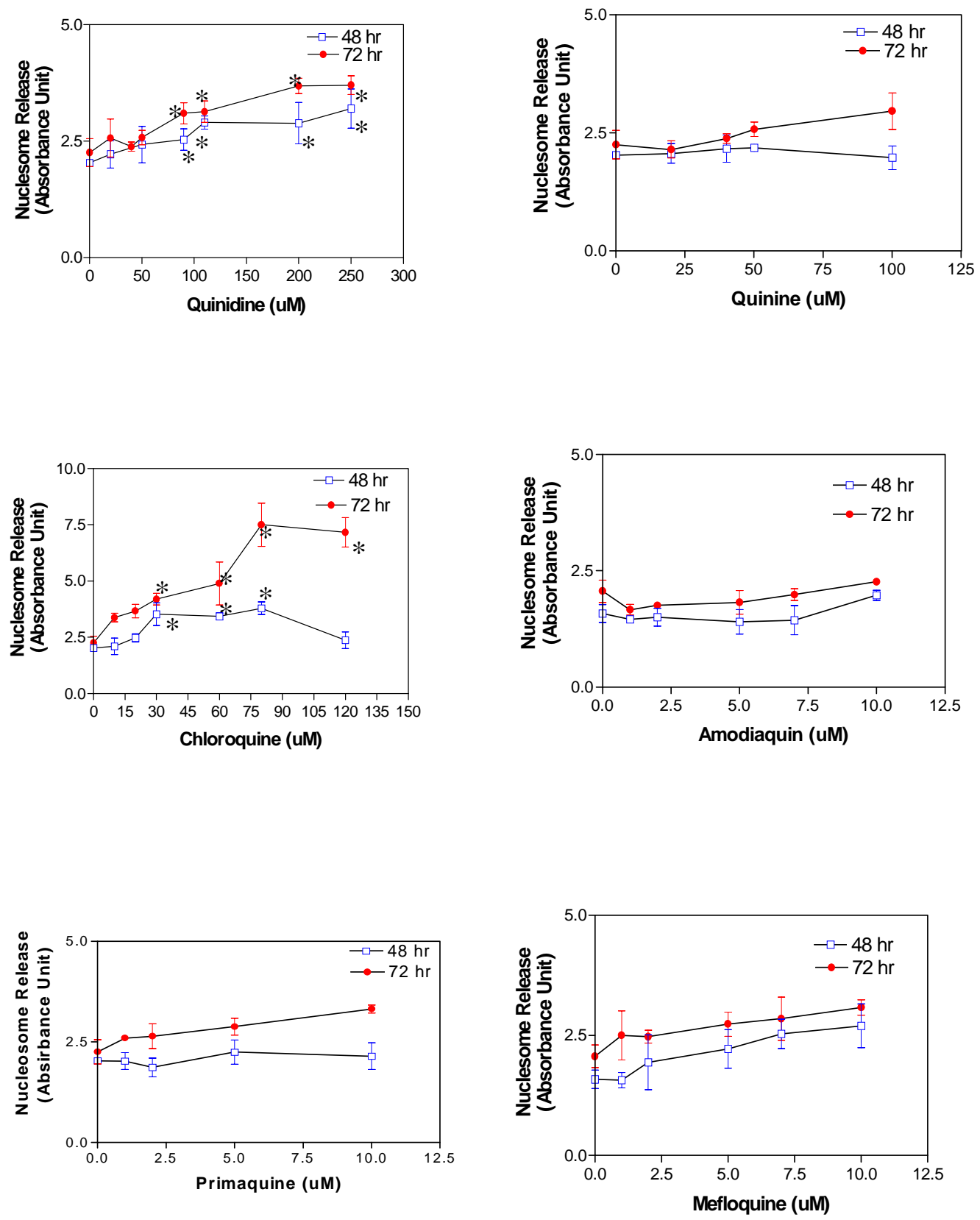

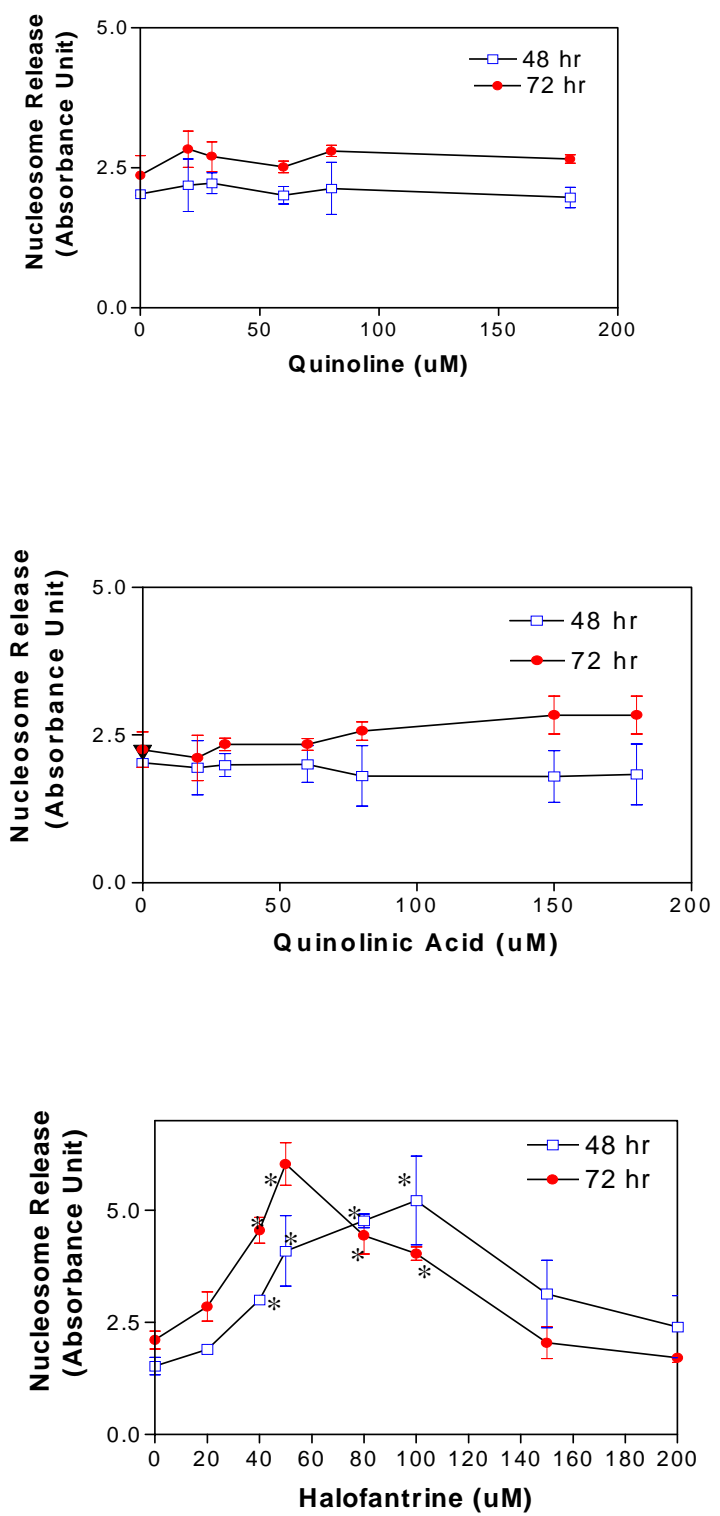
Table 2. Enrichment of nucleosome release in the cytoplasm of MCF-7 cells treated with MTS IC50 antimalarials, etoposide, and TSA for 48 or 72 h. Cells were lysed, and mono- and oligonucleosome levels were determined by photometric enzyme immunoassay using cell death detection ELISA. The released nucleosome level of each sample was indicated as the absorbance at $405 \mathrm{~nm}$. Each experiment was performed in triplicate. The apoptosis enrichment factor of nucleosomes released into the cytoplasm for each sample is calculated using the ratio: units of absorbance of sample divided by units of absorbance of control group. Data are mean \pm SER of three experiments, each performed in triplicate. *, p<0.05 for compound vs. control using ANOVA followed by Bonferroni's t-tests. 
Compounds

(MTS IC50)
Apoptosis Enrichment Factor (Mean \pm SER, N=3)

$48 \mathrm{~h}$

$72 \mathrm{~h}$

\begin{tabular}{|c|c|c|}
\hline Amodiaquin (AQ) & $0.71 \pm 0.09$ & $0.86 \pm 0.03$ \\
\hline Quinolinic Acid (QA) & $0.98 \pm 0.05$ & $1.01 \pm 0.02$ \\
\hline Quinoline (QL) & $1.00 \pm 0.06$ & $1.09 \pm 0.03$ \\
\hline Primaquine (PQ) & $0.92 \pm 0.07$ & $1.17 \pm 0.07$ \\
\hline Mefloquine (MQ) & $1.09 \pm 0.11$ & $1.19 \pm 0.06$ \\
\hline Quinine (QN) & $1.13 \pm 0.09$ & $1.19 \pm 0.07$ \\
\hline Quinidine (QD) & $1.50 \pm 0.10$ * & $1.73 \pm 0.09$ * \\
\hline Halofantrine (HL) & $1.2 \pm 0.02$ & $1.1 \pm 0.2$ \\
\hline Chloroquine (CL) & $1.75 \pm 0.14^{*}$ & $1.82 \pm 0.07$ * \\
\hline Etoposide (ET 30uM) & $2.74 \pm 0.13^{*}$ & $1.23 \pm 0.20$ \\
\hline Trichostatin A (35nM) & $0.96 \pm 0.06$ & $0.91 \pm 0.05$ \\
\hline
\end{tabular}


Table 3. A comparison of Ki67, ORO, p21(WAF1) protein, acetylated histone $\mathrm{H} 4$ and apoptotic response in MCF-7 human breast cancer cells treated with MTS IC50 antimalarials. Cells were treated with MTS IC50 of each antimalarial for $48 \mathrm{~h}$. The Ki67 immunohistochemical assay is index of cell exit to G0. “-”, Ki67 negative cell population is less than 10\%; “+”, Ki67 negative cell population is more than 20\%. Cells accumulating lipid droplets were determined by Oil-Red O (ORO) assay. “-”, ORO positive cells are less than 10\% or 19\%; “+”, ORO positive cells are more than $20 \%$ and less than 50\%; “++”, ORO positive cells are more than 50\%. P21(WAF1) protein was measured by p21(WAF1) ELISA. “-”, induction of p21(WAF1) protein by antimalarial agent treatment for $24 \mathrm{~h}$ was not increased compared with control cells; “++”, induction of p21(WAF1) protein in treated cells was increased compared with control cells. Acetylated histone H4 was analyzed in MCF-7 cells exposed antimalarials for $24 \mathrm{~h}$ by Western blot. “+”, agent induced acetylated histone H4; “-”, agent did not cause induction of acetylated H4. Apoptotic response for $72 \mathrm{~h}$ treatment in MCF-7 cells was examined using cell death ELISA. *, $\mathrm{p}<0.05$, treated versus control group as evaluated using ANOVA followed by Bonferroni's t-tests. 
Table 3. Summary of Antimalarials on G1/G0 Transition, p21(WAF1), Differentiation, Hyperacetylated Histone $\mathrm{H} 4$ and Apoptosis in MCF-7 Cells

\begin{tabular}{|c|c|c|c|c|c|c|}
\hline Quinolin & No & - & - & - & - & \\
\hline $\begin{array}{c}\text { Quinolinic } \\
\text { Acid }\end{array}$ & No & - & & - & - & \\
\hline Amodiaquin & YES & + & - & - & + & - \\
\hline Chloroquine & YES & + & + & ++ & + & $*$ \\
\hline Halofantrine & YES & - & - & - & + & \\
\hline Mefloquine & No & - & - & - & & - \\
\hline Quinidine & YES & + & ++ & + & + & * \\
\hline Quinine & YES & + & + & - & + & - \\
\hline Primaquine & YES & - & + & - & + & . \\
\hline
\end{tabular}


in the number of soluble nucleosome complexes released $(\mathrm{p}<0.01)$ compared with control cells (Figure 27). However, neither quinine, a quinidine stereoisomer, nor amodiaquin, an analog of chloroquine, enhanced the apoptotic response ( $>>0.05)$ after 48 or $72 \mathrm{~h}$ of treatment compared with control cells.

When MCF-7 cells were treated with halofantrine for either 48 or $72 \mathrm{~h}$, nucleosome release displayed an increase as the drug concentration was increased from 40 to $100 \mathrm{uM}$ (Figure 27).

The enrichment of apoptotic response in MCF-7 cells treated with MTS IC50 concentrations of antimalarials for 48 and $72 \mathrm{~h}$ are summarized in Table 2. Quinidine (110uM) and chloroquine (33uM) induced apoptosis in MCF-7 cells $(\mathrm{p}<0.05)$.

\subsubsection{Role of caspase-3 in quinidine-induced apoptosis}

MCF-7 human breast cancer cells are relatively resistant to apoptosis and lack the effector caspase-3 (Prokop et al., 2000). The apoptotic response to quinidine was compared in caspase $3^{-/-} \mathrm{MCF}-7$ cells and caspase- $3^{+/+}$reconstituted MCF-7 cells. Apoptosis was evaluated on the basis of nucleosome release, a characteristic of apoptosis. Figure 28 shows that the nucleosome release (DNA-histone fragmentation) profiles of caspase $3^{-/-} \mathrm{MCF}-7$ cells as compared with caspase- $3^{+/+} \mathrm{MCF}-7$ cells after treatment with increasing concentrations of quinidine. Both cell lines were incubated with quinidine for 48 or $72 \mathrm{~h}$. Caspase $3^{-/-}$MCF-7 cells, as well as caspase- $3^{+/+}$MCF-7 cells, exhibited increased DNA-histone fragmentation in response to quindine treatment. Caspase $3^{-/-} \mathrm{MCF}-7$ cells were less sensitive to quinidine in the DNA-histone fragmentation assay, induction of DNA-histone fragmentation by quinidine did not exceed $170 \%$ compared to control cells, even in cells treated with high concentrations of quinidine for 48 or $72 \mathrm{~h}$. In contrast, caspase- $3^{+/+}$MCF-7 cells displayed high sensitivity towards quinidine-induced apoptosis, and incubation with 200 and $250 \mathrm{uM}$ quinidine led to a 2-3-fold increase in apoptotic response by $72 \mathrm{~h}$ compared with control group. The $48 \mathrm{~h}$ apoptosis response in the quinidine-treated caspase- $3^{-/-} \mathrm{MCF}-7$ cells and quinidine-treated caspase- $3^{+/+} \mathrm{MCF}-7$ 
cells was not different statistically $(\mathrm{p}>0.05)$. However, the apoptosis response to quinidine-treated caspase- $3^{+/+}$MCF-7 cells was significantly increased as compared with caspase- $3^{-/-}$MCF-7 cells $(\mathrm{p}<0.05)$ at $72 \mathrm{~h}$. The results indicated that caspase-3 reconstitution sensitized MCF-7 cells to quinidine-induced apoptosis.

\subsubsection{Role of $\mathbf{R b}$ on quinidine-induced apoptosis}

Inactivating mutations in the tumor suppressor gene, $\mathrm{pRb}$, have been found not only in $100 \%$ of retinoblastomas but also in many other adult cancers, including breast cancers (Lee et al., 1988). Rb is necessary to initiate and maintain the cell cycle exit in the differentiation pathway; pRb-mutations in cells prevent cell cycle exit and block differentiation (Maione et al., 1997). MDA-MB-468 human breast cancer cells contain mutated pRb (Munster et al., 2001). The growth of MDA-MB-468 cells treated with quinidine was inhibited over a concentration range similar to that for MCF-7 cells. MDAMB-468 cells exposed to $110 \mathrm{uM}$ quinidine are not as sensitive as MCF-7 cells in the MTS assay (Figure 29A). There was however no statistically significant difference in DNA-histone fragmentation even in MDA-MB-468 cells exposed to high concentrations of quinidine for 48 or $72 \mathrm{~h}$ (Figure 29B ). MDA-MB-468 cells were resistant to quinidine-induced apoptosis. In order to examine the hypothesis that wild-type $\mathrm{pRb}$ is required for quinidine-induced apoptosis, further studies are necessary to test whether $\mathrm{pRb}$ reconstituted MDA-MB-468 cells are more sensitive to quinidineinduced apoptosis compared to parental MDA-MB-468 cells. 


\section{Figure 28. Quinidine induces apoptotic response in caspase-3 (-/-) MCF-7 and}

YAMA (MCF-7, caspase-3 (+/+)) cells. Cells (4000 cells/well in 96-well plate) were treated with increasing concentrations of quinidine for 48 or $72 \mathrm{~h}$. The nucleosome levels were determined by photometric enzyme immunoassay using a cell death detection ELISA as described in "Materials and Methods". The release of nucleosomes into cytoplasm of each sample was indicated as the absorbance at $405 \mathrm{~nm}$. Data represent the mean of three different experiments, each performed in triplicate; bars, SER. $* \mathrm{P}<0.05$, quinidine-treated caspase-3(+/+) cells vs. quinidine-treated caspase-3(-/-) cells as evaluated using ANOVA followed by Bonferroni's t-tests. 
A. 48 h Treatment

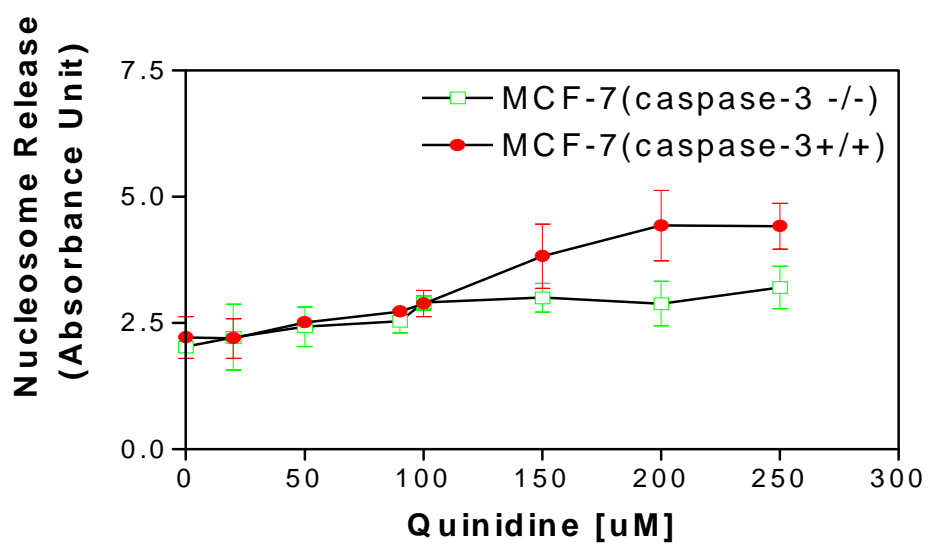

B. 72 h Treatment

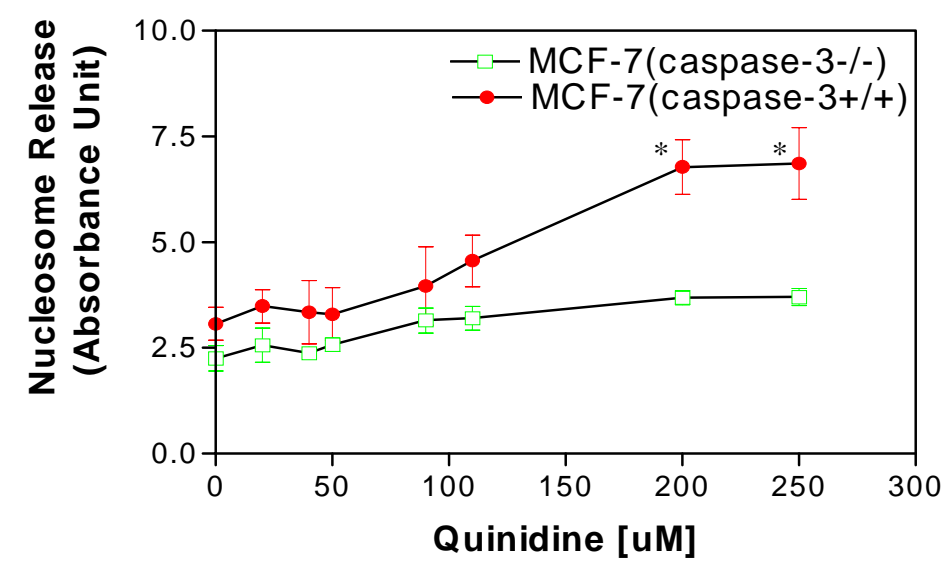




\section{Figure 29. Effects of quinidine on cell proliferation and apoptosis in MCF-7 and MDA-}

MB-468 human breast cancer cells. (A) MCF-7 and MDA-MB-468 cell viability were assessed by MTS assay. 4000 cells/well in 96 well plates were treated with increasing concentrations of quinidine for $48 \mathrm{~h}$. The percentage of living cells was calculated as percentage of control by dividing average absorbances of triplicated drug-treated wells by that of control ones. Data are presented as the mean of three independent experiments, each performed in quintuplicate; bars, SER. (B) Effect of quinidine on apoptotic response in MDA-MB-468 cells. Cells (4000 cells/well in 96-well plate) were treated with increasing concentrations of quinidine either for 48 or for $72 \mathrm{~h}$. The released nucleosome levels were determined by photometric enzyme immunoassay using cell death detection ELISA as described in "Materials and Methods". The released nucleosome levels of each sample was indicated as the absorbance at $405 \mathrm{~nm}$. Data represent the mean of three different experiments, each performed in triplicate. 
A.

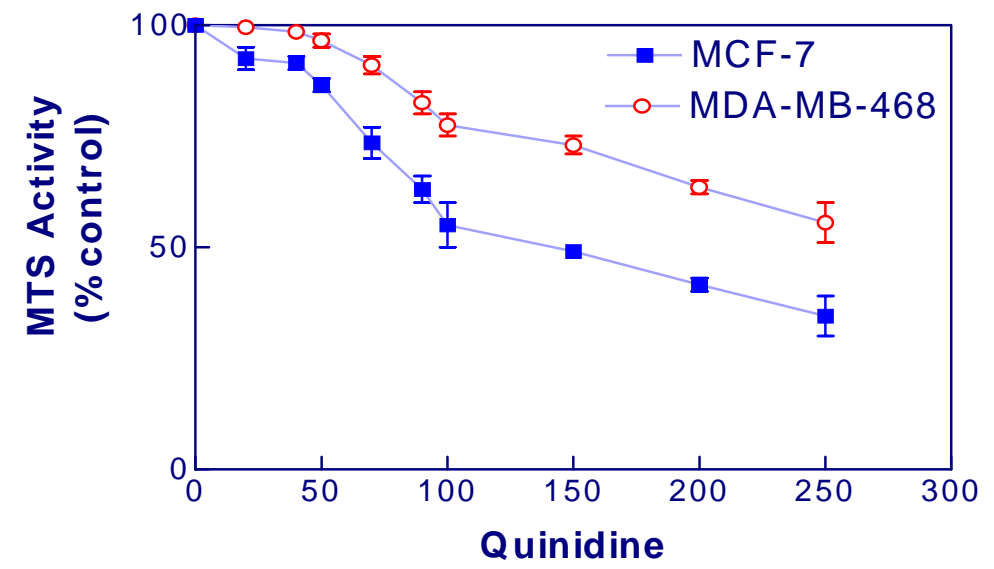

B. MDA-MB-468 cells

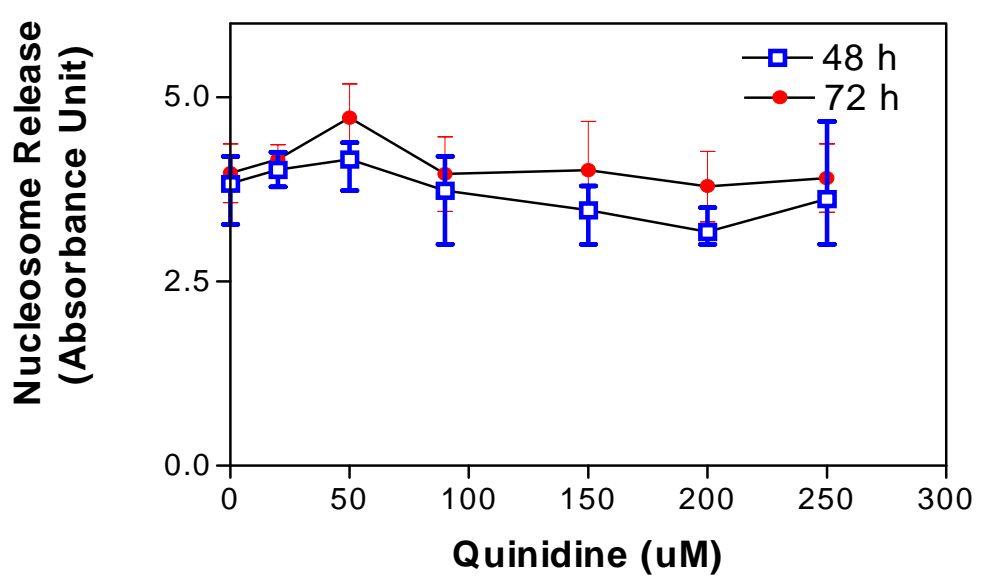




\subsection{Discussion}

The enzyme histone deacetylase (HDAC) is a new target for anticancer drug development. TSA is an irreversible inhibitor of HDAC activity in cultured mammalian cells and in fractionated cell nuclear extracts at low nanomolar concentrations (Kijima et al., 1993). TSA has been shown to arrest cells in G1 and G2 phases of the cell cycle, to induce differentiation and apoptosis in cultured cells (Yoshida et al., 1995). G1 arrest by TSA in HeLa cells was accompanied by induction of p21(WAF1) (Kim et al., 2000). p21(WAF1) plays a critical role in TSA-induced growth inhibition because HCT116 $\left(\mathrm{p} 21^{-/-}\right)$cells were resistant to TSA treatment compared with the parental line $\left(\mathrm{p} 21^{+/+}\right)(\mathrm{Kim}$ et al., 2000). TSA caused a rapid decrease in c-myc gene expression in human lymphoid cell line (Van Lint et al., 1996). Consistent with these literature reports, we observed that TSA affects cell growth, p21(WAF1), differentiation, cell cycle progression and apoptosis in MCF-7 cells. The TSA IC50 for HDAC activity in HeLa nuclear extract was $8.5 \mathrm{nM}$. The MTS IC50 of TSA (35nM) increased expression of $\mathrm{p} 21(\mathrm{WAF} 1)$ protein in MCF-7 cells. One interesting finding was that MTS IC50 of TSA did not trigger apoptosis but caused cell differentiation in MCF-7 cells. Higher concentrations of TSA (at least $100 \mathrm{nM}$ ) were required for induction of apoptosis in MCF-7 cells. These results demonstrate that cellular differentiation could be dissociated from apoptotic response in MCF-7 cells treated with TSA.

Although a variety of structurally unrelated natural inhibitors of HDAC such as butyrate, trapoxin, FR901228, and TSA have been isolated (Kijima et al., 1993 and Jung, 2001), the major limitation for natural HDAC inhibitors is that the efficacies are very limited because of its low antiproliferative activity and short half life (rapidly metabolized and excreted in vivo) in blood. On the other hand, these inhibitors such as butyrate ( a natural fatty acid derived from a high-fiber diet) are weak and non-specific inhibition of HDAC activity (Jung, 2001). Therefore, several derivatives of butyrate have been studied to improve the rapid metabolism in the body (Pouillart et al., 1991). TSA, trapoxin and 
FR901228 were reported to exhibit strong HDAC inhibition in vitro, no in vivo antitumor efficacy has been reported, presumably because of instability, low retention, or nonspecific toxicity of the compounds in the body. These limitations might be circumvented by development of antimalarials as new HDAC inhibitors, which have more favorable pharmacological properties. In this study, we summarized a series of experiments that addressed antimalarial induced changes in cell proliferation, cell cycle regulation, HDAC activity, histone acetylation and apoptosis in MCF-7 cells. These studies also advance the fundamental understanding of antitumor activity by antimalarials, and provide knowledge that is essential to developing appropriate anticancer strategies.

We demonstrated that antimalarials inhibited cell growth. Inhibition of cell growth by antimalarials was examined using the MTS assay and cell counting in MCF-7 cells. All antimalarials tested inhibited MCF-7 cell growth after $48 \mathrm{~h}$ treatment. Inhibition of cell growth by these compounds was concentration dependent. A comparison of the IC50 values for the nine tested antimalarials indicated that mefloquine and primaquine are the most potent agents in MCF-7 cells. In contrast, quinidine is the least potent MTS inhibitor in MCF-7 cells. The variety of MTS IC50 might involve difference in composition and orientation of the side-chain structure attached to quinoline rings in each compound. Such experimental observations implicate a mitochondria contribution to cell proliferation control.

Mitochondria are vital in controlling cell life by at least three general mechanisms, including (1) disruption of electron transport, oxidative phosphorylation, and adenosine triphosphate (ATP) production; (2) change of the permeability transition pore in the mitochondrial membrane and release of proteins that induce cell apoptosis; (3) alteration of mitochondria membrane potential via potassium channels. MTS assay measures the activity of mitochondrial dehydrogenase in cells alive. MCF-7 cells were exposed to MTS IC50 of each antimalarial for $2 \mathrm{~h}$ or $6 \mathrm{~h}$, we only found that primaquine-treated-cells for $6 \mathrm{~h}$ significantly inhibited the activity of dehydrogenase compared with control cells $(\mathrm{p}<0.05)$, this result is consistent with previous report that primaquine targeted succinate 
dehydrogenase in mitochondria of malarial parasites (Kokaze, et al., 2000). Cell viability measured by trypan blue assay showed that those treatments did not inhibit MCF-7 cell growth within 2 h. These results suggest that except for primaquine, antimalarial effects on mitochondrial dehydrogenase reflect cell numbers. In the future, it is necessary to test if antimalarials regulate mitochondrial pore transportation and mitochondrial membrane potential, which might help us to understand the mechanisms by which antimalarials inhibit cell growth in MCF-7 cells.

Theoretically, apoptosis could contribute to the observed antimalarial inhibition of MTS metabolism in MCF-7 cells at $48 \mathrm{~h}$. However, in time course experiments, apoptotic cell death was detected not earlier than $48 \mathrm{~h}$ after quinidine treatment, and maximal yields of apoptosis were induced as late as $120 \mathrm{~h}$ after treatment (Wang et al., 1998). Therefore, to determine whether antimalarials cause apoptosis and whether apoptosis could contribute to breast cancer cell growth inhibition, the yield of nucleosomes released was measured after $48 \mathrm{~h}$ treatment of MCF-7 cells with increasing concentrations of antimalarials. Apoptosis occurred in MCF-7 cells treated with MTS IC50 of quinidine and chloroquine $(\mathrm{p}<0.05)$. Enhanced apoposis in MCF-7 cells treated with halofantrine only occurred above $40 \mathrm{uM}$, but it's MTS IC50 (11uM) treatment did not increase the rate of apoptosis. These data indicate that induction of apoptosis by chloroquine, halofantrine and quinidine was concentration dependent and might be a contributor to cell killing (cell death). However, other tested antimalarials could not trigger apoptotic cell death pathways to inhibit cell growth.

A more intriguing mechanism of quinidine-induced cell growth inhibition was explored. This study was performed to gain insight into the molecular mechanism of quinidine-induced cell killing by the apoptotic pathway in breast cancer cell lines. Damage to mitochondria can result in release of cytochrome $\mathrm{c}$ to the cytosol. Cytochrome c causes caspase activation by forming a complex with Apaf1 and procaspase-9, leading to activation of casapse-9, which in turn activates procaspase-3, leading to DNA cleavage. In this process, Bcl-2 is thought to be involved by preventing the release of 
cytochrome c from mitochondria thereby inhibition of apoptotic pathway. We previously demonstrated that decline of Bcl-2 triggered by quinidine was accompanied by accumulation of cytosolic cytochrome c (Zhou and Strobl 2000). It has been reported that MCF-7 cells lack expression of caspase-3 mRNA and protein because of a mutation in the caspase-3 (CPP/YAMA) gene (Kurokawa et al., 1999). Abrogation of caspase-3 has been associated with acquired multidrug resistance (Kojima et al, 1998). High concentration of quinidine induced apoptosis in a caspase-3 independent fashion. We tested whether caspase-3 would enhance quinidine-induced apoptosis.

MCF-7 (caspase- $3^{-/}$) and MCF-7/YAMA (caspase- $3^{+/+}$) cells were useful for studying the specific role of caspase-3 and caspase-3-dependent signaling in response to quinidine. We characterized the apoptotic responses of the MCF-7 cells to quinidine in comparison with MCF-7/YAMA cells. As demonstrated by the cell death ELISA, caspase-3 reconstituted MCF-7/YAMA cells showed sensitization to apoptosis. Treatment with quinidine between 110 and $250 \mathrm{uM}$ for $72 \mathrm{~h}$ exerted more dramatic effects on growth inhibition and apoptosis in caspase- $3^{+/+}$MCF-7/YAMA cells than did quinidine in MCF-7 cells, suggesting caspase-3 defects are one mechanism for chemoresistance to quinidine.

HDACs regulate histone acetylation by catalyzing the removal of acetyl groups on the NH2terminal lysine residues of the core nucleosomal histones. Modulation of the acetylation status of core histones is involved in the regualtion of the transcriptional activity of certain genes. HDAC activity is associated with transcriptional repression. Aberrant recruitment of HDAC activity has been associated with the development of certain cancers (Lin, et al., 1998), because the cells are unable to undergo differentiation and lead to excess proliferation. Inhibition of HDAC activity results in the accumulation of acetylated histones $\mathrm{H} 2 \mathrm{a}, \mathrm{H} 2 \mathrm{~b}, \mathrm{H} 3$, and $\mathrm{H} 4$. The result of hyperacetylation of histones by HDAC inhibitors is believed to activate a small subset of the genes, which involve cell differentiation and apoptosis in cancer cells (Jung, 2001). The HDAC inhibitor sodium butyrate 
induces hyperacetylation of histone H4, and activates the four genes including actin, adipsin, lipoprotein, and adipocyte P2, which mainly modulate differentiation of the preadipocytes into mature adipocytes (Toscani, et al., 1990). Sodium butyrate as well as TSA enhanced p21(WAF1) transcriptional activation and apoptosis (Lee, et al., 1996; Archer, et al., 2001). Recently, the p21(WAF1) has attracted more attention, because the p21 gene appears to be rarely mutated in common human cancer cells, whereas the p53 gene is frequently mutated.

Previously we showed that quinidine induced hyperacetylation of histone H4 without inhibition of HDAC activity (Zhou et al., 2000). HDAC1 protein levels were reduced by quinidine treatment, and co-treatment with quinidine plus MG-132, a proteasome inhibitor, restored HDAC1 in MCF-7 cells within $12 \mathrm{~h}$ (Zhou et al., 2000). We hypothesize that other quinoline antimalarials might share these properties. The present study proved that the tested antimalarials do not inhibit HDAC activity in vitro. These data are consistent with previous observations that chloroquine, quinidine and quinine did not directly inhibit HDAC activity in a cell free assay (Zhou, et al., 2000). Moreover, amodiaquin, halofantrine, chloroquine, quinidine, quinine and primaquine stimulated acetylation of histone $\mathrm{H} 4$ in MCF-7 cells. These results indicate that alkylamino-substituted antimalarial ring might play a role for acetylation of histone H4. Further studies are necessary to examine if HDAC1 protein degradation is stimulated by all antimalarials that induce $\mathrm{H} 4$ acetylation in MCF-7 cells.

The manner of activation of p21(WAF1) gene expression by antimalarials might contribute to understanding the mechanisms that mediate the anti-proliferative effects of antimalarials. p21(WAF1) expression is usually controlled at the transcriptional level by both p53-dependent and p53independent mechanisms. An up-regulation of p21(WAF1) strongly correlates with cell growth inhibition, and can force cellular decision between differentiation and/or cell death. Inhibition of p21(WAF1/Cip1) expression through transfection of p21(WAF1/Cip1) antisense oligonucleotides has been shown to block growth factor-induced apoptosis of SH-SY5Y neuroblastoma cells (Guo et al., 
1995). Conversely, transfection of $\mathrm{p} 21$ (WAF1/Cip1) promotes a variety of cell lines into differentiation and /or apoptosis (Jiang et al., 1995, Pagliacci et al., 1995; Sheikh et al., 1995). These lines of evidence indicate that antiproliferative actions of chemotherapeutic agents may be mediated by up-regulation of $\mathrm{p} 21(\mathrm{WAF} 1)$. We hypothesize that $\mathrm{p} 21(\mathrm{WAF} 1)$ might play a determining role in apoptosis and /or differentiation in MCF-7 cells treated with antimalarials.

The different effects of quinidine and chloroquine in comparison with quinine and amodiaquin may be related to differences in p21(WAF1) gene expression. Amodiaquin, primaquine and quinine did not induce p21(WAF1) expression and apoptosis in MCF-7 cells, but chloroquine and quinidine both elevated p21(WAF1) protein levels and increased apoptosis compared to control cells. At the chloroquine concentration used in this study, chloroquine exerted a more dramatic effect on MCF-7 cell cycle arrest and apoptosis than did quinidine. Our data suggest that p21(WAF1) protein induction might be used to predict the ability of antimalarials to cause apoptosis.

Halofantrine (11uM) was not as effective as chloroquine in inducing p21(WAF1) expression and apoptosis, but exhibited comparable apoptotic responses at 40uM in MCF-7 cells. Halofantrine is not a quinoline antimalarial, and we concluded that halofantrine-induced apoptosis might be mediated via a different pathway. It is clear that the growth inhibitory effects of antimalarials in breast cancer cells as reflected a 50\% inhibition of MTS metabolism can be dissociated from apoptosis. Individual agents, while all are able to inhibit MTS metabolism, vary with respect to induction of p21(WAF1) and apoptosis.

The cell cycle transition into G0 is a prerequisite step for differentiation. Only amodiaquin, chloroquine, quinidine, and quinine at their MTS IC50 led to an increase in the number of cells in the G0 phase in MCF-7 cells (Ki67 assay). These data indicate that up-regulation of p21(WAF1) by chloroquine and quinidine must contribute to cell cycle arrest at G0 phase. However, amodiaquin as well as quinine-induced cells into G0 phase are independent of P21(WAF1), which might involve 
other cyclin-dependent kinase inhibitors. Using lipid droplet accumulation measured by ORO staining as a marker of mammary cell differentiation, only MTS IC50 of chloroquine, quinidine, quinine and primaquine were observed to induce differentiation in MCF-7 cells. We found that $\mathrm{p} 21$ (WAF1) is not determined factor to contribute to antimalarial-mediated differentiation. Furthermore, quinine and primaquine did not exhibit signs of cell apoptosis during the following 48 or $72 \mathrm{~h}$ treatment. Therefore, induction of differentiation by quinine and primaquine was dissociated from apoptosis, suggesting that apoptosis is not the only mechanism for inhibition of cell growth by antimalarials. The data also suggested that lipid droplet accumulation is not always a marker of cell differentiation, because there was dissociation between the ORO and Ki67 assay, which was observed in either amodiaquin or primaquine treatment. In an effort to confirm our conclusion, we need to test the milk fat protein expression, another cellular differentiation marker (Munster, et al., 2001), in MCF7 cells exposed to amodiaquin and primaquine.

In summary, our major conclusion is that quinidine and chloroquine induce growth arrest, cell cycle exit, differentiation, hyperacetylation of histone H4, p21(WAF1) and apoptosis in MCF-7 cells. Our data is the first report of induction of apoptosis in breast cancer cell lines by the antimalarial chloroquine. Quinine (a steric configuration of quinidine) as well as amodiaquin ( an analogue of chloroquin) induced cell arrest without apoptosis. We conclude that tertiary amine side chain and its configuration may be fundamental requirements for triggering apoptosis or histone hyperacetylation in MCF-7 cells.

Although quinidine and chloroquine exerted similar effects on the cell cycle regulatory protein p21(WAF1), distinct differences in the kinetics and magnitude of p21(WAF1) protein regulation were observed in response to these agents. The activity of chloroquine was significantly more potent than that of quinidine. Induction of apoptosis following treatment with halofantrine was not correlated with induction of differentiation. These data suggest that differentiation is not obligatory response for 
apoptosis in MCF-7 cells, implying that antimalarials might trigger multiple cell death pathways. Chloroquine is the most potent p21(WAF1) gene regulatory therapy agent and may be of use as a lead compound in the design of breast cancer cell apoptotic agents. 


\section{REFERENCE CITED}

Abolhoda A, Wilson AE, Ross H, Danenberg PV, Burt M, Scotto KW.(1999) Rapid activation of MDR1 gene expression in human metastatic sarcoma after in vivo exposure to doxorubicin. Clin Cancer Res. 5(11):3352-6.

Ameyar, M., Shatrov, V., Bouquet, C., Capoulade C., Cai, Z., Stancou, R., Badie, C., Haddada, H., and Chouaib. S (1999) Adenovirus-mediated transfer of wild-type p53 gene sensitizes TNF resistant MCF7 derivatives to the cytotoxic effect of this cytokine: relationship with c-myc and $\mathrm{Rb}$. Oncogene 18: 5464-5472.

A., Ip, M.M., Darcy, K., Black, J.D., Shea, W.K., Forczek, S., Yoshimura, M., and Oka, T. (1990) Primary cultures of normal rat mammary epithelial cells within a basement membrane matrix II. Functional differentiation under serum-free conditions. In Vitro. Cell Dev. Biol. 26: 803-814.

Anderson D, Bishop JB, Garner RC, Ostrosky-Wegman P, Selby PB. (1995) Cyclophosphamide:

review of its mutagenicity for an assessment of potential germ cell risks. Mutat Res. 330(1-2):115-81

Archer SY, Hodin RA.(1999) Histone acetylation and cancer. Curr Opin Genet Dev. 9(2):171-4.

Archer SY, Johnson JJ, Kim HJ, Hodin RA.(2001) p21 gene regulation during enterocyte differentiation. J Surg Res. 98(1):4-8.

Bacus, S.S., Kiguchi, K., Chin, D., King, C.R., and Huberman, E. (1990) Differentiation of cultured human breast cancer cells (AU-565 and MCF-7) associated with loss of cell surface HER-2/neu antigen. Mol. Carcinog. 3: 350-362.

Bancroft, J. D and Cook, H.C. (1984) Manual of Histological Techniques, pp.132-133. Edinburgh: Churchill Livingstone

Bargou RC, Wagener C, Bommert K, Mapara MY, Daniel PT, Arnold W, DietelM,Guski H, Feller A, Royer HD, Dorken B. (1996) Overexpression of the death-promoting gene bax-alpha which is downregulated in breast cancer restores sensitivity to different apoptotic stimuli and reduces tumor growth in SCID mice. J Clin Invest. 97(11):2651-9

Basco, L.K and Le Bras, I (1992) In vitro activity of halofantrine and its relationship to other standard antimalarial drugs against African isolates and clones of Plasmodium falciparum. Am. J. Trop. Med. Hyg. 47:521-527. 
Baselga J, Tripathy D, Mendelsohn J, Baughman S, Benz CC, Dantis L, Sklarin NT, Seidman AD, Hudis CA, Moore J, Rosen PP, Twaddell T, Henderson IC, Norton L.(1996) Phase II study of weekly intravenous recombinant humanized anti-p185HER2 monoclonal antibody in patients with HER2/neuoverexpressing metastatic breast cancer. J Clin Oncol. 14(3):737-44

Baselga J, Norton L, Albanell J, Kim YM, Mendelsohn J.(1998) Recombinant humanized anti-HER2 antibody (Herceptin) enhances the antitumor activity of paclitaxel and doxorubicin against HER2/neu overexpressing human breast cancer xenografts. Cancer Res. 58(13):2825-31

Beato M and Sanchez-Pacheco A (1996) Interaction of steroid hormone receptors with the transcription initiation complex. Endocr Rev 17:587-609

Brehm A, Miska EA, McCance DJ, Reid JL, Bannister AJ, Kouzarides T. (1998) Retinoblastoma protein recruits histone deacetylase to repress transcription. Nature. 391(6667):597-601.

Berridge MV, Tan AS.(1993) Characterization of the cellular reduction of 3-(4,5-dimethylthiazol-2yl)-2,5-diphenyltetrazolium bromide (MTT): subcellular localization, substrate dependence, and involvement of mitochondrial electron transport in MTT reduction. Arch Biochem Biophys. 303(2):474-82.

Boelaert, JR, Piette, J and Sperber K (2001) The potential place of chloroquine in the treatment of HIV-1-infected patients. J. Clin Viol 20(3):137-140.

Brenner AJ, Aldaz CM.(1995) Chromosome 9p allelic loss and p16/CDKN2 in breast cancer and evidence of p16 inactivation in immortal breast epithelial cells. Cancer Res. 55(13):2892-5

Brodie A, Lu Q, Liu Y, Long B, Wang JP, Yue W.(1998) Preclinical studies using the intratumoral aromatase model for postmenopausal breast cancer. Oncology (Huntingt) 12(3 Suppl 5):36-40

Brown JM, Wouters BG. (1999) Apoptosis, p53, and tumor cell sensitivity to anticancer agents. Cancer Res. 59(7):1391-9

Buckley MF, Sweeney KJ, Hamilton JA, Sini RL, Manning DL, Nicholson RI, deFazio A, Watts CK, Musgrove EA, Sutherland RL.(1993) Expression and amplification of cyclin genes in human breast cancer. Oncogene. 8(8):2127-33.

Bukholm IK, Nesland JM, Karesen R, Jacobsen U, Borresen AL.(1997) Relationship between abnormal p53 protein and failure to express p21 protein in human breast carcinomas. J Pathol. 181(2):140-5.

Bunone G, Briand PA, Miksicek RJ, Picard D.(1996) Activation of the unliganded estrogen receptor by EGF involves the MAP kinase pathway and direct phosphorylation. EMBO J. 15(9):2174-83

Carrol,F.I, Berrang, B and Linn, CP (1978) Resolution of antimalarial agents via complex formation with $\alpha$-(2,4,5,7-tetranitro-9-fluorenylideneaminooxy;) propionic acid.

J. Med Chem 21:581-586. 
Chang, B.D., Wuan, Y., Broude, E.V., Zhu, H., Schott, B., Fang, J., and Roninson, I.B. (1999) Role of p53 and p21waf1/cip1 in senescence-like terminal proliferation arrest induced in human tumor cells by chemotherapeutic drugs. Oncogene 18: 4808-4018.

Chen H, Lin RJ, Xie W, Wilpitz D, Evans RM. (1999) Regulation of hormone-induced histone hyperacetylation and gene activation via acetylation of an acetylase. Cell. 98(5):675-86.

Chen YQ, Cipriano SC, Arenkiel JM, Miller FR.(1995) Tumor suppression by p21WAF1. Cancer Res. 55(20):4536-9.

Chin KV, Tanaka S, Darlington G, Pastan I, Gottesman MM.(1990) Heat shock and arsenite increase expression of the multidrug resistance (MDR1) gene in human renal carcinoma cell. J Biol Chem. 265(1):221-6.

Conroy SE, Latchman DS. (1996) Do heat shock proteins have a role in breast cancer?

Br J Cancer. 74(5):717-21.

Ciocca DR, Fuqua SA, Lock-Lim S, Toft DO, Welch WJ, McGuire WL.(1992) Response of human breast cancer cells to heat shock and chemotherapeutic drugs.

Cancer Res. 52(13):3648-54.

Cornwell MM, Smith DE. (1993) SP1 activates the MDR1 promoter through one of two distinct G-rich regions that modulate promoter activity. J Biol Chem. 268(26):19505-11.

Davidson,M.W Griggs, B.G., Boykin, D.W and Wilson, WD (1997) Molecular structure effects involved in the interaction of quinolinemethanolamines with DNA. Implications of antimalarial action. J. Med.Chem 20:1117-1122

Davie, J.R., and Chadee, D.N. (1998) Regulation and regulatory parameters of histone modifications. J. Cellular Biochem. Suppl. 30/31: 203-213.

Douglas, A.M., Grant, S.L., Goss, G.A., Clouston, D.R., Sutherland, R.L., and Begley, C.G. (1998) Oncostatin $\mathrm{M}$ induces the differentiation of breast cancer cells.

Int. J. Cancer 75: 64-73.

Doglioni C, Pelosio P, Laurino L, Macri E, Meggiolaro E, Favretti F, Barbareschi M.(1996) p21/WAF1/CIP1 expression in normal mucosa and in adenomas and adenocarcinomas of the colon: its relationship with differentiation. J Pathol. 179(3):248-53.

Dole M, Nunez G, Merchant AK, Maybaum J, Rode CK, Bloch CA, Castl, VP.(1994)

Bcl-2 inhibits chemotherapy-induced apoptosis in neuroblastoma. Cancer Res.54(12):3253-9.

Drewinko B, Patchen M, Yang LY, Barlogie B.(1981) Differential killing efficacy of twenty antitumor drugs on proliferating and nonproliferating human tumor cells.

Cancer Res. 41(6):2328-33. 
Durrin LK, Mann RK, Kayne PS, Grunstein M.(1991) Yeast histone H4 N-terminal sequence is required for promoter activation in vivo. Cell. 65(6):1023-31.

Early Breast cancer Trialists' Collaborative Group (1995) Effects of radiotherapy and surgery in early breast cancer. N. Engl J. Med 333:1444-1455

El-Deiry WS, Tokino T, Waldman T, Oliner JD, Velculescu VE, Burrell M, Hill DE, Healy E, Rees JL, Hamilton SR, et al.(1995) Topological control of p21WAF1/CIP1 expression in normal and neoplastic tissues. Cancer Res. 55(13):2910-9.

Elledge RM, Green S, Ciocca D, Pugh R, Allred DC, Clark GM, Hill J, Ravdin P, O'Sullivan J, Martino S, Osborne CK (1998) HER-2 expression and response to tamoxifen in estrogen receptorpositive breast cancer: a Southwest Oncology Group Study. Clin Cancer Res. 4(1):7-12

Evers, B.M., Ko, T.C., Li, J., and Thompson, E.A. (1996) Cell cycle protein suppression and p21 induction in differentiating Caco-2 cells. Am. J. Physiol. 271: G722-G727.

Feyerabend T, Steeves R, Wiedemann GJ, Weiss C, Wagner T, Richter E, Robins HI.(1996) Local hyperthermia, radiation, and chemotherapy in locally advanced malignancies. Oncology. 53(3):214-20.

Finnin, M.S., Donigian, J.R., Cohen, A., Richon, V.M., Rifkind, R.A., Marks, P.A., Breslow, R., and Pavletich N.P. (1999) Structure of a histone deacetylase homologue bound to the TSA and SAHA inhibitors. Nature 401: 188-193.

Fisher B, Redmond C, Legault-Poisson S, Dimitrov NV, Brown AM, Wickerham DL, Wolmark N, Margolese RG, Bowman D, Glass AG, et al.(1990) Postoperative chemotherapy and tamoxifen compared with tamoxifen alone in the treatment of positive-node breast cancer patients aged 50 years and older with tumors responsive to tamoxifen: results from the National Surgical Adjuvant Breast and Bowel Project B-16.

J Clin Oncol. 8(6):1005-18.

Fisher DE.(1994) Apoptosis in cancer therapy: crossing the threshold. Cell. 78(4):539-42.

Freemerman, A.J., Vrana, J.A., Tombes, R.M., Jiang, H., Chellappan, S.P., Fisher, P.B., and Grant, S. (1997) Effects of antisense p21 (WAF1/CIP1/MDA6) expression on the induction of differentiation and drug-mediated apoptosis in human myeloid leukemia cells (HL-60). Leukemia 11: 504-513.

Furumai R, Komatsu Y, Nishino N, Khochbin S, Yoshida M, Horinouchi S.(2001) Potent histone deacetylase inhibitors built from trichostatin A and cyclic tetrapeptide antibiotics including trapoxin. Proc Natl Acad Sci U S A. 98(1):87-92.

Fuqua, S.A., Schiff, R., Parra, I., Friedrichs, W.E., Su, J.L., McKee, D.D., Slentz-Kesler, K., Moore, L.B., Willson, T.M., and Moore, J.T. (1999) Expression of wild-type estrogen receptor beta and variant isoforms in human breast cancer. Cancer Res. 59: 5425-5428. 
Futamura, M., Monden, Y., Okabe, T., Fujita-Yoshigaki, J., Yokoyama, S., and Nishimura, S. (1995) Trichostatin A inhibits both ras-induced neurite outgrowth of PC12 cells and morphological transformation of NIH3T3 cells. Oncogene 10: 1119-1123.

Galinski, MR and Barnwell JW (1996) Plasmodium vivax merozoites, invasion of reticulocytes and considerations for malaria vaccine development. Parasitol. Today 12:20-29

Katzenellenbogen BS, Katzenellenbogen JA.(2000) Estrogen receptor transcription and transactivation: Estrogen receptor alpha and estrogen receptor beta: regulation by selective estrogen receptor modulators and importance in breast cancer. Breast Cancer Res. 335-44

Kornberg RD (1974) Chromatin structure: repeating unit of histones and DNA Science 184:868-71

Germann UA, Pastan I, Gottesman MM.(1993) P-glycoproteins: mediators of multidrug resistance. Semin Cell Biol. 4(1):63-76.

Giani, C., Casalini, P., Pupa, S.M., De Vecchi, R., Ardini, E., Colnaghi, M.I., Giordano, A., and Menard, S. (1998) Increased expression of c-erbB-2 in hormone-dependent breast cancer cells inhibits cell growth and induces differentiation. Oncogen 17(4):425-32

Goldsmith ME, Madden MJ, Morrow CS, Cowan KH. (1993) A Y-box consensus sequence is required for basal expression of the human multidrug resistance (mdr1) gene.

J Biol Chem. 268(8):5856-60.

Graham KA, Buick RN.(1988) Sodium butyrate induces differentiation in breast cancer cell lines expressing the estrogen receptor. J Cell Physiol. 136(1):63-71.

Green DR, Reed JC(1998) Mitochondria and apoptosis. Science. 281(5381):1309-12.

Greenlee, R.T., Murray, T., Bolden, S., and Wingo, P.A (2000) Cancer Statistics, 2000, CA Cancer J. Clin, 50, 7-33

Greenspan, P., Mayer, E.P., and Fowler, S.D. (1985) Nile red: A selective fluorescent stain for intracellular lipids. J. Cell. Biol. 100: 965-973.

Gregory MA, Hann SR.(2000) c-Myc proteolysis by the ubiquitin-proteasome pathway: stabilization of c-Myc in Burkitt's lymphoma cells. Mol Cell Biol. 20(7):2423-35.

Grozinger CM, Hassig CA, Schreiber SL. (1999) Three proteins define a class of human histone deacetylases related to yeast Hda1p. Proc Natl Acad Sci U S A. 96(9):4868-73.

Grunstein, M 1997 Histone acetylation in chromatin structure and transcription Nature 389:349-352

Gorospe M, Shack S, Guyton KZ, Samid D, Holbrook NJ.(1996) Up-regulation and functional role of p21Waf1/Cip1 during growth arrest of human breast carcinoma MCF-7 cells by phenylacetate. Cell Growth Differ. 7(12):1609-15. 
Gottesman MM, Pastan I.(1988) The multidrug transporter, a double-edged sword.

J Biol Chem. 263(25):12163-6.

Grozinger CM, Hassig CA, Schreiber SL. (1999) Three proteins define a class of human histone deacetylases related to yeast Hda1p. Proc Natl Acad Sci U S A. 96(9):4868-73.

Guo K, Wang J, Andres V, Smith RC, Walsh K.(1995) MyoD-induced expression of p21 inhibits cyclin-dependent kinase activity upon myocyte terminal differentiation.

Mol Cell Biol. 15(7):3823-9.

Hagihara N, Walbridge S, Olson AW, Oldfield EH, Youle RJ.(2000) Vascular protection by chloroquine during brain tumor therapy with Tf-CRM107. Cancer Res. 60(2):230-4.

Halevy O, Novitch BG, Spicer DB, Skapek SX, Rhee J, Hannon GJ, Beach D,Lassar AB. (1995) Correlation of terminal cell cycle arrest of skeletal muscle with induction of p21 by MyoD. Science. 267(5200):1018-21.

Halm, H. Nakanishi, M., Kanedo, Y., Matsushime, H., and Ikeda, K. (1999) Direct interaction of p21 cyclin-dependent kinase inhibitor with the retinoblastoma tumor suppressor protein. Biochem. Biophys. Res. Comm. 263: 35-40.

Harvey HA(1998) Emerging role of aromatase inhibitors in the treatment of breast cancer. Oncology (Huntingt)12(3 Suppl 5):32-5

Hawking F, Worms MJ, Gammage K. (1968) 24- and 48-hour cycles of malaria parasites in the blood; their purpose, production and control. Trans R Soc Trop Med Hyg. 62(6):731-65

Hemminki K.(1985) Binding of metabolites of cyclophosphamide to DNA in a rat liver microsomal system and in vivo in mice. Cancer Res. 45(9):4237-43

Hendzel, M.J., Delcuve, G.P., and Davie, J.R. (1991) Histone deacetylase is a component of the internal nuclear matrix. J. Biol. Chem. 266: 21936-21942

Hortobagyi,GN(2000) Developments in chemotherapy of breast cancer. Cancer 88:3073-9

Houstone SJ Richards MA, Bentley AE Smith P and Rubens RD (1993) The influence of adjuvant chemotherapy on outcome after relapse for patients with breast cancer. Eur J Cancer 29A:1513-18

Houston SJ, Plunkett TA, Barnes DM, Smith P, Rubens RD, Miles DW.(1999) Overexpression of cerbB2 is an independent marker of resistance to endocrine therapy in advanced breast cancer. $\mathrm{Br} \mathrm{J}$ Cancer. 79(7-8):1220-6

Hu Z, Jin S, Scotto KW.(2000) Transcriptional activation of the MDR1 gene by UV irradiation. Role of NF-Y and Sp1. J Biol Chem. 275(4):2979-85 
Hughes CS, Shen JW, Subjeck JR.(1989) Resistance to etoposide induced by three glucose-regulated stresses in Chinese hamster ovary cells. Cancer Res. 49(16):4452-4.

Hunter T, Pines J.(1994) Cyclins and cancer. II: Cyclin D and CDK inhibitors come of age. Cell. 79(4):573-82

Huot J, Lambert H, Lavoie JN, Guimond A, Houle F, Landry J. (1995) Characterization of 45-kDa/54kDa HSP27 kinase, a stress-sensitive kinase which may activate the phosphorylation-dependent protective function of mammalian 27-kDa heat-shock protein HSP27. Eur J Biochem. 227(1-2):41627.

Hurd C and Moudgil VK (1998) Steroid hormone receptor families. In Conn M(ed): “ Handbook of Physiology, Vol 1: Cellular Endocrinology. Oxford University Press, p 383-411)

Imai S, Armstrong CM, Kaeberlein M, Guarente L. (2000) Transcriptional silencing and longevity protein Sir2 is an NAD-dependent histone deacetylase. Nature 403(6771):795-800.

Ince, T.A., and K.W. Scotto (1997) Transcriptional regulation of multidrug resistanct genes, p.17511764. Int J. R.Bertino(ed), Encyclopedia of cancer, vol.3, Academic press, San Diego, Calif.

Itazaki, H., Nagashima, K., Sugita, K., Yoshida, H., Kawamura, Y., Yasuda, Y., Matsumoto, K., Ishii, K., Uotani, N., Nakai, H., Terui, A., Yoshimatsu, S., Ikenishi, Y., and Nakagawa, Y. (1990) Isolation and structural elucidation of new cyclotetrapeptides, trapoxins $\mathrm{A}$ and $\mathrm{B}$, having detransformation activities as antitumor agens. J. Antibiot. (Tokyo) 43: 1524-1532.

Jaattela M, Wissing D, Kokholm K, Kallunki T, Egeblad M. (1998) Hsp70 exerts its anti-apoptotic function downstream of caspase-3-like proteases. EMBO J. 17(21):6124-34.

Janson W, Brandner G, Siegel J.(1997) Butyrate modulates DNA-damage-induced p53 response by induction of p53-independent differentiation and apoptosis. Oncogene. 15(12):1395-406.

Jeppesen P, Turner BM. (1993) The inactive X chromosome in female mammals is distinguished by a lack of histone H4 acetylation, a cytogenetic marker for gene expression. Cell. 74(2):281-9.

Jiang H, Lin J, Su ZZ, Herlyn M, Kerbel RS, Weissman BE, Welch DR, Fisher PB. (1995) The melanoma differentiation-associated gene mda-6, which encodes the cyclin-dependent kinase inhibitor p21, is differentially expressed during growth, differentiation and progression in human melanoma cells. Oncogene. 10(9):1855-64.

Jin S, Scotto KW.(1998) Transcriptional regulation of the MDR1 gene by histone acetyltransferase and deacetylase is mediated by NF-Y. Mol Cell Biol. 18(7):4377-84.

Jing, Y., Zhang, J., Waxman, S., and Mira-y-Lopez, R. (1996) Upregulation of cytokeratins 8 and 18 in human breast cancer T47D cells is retinoid-specific and retinoic acid receptor-dependent. Differentiation 60: 109-117. 
Jones, J.L., Royall, J.E., Critchley, D.R., and Walker, R.A. (1997) Modulation of myoepithelialassociated alpha6beta4integrin in a breast cancer cell line alters invasive potential. Exp. Cell Res. 235: 325-333.

Jung M. (2001) Inhibitors of histone deacetylase as new anticancer agents. Curr Med Chem. 8(12):1505-11.

Kajima, M.M., Yoshida, K., Sugita, K., Horinouchi S., and Beppu T. (1993) Trapoxin, an antitumor cyclic tetrapeptide is an irreversible inhibitor of mammalian histone deacetylase. J. Biol. Chem. 268: 22429-22435.

Kao HY, Downes M, Ordentlich P, Evans RM. (2000) Isolation of a novel histone deacetylase reveals that class I and class II deacetylases promote SMRT-mediated repression. Genes Dev. 14(1):55-66.

Kasid A, Lippman ME, Papageorge AG, Lowy DR, Gelmann EP. (1985) Transfection of v-rasH DNA into MCF-7 human breast cancer cells bypasses dependence on estrogen for tumorigenicity. Science. 228(4700):725-8

Katzenellenbogen BS, Katzenellenbogen JA.(2000) Estrogen receptor transcription and transactivation: Estrogen receptor alpha and estrogen receptor beta: regulation by selective estrogen receptor modulators and importance in breast cancer. Breast Cancer Res. 335-44

Keil O, Bojar H, Prisack HB, Dall P. (2001) Novel lipophilic chloroquine analogues for a highly efficient gene transfer into gynecological tumors. Bioorg Med Chem Lett. 11(19):2611-3.

Kijima M, Yoshida M, Sugita K, Horinouchi S, Beppu T. (1993) Trapoxin, an antitumor cyclic tetrapeptide, is an irreversible inhibitor of mammalian histone deacetylase. $J$ Biol Chem. 268(30):22429-35.

Kim, Y.B., Lee, K.H., Sugita,K., Yoshida, M., and Horinouchi, S. (1999) Oxamflatin is a novel antitumor compound that inhibits mammalian histone deacetylase. Oncogene 18: 2461-2470.

Kim YB, Ki SW, Yoshida M, Horinouchi S. (2000) Mechanism of cell cycle arrest caused by histone deacetylase inhibitors in human carcinoma cells. J Antibiot (Tokyo). 53(10):1191-200.

Kisselev AF, Akopian TN, Woo KM, Goldberg AL.(1999) The sizes of peptides generated from protein by mammalian 26 and $20 \mathrm{~S}$ proteasomes. Implications for understanding the degradative mechanism and antigen presentation. J Biol Chem. 274(6):3363-71.

Klimatcheva, E., and Wonderlin, W.F. (1999) An ATP-sensitive K+ current that regulates progression through early G1 phase of the cell cycle in MCF-7 human breast cancer cells. J. Membr. Biol. 171: 35 46. 
Kojima, Hiromi Kazuya Endo, Hiroshi Moriyama, Yasuhiro Tanaka, Emad S. Alnemri,

Christopher A. Slapak, Beverly Teicher, Donald Kufe, and Rakesh Datta (1998) Abrogation of Mitochondrial Cytochrome c Release and Caspase-3 Activation in Acquired Multidrug Resistance. $J$. Biol. Chem. 273: 16647-16650.

Kornberg RD (1974) Chromatin structure: repeating unit of histones and DNA Science 184:868-71

Kosugi H, Towatari M, Hatano S, Kitamura K, Kiyoi H, Kinoshita T, Tanimoto M, Murate T, Kawashima K, Saito H, Naoe T.(1999) Histone deacetylase inhibitors are the potent inducer/enhancer of differentiation in acute myeloid leukemia: a new approach to anti-leukemia therapy. Leukemia. 13(9):1316-24.

Kurokawa H, Nishio K, Fukumoto H, Tomonari A, Suzuki T, Saijo N. (1999) Alteration of caspase-3 (CPP32/Yama/apopain) in wild-type MCF-7, breast cancer cells.

Oncol Rep. 6(1):33-7.

Lagneaux L, Delforge A, Carlier S, Massy M, Bernier M, Bron D.(2001) Early induction of apoptosis in B-chronic lymphocytic leukaemia cells by hydroxychloroquine: activation of caspase-3 and no protection by survival factors. Br J Haematol. 112(2):344-52.

Levine, A.J. (1997) p53, the cellular gatekeeper for growth and division. Cell 88: 323-331

Lavoie JN, Lambert H, Hickey E, Weber LA, Landry J.(1995) Modulation of cellular thermoresistance and actin filament stability accompanies phosphorylation-induced changes in the oligomeric structure of heat shock protein 27. Mol Cell Biol. 15(1):505-16.

Lee E, Furukubo T, Miyabe T, Yamauchi A, Kariya K.(1996) Involvement of histone hyperacetylation in triggering DNA fragmentation of rat thymocytes undergoing apoptosis. FEBS Lett. 395(2-3):183-7.

Lee EY, To H, Shew JY, Bookstein R, Scully P, Lee WH.(1988) Inactivation of the retinoblastoma susceptibility gene in human breast cancers. Science. 241(4862):218-21.

Lin RJ, Nagy L, Inoue S, Shao W, Miller WH Jr, Evans RM.(1998) Role of the histone deacetylase complex in acute promyelocytic leukaemia. Nature. 391(6669):811-4.

Lippman, M.E., Papageorge, A.G., Lowy, D.R., and Gelmann, E.P. (1985) Transfection of v-rasH DNA into MCF-7 human breast cancer cells bypasses dependence on estrogen for tumorigenicity. Science 228: 725-728.

Liu X, Zou H, Widlak P, Garrard W, Wang X. (1999) Activation of the apoptotic endonuclease DFF40 (caspase-activated DNase or nuclease). Oligomerization and direct interaction with histone H1. $J$ Biol Chem. 274(20):13836-40.

Lotem J, Sachs L.(1993) Regulation by bcl-2, c-myc, and p53 of susceptibility to induction of apoptosis by heat shock and cancer chemotherapy compounds in differentiation competent and defective myeloid leukemic cells. Cell Growth Differ. 4(1):41-7. 
Mehta, R.R., Bratescu, L., Graves, J.M., Green, A., and Mehta, R.G. (2000) Differentiation of human breast carcinoma cells by a novel vitamin D analog: 1alpha-hydroxyvitamin D5. Int. J. Oncol. 16: 6573.

Magnaghi-Jaulin L, Groisman R, Naguibneva I, Robin P, Lorain S, Le Villain JP, Troalen F, Trouche D, Harel-Bellan A. (1998) Retinoblastoma protein represses transcription by recruiting a histone deacetylase. Nature. 391(6667):601-5.

Maione R, Amati P.(1997) Interdependence between muscle differentiation and cell-cycle control. Biochim Biophys Acta. 1332(1):M19-30.

Mairesse N, Horman S, Mosselmans R, Galand P.(1996) Antisense inhibition of the $27 \mathrm{kDa}$ heat shock protein production affects growth rate and cytoskeletal organization in MCF-7 cells. Cell Biol Int. 20(3):205-12.

Marks PA, Richon VM, Rifkind RA.(2000) Histone deacetylase inhibitors: inducers of differentiation or apoptosis of transformed cells. J Natl Cancer Inst. 92(15):1210-6

Matsumura, I., Ishikawa, J., Nakajima, K., Oritani, K., Tomiyama, Y., Miyagawa, J.-I., Kato, T., Miyazaki, H., Matsuzawa, Y., and Kanakura, Y. (1997) Thrombopoietin-induced differentiation of a human megakaryoblastic leukemia cell line, CMK, involves transcriptional activation of p21/WAF1/Cip1 by STAT5. Mol. Cell. Biol.17: 2933-2943.

Medina, V., Edmonds, B., Young, G.P., James, R., Appleton, S., and Zalewski, P.D (1997) Induction of caspase-3 protease activity and apoptosis by butyrate and trichostatin A (Inhibitors of histone deacetylase): dependence on protein synthesis and synergy with a mitochondrial/cytochrome cdependent pathway. Cancer Research 57: 3697-3707.

Michieli P, Chedid M, Lin D, Pierce JH, Mercer WE, Givol D.(1994) Induction of WAF1/CIP1 by a p53-independent pathway. Cancer Res 54(13):3391-5.

Mickley LA, Bates SE, Richert ND, Currier S, Tanaka S, Foss F, Rosen N, Fojo AT. (1989) Modulation of the expression of a multidrug resistance gene (mdr-1/P-glycoprotein) by differentiating agents. J Biol Chem. 264(30):18031-40.

Missero, C., Di Cunto, F., Kiyokawa, H., Koff, A., and Dotto, G.P. (1996) The absence of p21cip1/WAF1 alters keratinocyte growth and differentiation and promotes ras-tumor progression. Genes \& Devel. 10: 3065-3075.

Molina MA, Codony-Servat J, Albanell J, Rojo F, Arribas J, Baselga J.(2001) Trastuzumab (herceptin), a humanized anti-Her2 receptor monoclonal antibody inhibits basal and activated Her2 ectodomain cleavage in breast cancer cells. Cancer Res. 61(12):4744-9 
Montagnoli A, Fiore F, Eytan E, Carrano AC, Draetta GF, Hershko A, Pagano M.(1999)

Ubiquitination of p27 is regulated by Cdk-dependent phosphorylation and trimeric complex formation. Genes Dev. 13(9):1181-9

Morrow M, Hager C, Berger D, Djordjevic B. (1989) Chloroquine as a hyperthermia potentiator. $J$ Surg Res. 46(6):637-9

Moscow JA.(1998) Methotrexate transport and resistance. Leuk Lymphoma. 30(3-4):215-2

Munster PN, Srethapakdi M, Moasser MM, Rosen N.(2001)Inhibition of heat shock protein 90 function by ansamycins causes the morphological and functional differentiation of breast cancer cells. Cancer Res. 61(7):2945-52

Nagasawa H, Keng P, Maki C, Yu Y, Little JB.(1998) Absence of a radiation-induced first-cycle G1-S arrest in p53+ human tumor cells synchronized by mitotic selection.

Cancer Res. 58(9):2036-41.

Nakajima, H., Kim, Y.B., Torano, H., Yoshida, M., and Horinouchi, S. (1998) FR901228, a potent antitumor antibiotic, is a novel histone deacetylase inhibitor.

Exp. Cell Research 241: 126-133.

Nieves-Neira, W., and Pommier, Y. (1999) Apoptotic response to camptothecin and 7hydroxystaurosporine (UCN-01) in the 8 human breast cancer cell lines of the NCI anticancer drug screen: multifactorial relationships with topoisomerase I, protein kinase C, Bcl-2, p53, MDM2 and caspase pathways. Int. J. Cancer 82: 396-404.

Nervi C, Borello U, Fazi F, Buffa V, Pelicci PG, Cossu G.(2001) Inhibition of histone deacetylase activity by trichostatin $\mathrm{A}$ modulates gene expression during mouse embryogenesis without apparent toxicity. Cancer Res. 61(4):1247-9.

Oesterreich S, Weng CN, Qiu M, Hilsenbeck SG, Osborne CK, Fuqua SA.(1993) The small heat shock protein hsp27 is correlated with growth and drug resistance in human breast cancer cell lines. Cancer Res. 53(19):4443-8.

Ogryzko VV, Hirai TH, Russanova VR, Barbie DA, Howard BH.(1996) Human fibroblast commitment to a senescence-like state in response to histone deacetylase inhibitors is cell cycle dependent. Mol Cell Biol. 16(9):5210-8.

Osborne CK, Kitten L, Arteaga CL.(1989) Antagonism of chemotherapy-induced cytotoxicity for human breast cancer cells by antiestrogens. J Clin Oncol. 7(6):710-7.

Pardee, A.B (1974) A restriction point for control of normal animal cell proliferation. Proc Natl Acad Sci U S A. 71(4):1286-90

Ortiz A, Gonzalez-Parra E, Alvarez-Costa G, Egido J.(1992) Bladder cancer after cyclophosphamide therapy for lupus nephritis. Nephron. 60(3):378-9 
Pagliacci MC, Smacchia M, Migliorati G, Grignani F, Riccardi C, Nicoletti I.(1995) Growth-inhibitory effects of the natural phyto-oestrogen genistein in MCF-7 human breast cancer cells. Eur J Cancer. 30A(11):1675-82.

Parker, S.B., Eichele, G., Zhang, P., Rawls, A., Sands, A.T., Bradley, A., Olson, E.N., Harper, J.W., and Elledge, S.T. (1995) p53-independent expression of p21Cip1 in muscle and other terminally differentiating cells. Science 267: 1024-1027.

Perry RR, Kang Y, Greaves B.(1995) Effects of tamoxifen on growth and apoptosis of estrogendependent and -independent human breast cancer cells. Ann Surg Oncol. 2(3):238-45

Petrij F, Giles RH, Dauwerse HG, Saris JJ, Hennekam RC, Masuno M, Tommerup N, van Ommen GJ, Goodman RH, and Peters DJ. (1995) Rubinstein-Taybi syndrome caused by mutations in the transcriptional co-activator CBP. Nature. 376(6538):348-51

Phillips RS (2001) Current status of malaria and potential for control. Cli Microbiol Rev 14(1):208-26

Polyak K, Xia Y, Zweier JL, Kinzler KW, Vogelstein B.(1997) A model for p53-induced apoptosis. Nature. 389:300-5.

Prokop A, Wieder T, Sturm I, Essmann F, Seeger K, Wuchter C, Ludwig WD, Henze G, Dorken B, Daniel PT.(2000) Relapse in childhood acute lymphoblastic leukemia is associated with a decrease of the Bax/Bcl-2 ratio and loss of spontaneous caspase-3 processing in vivo. Leukemia. 14(9):1606-13.

Pouillart P, Cerutti I, Ronco G, Villa P, Chany C. (1991) Butyric monosaccharide ester-induced cell differentiation and anti-tumor activity in mice. Importance of their prolonged biological effect for clinical applications in cancer therapy. Int J Cancer. 49(1):89-95.

Reed JC.(1997) Cytochrome c: can't live with it--can't live without it. Cell. 91(5):559-62.

Regnard CFB and Tempest S (1998) A guide to symptom relief in advanced disease Hochland and Hochland Ltd,

Reiner U. Jänicke, Michael L. Sprengart, Mas R. Wati, and Alan G. Porter (1998) Caspase-3 Is Required for DNA Fragmentation and Morphological Changes Associated with Apoptosis . J. Biol. Chem. 273: 9357-9360.

Richon, V.M., Emiliani, S., Verdin, E., Webb, Y., Breslow, R., Rifkind, R.A., and Marks, P.A. (1998) A class of hybrid polar inducers of transformed cell differentiation inhibits histone deacetylases. Proc. Natl. Acad. Sci. USA 95: 3003-3007.

Riese DJ 2nd, Stern DF. (1998) Specificity within the EGF family/ErbB receptor family signaling network. Bioessays.20(1):41-8 
Roninson IB, Chin JE, Choi KG, Gros P, Housman DE, Fojo A, Shen DW, Gottesman MM, Pastan I (1986) Isolation of human mdr DNA sequences amplified in multidrug-resistant KB carcinoma cells. Proc Natl Acad Sci U S A. 83(12):4538-42.

Saito, A., Yamashita, T., Mariko, Y., Nosaka, Y., Tsuchiya, K., Ando, T., Suzuki, T., Tsuruo, T., and Nakanishi, O. (1999) A synthetic inhibitor of histone deacetylase, MS-27-275, with marked in vivo antitumor activity against human tumors. Proc. Natl. Acad. Sci. USA 96: 4592-4597

Sakorafas GH, Tsiotou AG, Pavlakis G.(2000) Follow-up after primary treatment for breast cancer. Acta Oncol. 39(8):935-40

Sambucetti LC, Fischer DD, Zabludoff S, Kwon PO, Chamberlin H, Trogani N, Xu H, Cohen D. (1999) Histone deacetylase inhibition selectively alters the activity and expression of cell cycle proteins leading to specific chromatin acetylation and antiproliferative effects. $J$ Biol Chem. 274(49):34940-7.

Saunders, N., Dicker, A., Popa, C., Jones, S., and Dahler, A. (1999) Histone deacetylase inhibitors as potential anti-skin cancer agents. Cancer Research 59: 399-404.

Schmidt, K., Gust, R., and Jung, M. (1999) Inhibitors of histone deacetylase suppress the growth of MCF-7 breast cancer cells. Arch Pharm (Weinheim) 332: 353-357.

Schuler M, Bossy-Wetzel E, Goldstein JC, Fitzgerald P, Green DR.(2000) p53 induces apoptosis by caspase activation through mitochondrial cytochrome c release. J Biol Chem. 275(10):7337-42.

Sheikh, M.S., Li, X.-S., Chen, J.-C., Shao, Z.-M., Ordonez, J.V., and Fontana, J.A. (1994) Mechanisms of regulation of WAF1/Cip1 gene expression in human breast carcinoma: role of p53-dependent and independent signal transduction pathways. Oncogene 9: 3407-3415.

Sheikh, M.S., Rochefort, H., and Garcia, M. (1995) Overexpression of p21/WAF1/CIP1 induces growth arrest, giant cell formation and apoptosis in human breast carcinoma cell lines. Oncogene 11: 1899-1905.

Shen J, Hughes C, Chao C, Cai J, Bartels C, Gessner T, Subjeck J. (1987) Coinduction of glucoseregulated proteins and doxorubicin resistance in Chinese hamster cells. Proc Natl Acad Sci U S A. 84(10):3278-82.

Sherr CJ (1996). Cancer cell cycles. Science. 274:1672-7

Shiau AK, Barstad D, Loria PM, Cheng L, Kushner PJ, Agard DA, Greene GL.(1998) The structural basis of estrogen receptor/coactivator recognition and the antagonisis of this interaction by tamoxifen. Cell. 95(7):927-37

Shoemaker JP.(1978) Fifty-five percent complete remission of mammary carcinoma in mice with 5fluorouracil and chloroquine. Cancer Res. 38(9):2700-2. 
Shoemaker JP, Dagher RK. (1979) Remissions of mammary adenocarcinoma in hypothyroid mice given 5-fluorouracil and chloroquine phosphate. J Natl Cancer Inst. 62(6):1575-8.

Silvestrini R, Veneroni S, Daidone MG, Benini E, Boracchi P, Mezzetti M, Di Fronzo G, Rilke F, Veronesi U.(1994) The Bcl-2 protein: a prognostic indicator strongly related to p53 protein in lymph node-negative breast cancer patients. J Natl Cancer Inst. 86(7):499-504.

Slansky JE, Farnham PJ.(1996) Introduction to the E2F family: protein structure and gene regulation. Curr Top Microbiol Immunol. 208:1-30.

Smyth MJ, Krasovskis E, Sutton VR, Johnstone RW (1998) The drug efflux protein, P-glycoprotein, additionally protects drug-resistant tumor cells from multiple forms of caspase-dependent apoptosis. Proc Natl Acad Sci U S A. 95(12):7024-9.

Sondel PM, Hank JA, Kohler PC, Chen BP, Minkoff DZ, Molenda JA(1986). Destruction of autologous human lymphocytes by interleukin 2-activated cytotoxic cells. J Immunol. 137(2):502-11.

Soule, H.D., Vazquez, J., Long, A., and Albert, S. (1973) A human cell line from a pleural effusion derived from a breast carcinoma. J. Natl. Cancer Inst. 51: 1409-1416.

Sowa, Y., Orita, T., Minamikawa-Hiranabe, S., Mizuno, T., Nomura, H., and Sakai, T. (1999) Sp3, but not Sp1, mediates the transcriptional activation of the p21/WAF1/Cip1 gene promoter by histone deacetylase inhibitor. Cancer Research 59: 4266-4270.

Srinivasula SM, Ahmad M, Fernandes-Alnemri T, Alnemri ES.(1998) Autoactivation of procaspase-9 by Apaf-1-mediated oligomerization. Mol Cell. 1(7):949-57

Stampfer, M.R., and Yaswen, P. (1993) Culture systems for study of human mammary epithelial cell proliferation, differentiation, and transformation. Cancer Surv. 18: 7-34.

Stingl, J., Eaves, C.J., Kuusk, U., and Emerman, J.T. (1998) Phenotypic and functional characterization in vitro of a multipotent epithelial cell present in the normal adult human breast. Differentiation 63: 201-213.

Sullivan JL, Byron KS, Brewster FE, Purtilo DT.(1980) Deficient natural killer cell activity in x-linked lymphoproliferative syndrome. Science 210 (4469):543-5.

Sun JM, Chen HY, Moniwa M, Samuel S, Davie JR. (1999) Purification and characterization of chicken erythrocyte histone deacetylase 1. Biochemistry. 38(18):5939-47.

Sun XM, MacFarlane M, Zhuang J, Wolf BB, Green DR, Cohen GM.(1999) Distinct caspase cascades are initiated in receptor-mediated and chemical-induced apoptosis. J Biol Chem. 274(8):5053-60.

Sutherland RL, Green MD, Hall RE, Reddel RR, Taylor I.(1983) Tamoxifen induces accumulation of MCF 7 human mammary carcinoma cells in the G0/G1 phase of the cell cycle. Eur J Cancer Clin Oncol. 19(5):615-21. 
Svensson K, Mattsson R, James TC, Wentzel P, Pilartz M, MacLaughlin J, Miller SJ,Olsson T, Eriksson UJ, Ohlsson R.(1998) The paternal allele of the H19 gene is progressively silenced during early mouse development: the acetylation status of histones may be involved in the generation of variegated expression patterns. Development. 125(1):61-9.

Sweeney, K.J., Swarbrick, A., Sutherland, R.L., and Musgrove, E.A. (1998) Lack of relationship between cdk activity and G1 cyclin expression in breast cancer cells. Oncogene 16: 2865-2878.

Tada-Oikawa S, Oikawa S, Kawanishi S.(1998) Role of ultraviolet A-induced oxidative DNA damage in apoptosis via loss of mitochondrial membrane potential and caspase-3 activation. Biochem Biophys Res Commun. 247(3):693-6.

Taillefer J, Brasseur N, van Lier JE, Lenaerts V, Le Garrec D, Leroux JC. (2001) In-vitro and in-vivo evaluation of $\mathrm{pH}$-responsive polymeric micelles in a photodynamic cancer therapy model. J Pharm Pharmacol. 53(2):155-66.

Takenaga K, Hozumi M. (1980) Induction by chloroquine of differentiation of cultured mouse myeloid leukemia cells. Gann. 71(1):141-5.

Takeo S, Kokaze A, Ng CS, Mizuchi D, Watanabe JI, Tanabe K, Kojima S, Kita K._(2000) Succinate dehydrogenase in Plasmodium falciparum mitochondria: molecular characterization of the SDHA and SDHB genes for the catalytic subunits, the flavoprotein (Fp) and iron-sulfur (Ip) subunits. Mol Biochem Parasitol. 107(2):191-205.

Tarlov, A.R Brewer, GJ, Carson PE and Alving AS (1962) Primaquine Sensitivity. Arch Interm Med 109:209-234

Taunton J, Hassig CA, Schreiber SL. (1996) A mammalian histone deacetylase related to the yeast transcriptional regulator Rpd3p. Science. 272(5260):408-11.

Taylor CM, Blanchard B, Zava DT.(1984) Estrogen receptor-mediated and cytotoxic effects of the antiestrogens tamoxifen and 4-hydroxytamoxifen. Cancer Res. 44(4):1409-14

Thomas R, Vane DW, Grosfeld JL, Faught PR. (1990) The effect of chloroquine and hyperthermia on murine neuroblastoma. J Pediatr Surg. 25(9):929-32.

Thor AD, Moore DH II, Edgerton SM, Kawasaki ES, Reihsaus E, Lynch HT, Marcus JN, Schwartz L, Chen LC, Mayall BH. (1992) Accumulation of p53 tumor suppressor gene protein: an independent marker of prognosis in breast cancers. J Natl Cancer Inst. 84(11):845-55

Torchia Jglass C and Rosenfeld MG (1998) Co-activators and co-repressors in the integration of transcriptional responses. Curr Opin Cell Biol 10:373-383

Toscani, A., Soprano, D.R., and Soprano, K.J. (1990) Sodium butyrate in combination with insulin or dexamethasone can terminally differentiate actively proliferating Swiss 3 T3 cells into adipocytes. $J$. Biol. Chem. 265: 5722-5730. 
Trail PA, Willner D, Lasch SJ, Henderson AJ, Hofstead S, Casazza AM, Firestone RA, Hellstrom I, Hellstrom KE. (1993) Cure of xenografted human carcinomas by BR96-doxorubicin immunoconjugates. Science. 261(5118):212-5.

Turner, BM (1991)Histone acetylation and control of gene expression. J Cell Sci. 99 ( Pt 1):13-20.

Utley JF, Sachatello CR, Maruyama Y, Avila J, King R. (1977) Radiosensitization of normal tissue by chloroquine. Radiology 124(1):255-7.

Van Lint C., Emiliani S, Verdin E., (1996) The expression of a small fraction of cellular genes is changed in response to histone hyperacetylation Gene Expr 5(4-5):245-253

Van Lint, C., Emiliani, S., and DiCunto, F., Topley, G., Calautti, E., Hsiao, J., Ong, L., Seth, P.K., and Dotto, G.P. (1998) Inhibitory function of p21cip1/waf1 in differentiation of primary mouse keratinocytes independent of cell cycle control. Science 280: 1069-1072.

Vaux DL, Korsmeyer SJ.(1999) Cell death in development. Cell 96(2):245-54

Verdel A, Khochbin S.(1999) Identification of a new family of higher eukaryotic histone deacetylases. Coordinate expression of differentiation-dependent chromatin modifiers. J Biol Chem. 274(4):24405.

Verdin, E. (1996) The expression of a small fraction of cellular genes is changed in response to histone hyperacetylation. Gene Expr. 5: 245-253.

Verheijen R, Kuijpers HJ, van Driel R, Beck JL, van Dierendonck JH,Brakenhoff GJ, Ramaekers FC.(1989) Ki-67 detects a nuclear matrix-associated proliferation-related antigen. II. Localization in mitotic cells and association with chromosomes. J Cell Sci. 92 ( Pt 4):531-40.

Vigushin DM, Ali S, Pace PE, Mirsaidi N, Ito K, Adcock I, Coombes RC.(2001)

Trichostatin A is a histone deacetylase inhibitor with potent antitumor activity against breast cancer in vivo. Clin Cancer Res. 7(4):971-6.

Vladusic, E.A., Hornby, A.E., Guerra-Vladusic, F.K., Lakins, J., and Lupu, R. (2000) Expression and regulation of estrogen receptor beta in human breast tumors and cell lines. Oncol. Rep. 7: 157-167.

Vogelstein B, Kinzler KW.(1994) Has the breast cancer gene been found? Cell. 79(1):1-3.

Wang, S., Melkoumian, Z.K., Woodfork, K.A., Cather, C., Davidson, A.G., Wonderlin, W.F., and Strobl, J.S. (1998) Evidence for an early G1 ionic event necessary for cell cycle progression and survival in the MCF-7 human breast carcinoma cell line. J. Cell. Physiol. 176: 456-464

Warhurst, D.C. (1987) Antimalarial interaction with ferriprotoporphyrin IX monomer and its relationship to activity of the blood schizontocides. Ann. Trop Med Parasitol 81:65-67 
Wallner KE, Wara WM, Sheline GE, Davis RL (1986) Intracranial ependymomas: results of treatment with partial or whole brain irradiation without spinal irradiation. Int J Radiat Oncol Biol Phys. 12(11):1937-41.

Warrell, R.P., Jr., He, L.-Z., Richon, V., Calleja, E., and Pandolfi, P.P. (1998) Therapeutic targeting of transcription in acute promyelocytic leukemia by use of an inhibitor of histone deacetylase. J. Natl. Cancer Inst. 90: 1621-1625.

Watson, S., and Girdlestone, D. (1996) Trends in Pharmacological Sciences (Ion Channel Supplement) 17: 72-77.

Wellens, T(1992) How chloroquine works. Nature 1992:335:108-109

Whinstanley, P., Newton, C., Watkins, W., Mberu, E., Ward, S., Warn, P, Mwangi, I, Waruiru, C, Pasvol, G, Warrel, D and Marsh, K (1993). Towards optimal regimens of parenteral quinine for young African children with cerebral malaria: importance of unbound quinine concentration. Trans. R. Soc. Trop. Med. Hyg 87:201-206.

White, N.J.,(1994) Mefloquine. Br. Med J. 30:286-287

Witters LM, Kumar R, Chinchilli VM, Lipton A.(1997) Enhanced anti-proliferative activity of the combination of tamoxifen plus HER-2-neu antibody. Breast Cancer Res Treat. 42(1):1-5

Wolffe AP 1995 Chromatin: Structure and Function, $2^{\mathrm{nD}}$ ed., Academic Press, San Diego. CA

Wolffe AP, Pruss D.(1996) Hanging on to histones. Chromatin.Curr Biol. 6(3):234-7

Wolffe AP, Pruss D. (1996) Targeting chromatin disruption: Transcription regulators that acetylate histones. Cell 84 (6):817-9

Woodfork, K.A., Wonderlin, W.F., Peterson, V.A., and Strobl, J.S. (1995). Inhibition of ATP-sensitive potassium channels causes reversible cell-cycle arrest of human breast cancer cells in tissue culture. $J$. Cell. Physiol. 162: 163-171.

Xiong, Y., Zhang, H., and Beach, D (1993) Subunit rearrangement of the cyclin-dependent kinases is associated with cellular transformation. Genes \& Devel. 7: 1572-1583.

Yang XJ, Ogryzko VV, Nishikawa J, Howard BH, Nakatani Y.(1996) A p300/CBP-associated factor that competes with the adenoviral oncoprotein E1A. Nature. 382(6589):319-24.

Yeola, S.W., Rich, T,C., Uebele, V.N., Tamkun, M.M., and Snyders, D.J. (1996) Molecular analysis of a binding site for quinidine in a human cardiac delayed rectifier $\mathrm{K}+$ channel. Role of $\mathrm{S} 6$ in antiarrhyhthmic drug binding. Circ. Res. 78: 1105-1114.

Yoshida M, Horinouchi S, Beppu T. (1995) Trichostatin A and trapoxin: novel chemical probes for the role of histone acetylation in chromatin structure and function. Bioessays. 17(5):423-30 
Yoshida M, Hoshikawa Y, Koseki K, Mori K, Beppu T.(1990) Structural specificity for biological activity of trichostatin A, a specific inhibitor of mammalian cell cycle with potent differentiationinducing activity in Friend leukemia cells. J Antibiot (Tokyo). 43(9):1101-6.

Yoshida, M., and Horinouchi, S. (1999) Trichostatin and leptomycin. Inhibtion of histone deacetylation and signal-dependent nuclear export. Ann. NY Acad. Sci. 886: 23-36.

Zhang, L., Chang, C.J., Bacus, S.S., and Hung, M.C(1995) Suppressed transformation and induced differentiation of HER-2/neu-overexpressing breast cancer cells by emodin. Cancer Res. 55: 38903896.

Zou H, Li Y, Liu X, Wang X. (1999) An APAF-1.cytochrome c multimeric complex is a functional apoptosome that activates procaspase-9. J Biol Chem. 274(17):11549-56.

Zhou,Q., and Strobl, J.S. (2000) Role of heat shock proteins in the apoptotic reponse to an ion channel blocker, quinidine, OC15/ASBMA-ASPET, Boston, MA, Abstract\#LB131

Zhou, Q., Melkoumian, Z.K.,Lucktong, A, Moniwa, M., Davie, JR and Strobl JS. (2000) Rapid induction of histone hyperacetylation and cellular differentiation in human breast tumor cell lines following degradation of histone deacetylase-1. J Biol Chem. 275(45):35256-63 
Appendix 1. Antimalarials inhibit MTS metabolism in MCF-7 cells. MCF-7 cells were grown in the presence of increasing concentrations of each compound for $48 \mathrm{~h}$, and cell viability was estimated using the MTS assay. These assays were performed after $2 \mathrm{~h}$ incubation, the MTS activity was then measured at $490 \mathrm{~nm}$ using the microtiter plate reader. A complete concentration response curve for each compound is shown. 

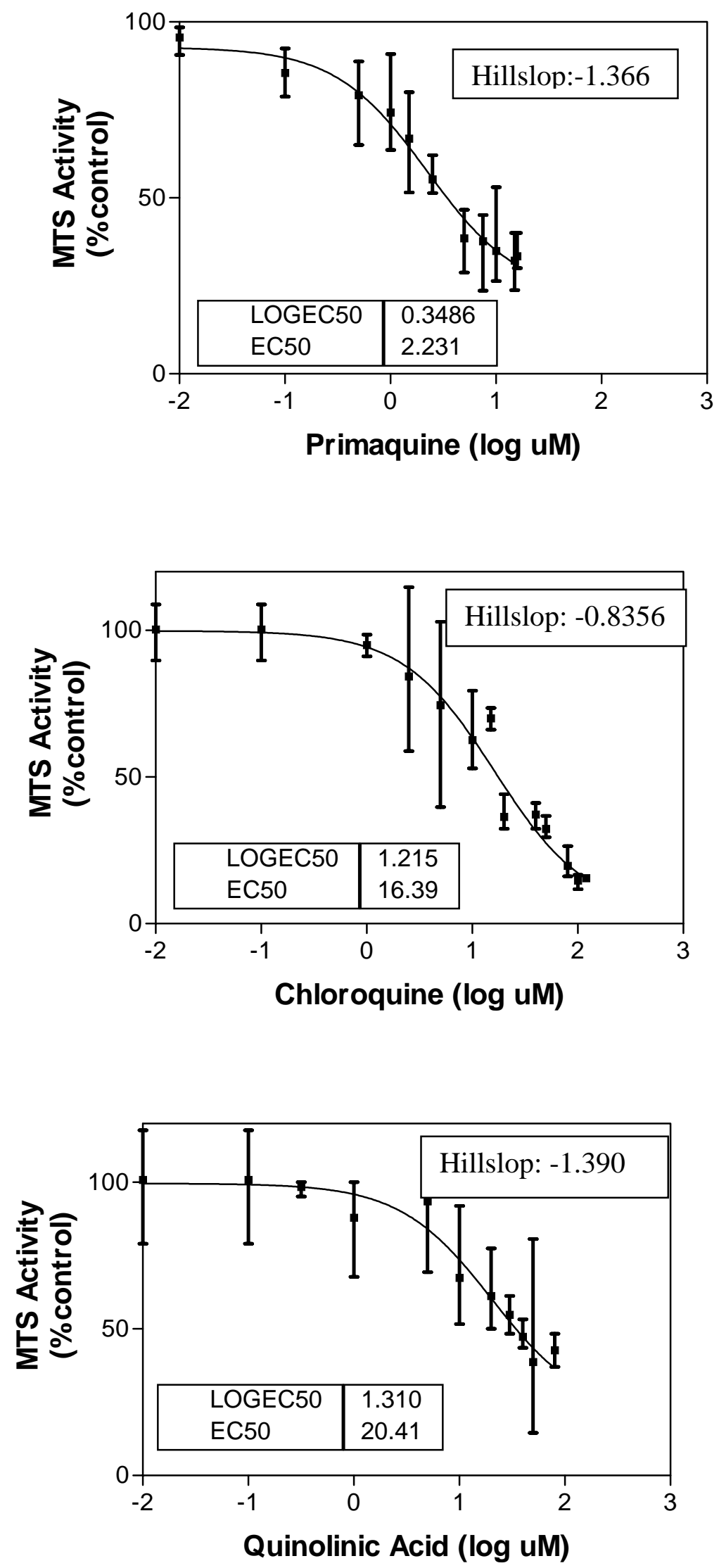

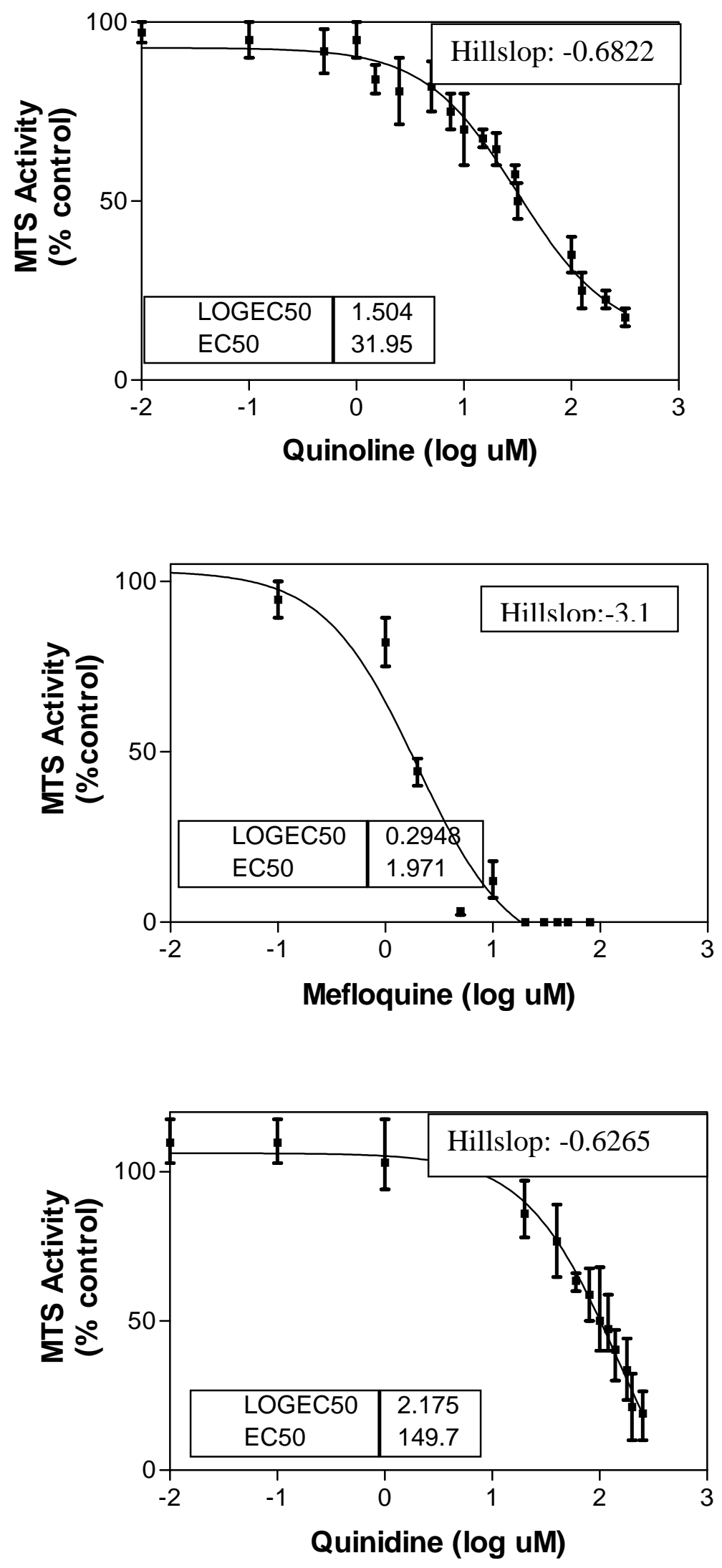

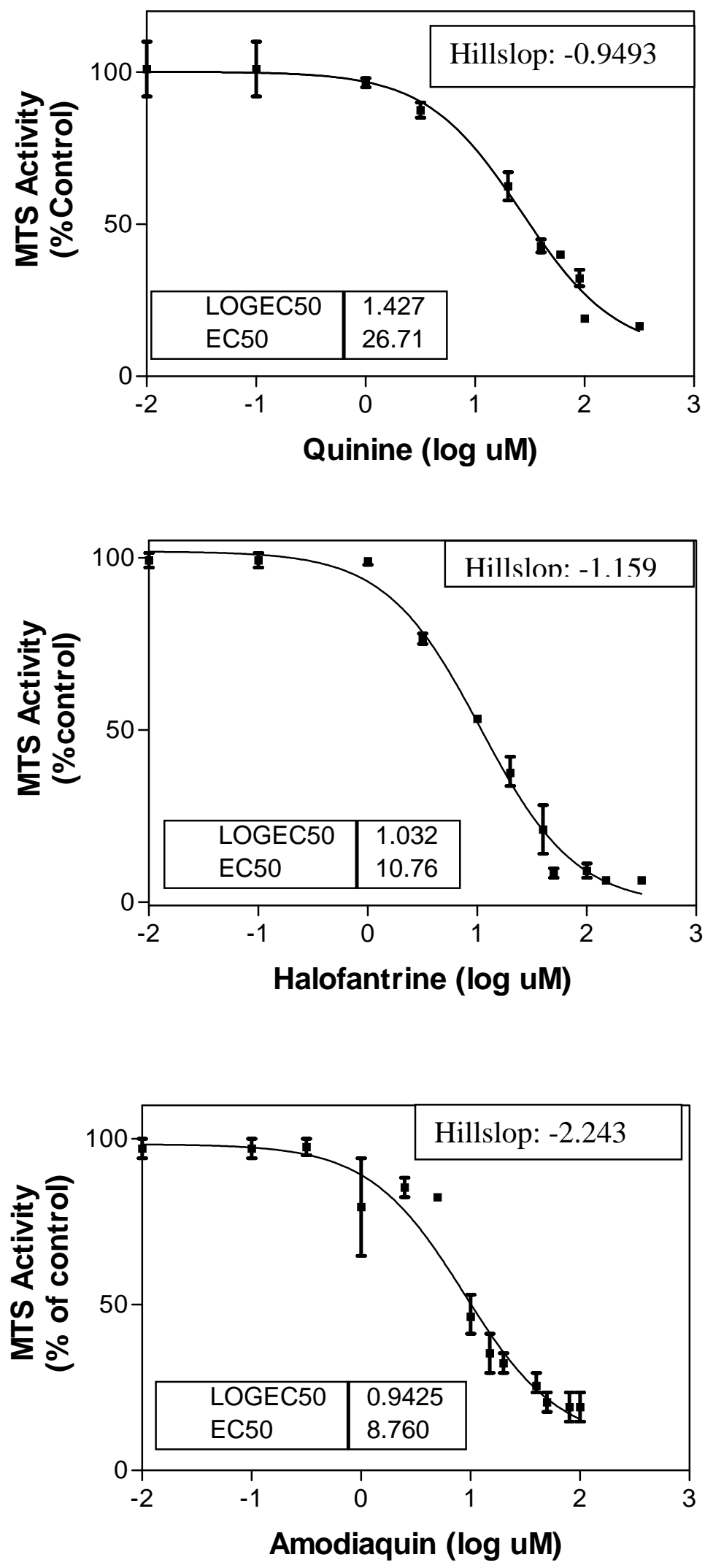